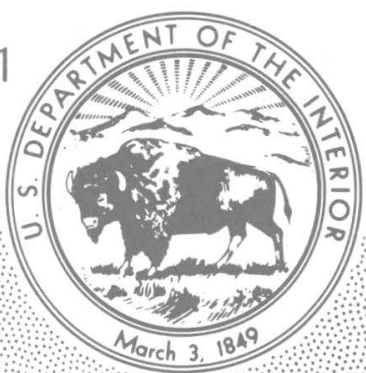

\title{
National Seismic System Science Plan
}




\section{AUTHORS' ADDRESSES}

Thomas H. Heaton

U.S. Geological Survey

525 S. Wilson Ave.

Pasadena, CA 91106

Don L. Anderson

Division of Geological and Planetary Sciences

California Institute of Technology

Pasadena, CA 91125

Walter J. Arabasz

Dept. of Geology and Geophysics

University of Utah

Salt Lake City, UT 84112

Ray Buland

U.S. Geological Survey

Denver Federal Center MS-967

Denver, CO 80225

William L. Ellsworth

U.S. Geological Survey

345 Middlefield Road MS-977

Menlo Park, CA 94025

Stephen H. Hartzell

U.S. Geological Survey

$525 \mathrm{~S}$. Wilson Ave.

Pasadena, CA 91106

Thorne Lay

Dept. of Geological Sciences

The University of Michigan

Ann Arbor, MI 48109-1063

Paul Spudich

U.S. Geological Survey

345 Middlefield Road MS-977

Menlo Park, CA 94025 


\section{National Seismic System Science Plan}

By THOMAS H. HEATON, DON L. ANDERSON, WALTER J. ARABASZ, RAY BULAND, WILLIAM L. ELLSWORTH, STEPHEN H. HARTZELL, THORNE LAY, and PAUL SPUDICH 


\section{U.S. DEPARTMENT OF THE INTERIOR}

MANUEL LUJAN, JR., Secretary

U.S. GEOLOGICAL SURVEY

Dallas L. Peck, Director

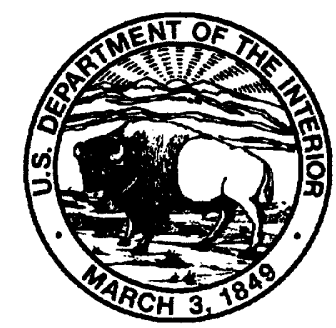

First printing 1989

Second printing 1993

Any use of trade, product, or firm names

in this publication is for descriptive purposes only

and does not imply endorsement by the U.S. Government

Library of Congress Catalog Card Number 89-600729

UNITED STATES GOVERNMENT PRINTING OFFICE, WASHINGTON : 1989

Free on application to the

Book and Open-File Reports Sales

U.S. Geological Survey

Federal Center, Box 25286

Denver, CO 80225 


\title{
CONTENTS
}

\author{
Executive summary 1 \\ Introduction 1 \\ Configuration and uses of existing networks 2 \\ Current regional networks 2 \\ Uses of current regional networks 3 \\ Earthquake physics and hazard analysis 4 \\ Structure of the Earth 8 \\ Current strong-motion instrumentation 10 \\ Limitations of existing networks 15 \\ Configuration of proposed digital National Seismic System 17 \\ U.S. National Seismic Network 17 \\ Relationship between regional and national seismic networks 21 \\ Need to develop digital regional networks 22 \\ Applications of a National Seismic System 24 \\ Estimation of current earthquake risk 24 \\ Short-term waming of imminent ground shaking 25 \\ Rapid estimation of shaking intensity 27 \\ Tsunami warning 28 \\ Volcano monitoring 29 \\ Prediction of site effects in strong ground motions 29 \\ Research possibilities of three-component digital regional networks 32 \\ Earthquake studies 32 \\ Seismicity patterns 32 \\ Source characteristics 34 \\ Strong-motion attenuation 36 \\ Strong-motion simulation 36 \\ Earth structure and wave propagation 37 \\ Shear waves 37 \\ Surface waves 37 \\ Understanding the coda 38 \\ Deep structure of basins and mountains 38 \\ Structure of the Earth's interior 39 \\ Nuclear discrimination $\mathbf{4 0}$ \\ Conclusions 40 \\ References cited 40
}

\section{FIGURES}

1. Seismicity map of the contiguous United States 3

2. Map of seismograph stations operated by regional networks in the contiguous United States 5

3. Map of seismograph stations operated by regional networks in California 6

4. Map of seismic activity in California and Nevada from 1980 through 19867

5. Diagram showing seismic hazard analysis methodology 8

6. Probabilities of the occurrence of major earthquakes on the San Andreas, Imperial, San Jacinto, and Hayward fault systems in California 9

7. Mislocation vectors from locating distant earthquakes using regional networks 11

8. Map of southem California crustal $P$-wave velocities derived from tomographic inversion of travel times of local earthquakes 12 
9. Map of southern California upper-mantle $P$-wave velocities derived from tomographic inversion of travel times of local earthquakes 13

10. Three-dimensional upper-mantle $P$-wave velocity structure beneath southern California derived from tomographic inversion of travel times from distant earthquakes 14

11. $P$-wave travel times for earthquakes located at regional distances and recorded on the Southern California Seismic Network 15

12. Waveforms of $P$-waves traveling through the upper mantle and recorded on the Southern California Seismic Network 16

13. Distribution of strong-motion accelerographs in the contiguous United States (excluding California) 18

14. Distribution of strong-motion accelerographs in California 19

15. Dynamic range plotted against frequency for typical regional network seismograph and strong-motion accelerograph 20

16. Map of proposed National Seismic Network stations in the contiguous United States

17. Schematic representation of National Seismic Network 22

18. Map showing seismicity of the intermountain region 23

19. Probability per hour of a large $(M \geq 7.5)$ earthquake following a $M 6.5$ earthquake on the San Andreas fault 24

20. Probability of a characteristic Parkfield earthquake following the occurrence of a potential foreshock 25

21. Conceptual design of a Seismic Computerized Alert Network (SCAN) to provide short-term warning of imminent strong shaking 27

22. Warning times expected in southern California from SCAN 28

23. Distribution of Holocene volcanoes in North America $\mathbf{3 0}$

24. Strong-motion waveforms together with geologic structure in the Los Angeles region from the 1971 San Fernando earthquake 31

25. Variation of strong-motion response spectra from $M 6.5$ earthquakes recorded at 50 $\mathbf{k m}$ distance 32

26. Stereoscopic views of aftershocks of the 1984 Morgan Hill, California, earthquake 33

27. Map of seismic activity in the central United States 35

28. Cross section of seismic activity beneath Kilauea volcano, Hawaii 36

29. Aftershocks of the 1984 Morgan Hill, California, earthquake coplotted with slip distribution inferred from modeling strong-motion waveforms 37

\section{TABLES}

1. Attendees of July 1987 meeting to discuss National Seismic System Science Plan 2

2. Summary of U.S. regional seismic networks 4

3. Summary of strong-motion accelerographs in the United States 17

4. Problems requiring high densities of seismographic stations 24

5. Holocene volcanism of North America and Hawaii $\mathbf{3 0}$ 


\title{
National Seismic System Science Plan
}

\author{
By Thomas H. Heaton, Don L. Anderson, Walter J. Arabasz, Ray Buland, William L. Ellsworth, \\ Stephen H. Hartzell, Thorne Lay, and Paul Spudich
}

\section{EXECUTIVE SUMMARY}

Recent developments in digital communication and seismometry are allowing seismologists to propose revolutionary new ways to reduce vulnerability from earthquakes, volcanoes, and tsunamis, and to better understand these phenomena as well as the basic structure and dynamics of the Earth. This document provides a brief description of some of the critical new problems that can be addressed using modern digital seismic networks. It also provides an overview of existing seismic networks and suggests ways to integrate these together into a National Seismic System.

A National Seismic System will consist of a number of interconnected regional networks (such as southern California, central and northern California, northeastern United States, northwestern United States, and so on) that are jointly operated by Federal, State, and private seismological research institutions. Regional networks will provide vital information concerning the hazards of specific regions. Parts of these networks will be linked to provide uniform rapid response on a national level (the National Seismic Network).

A National Seismic System promises to significantly reduce societal risk to earthquake losses and to open new areas of fundamental basic research. The following is a list of some of the uses of a National Seismic System.

\section{Emergency Information Management:}

- Near real-time estimation of damage patterns after significant earthquakes.

- Very short term (less than several minutes) warning of imminent strong shaking during significant earthquakes.

- Real-time probabilistic estimation of seismic risk by monitoring of potential foreshock sequences.

- Short-term warning of imminent danger from tsunamis.

- Monitoring of volcanic activity.

\section{Estimation of Long-Term Risk:}

- Accurate prediction of ground motions during future earthquakes.

Manuscript approved for publication, February 23, 1989.
- Seismicity maps of active fault systems.

- Recognition of seismic gaps.

\section{Basic Research:}

- Uniform catalog of earthquake activity.

- Systematic mapping of crustal stress.

- Better understanding of U.S. earthquakes.

- Better understanding of worldwide earthquakes.

- Systematic mapping of crustal and upper mantle structure beneath the United States.

- Mapping of whole-Earth velocity structure.

- Recognition of magma bodies.

- Nuclear-test treaty verification research.

\section{INTRODUCTION}

In this document we describe ways that seismic information can be used to significantly reduce the hazards from earthquakes, tsunamis, and volcanoes. We also describe some of the fundamental problems about the structure and dynamics of the Earth that can be addressed.

Elastic waves in the Earth are generated by a number of sources that range from earthquakes to weather, machinery, and explosions. The nature of seismic waves varies tremendously with time and space. Ground motions may have accelerations of about $10^{-8} \mathrm{~g}$ during relatively quiet times and they may exceed $2 g$ at distances close to large earthquakes. Similarly, the frequency of these waves varies from less than one cycle per hour to hundreds of cycles per second. Seismometer systems have been constructed to record these motions, but because of practical mechanical limitations, the range of amplitudes (dynamic range) and frequencies (bandwidth) that can be recorded by traditional systems is severely limited. Dynamic range and bandwidth have generally been less than three orders of magnitude and two orders of magnitude, respectively. Furthermore, the analysis of data from these systems has been time consuming.

These instrumental limitations have profoundly affected the nature of problems that seismologists could address. The application of modern digital technology to seismic recording systems has dramatically expanded their capabilities. It is now practical to build systems that have dynamic ranges of ten orders of magnitude and bandwidths that range from one cycle 
per hundreds of seconds to one cycle per hundredth of a second (four orders of magnitude). Furthermore, data can be rapidly collected and analyzed using computer systems. These new systems dramatically expand the types of problems that can solved.

We now describe some of the events that led to the writing of this document. The development of regional seismic networks and of modern digital seismometry both have long and complex histories that will not be covered. This document is an immediate result of a plan for a United States National Seismic Network developed by the National Earthquake Information Center (NEIC) of the U.S. Geological Survey (Massé and Buland, 1987). The network is to consist of approximately 150 modern digital stations that are distributed throughout the United States. Data from these stations are to be transmitted via satellite telemetry to a central recording site in Golden, Colorado, and the network will provide uniform (but rather sparse) national coverage. Funding from the U.S. Nuclear Regulatory Commission will permit installation of approximately 60 stations in the Eastern and central United States. The U.S. Department of the Interior has yet to make funding commitments to install stations in other parts of the country.

Many seismologists who have reviewed the NEIC plan have been very excited about capabilities of stations in this network. These stations appear to be able to record and rapidly telemeter ground motions that range from the largest motions expected during destructive earthquakes to ambient ground noise at quiet sites. They also record ground motion over a very large frequency band (approximately $30 \mathrm{~Hz}$ to 0.01 $\mathrm{Hz}$ ). Thus stations in the National Seismic Network will provide data that can be used to study a very broad range of seismic problems.

At present, there are currently about 1,600 seismic stations in locally operated regional networks that are distributed throughout the United States, and this new National Seismic Network cannot (and is not intended to) perform the many functions of existing regional networks. Unfortunately, instrumentation in the existing regional seismic networks has very limited dynamic range and bandwidth. This has severely limited the applications and types of basic research problems that can be addressed with existing regional networks.

Many seismologists recognized that applying the technology planned for the National Seismic Network to the problem of regional seismic networks will greatly expand our abilities to reduce our risks from natural phenomena and to better understand the structure and dynamics of the Earth. A small group of seismologists (listed in table 1) from universities and the Federal government convened to discuss these issues in July 1987 at Alta Lodge in Utah. There was a strong consensus that we need to develop an integrated, nationwide approach to the recording, reporting, and exchange of seismological data in the United States. In this document we present a common vision that arose in the Alta meeting of what a National Seismic System might look like.
Table 1. Attendees of meeting at Alta Lodge, Utah, to discuss a National Seismic System July 8-10, 1987

\begin{tabular}{|c|c|}
\hline Prof. Walter Arabasz & Dr. Thomas Heaton \\
\hline University of Utah & Scientist in Charge of the \\
\hline Salt Lake City, Utah & Pasadena Field Office \\
\hline & U.S. Geological Survey \\
\hline Dr. William Bakun & Pasadena, California \\
\hline \multicolumn{2}{|l|}{ Chief Scientist for the } \\
\hline Parkfield Prediction Project & Prof. Robert Herrmann \\
\hline U.S. Geological Survey & St. Louis University \\
\hline Menlo Park, California & St. Louis, Missouri \\
\hline Prof. James Brune & Prof. Arch Johnston \\
\hline University of Nevada & Memphis State University \\
\hline Reno, Nevada & Memphis, Tennessee \\
\hline Prof. Robert Clayton & Prof. Hiroo Kanamori \\
\hline Califomia Institute of Technology & California Institute of Technology \\
\hline Pasadena, California & Pasadena, Califormia \\
\hline Prof. Robert Crosson & Dr. Robert Massé \\
\hline University of Washington & Chief of Branch of Global Seismology \\
\hline \multirow[t]{2}{*}{ Seattle, Washington } & U.S. Geological Survey \\
\hline & Denver, Colorado \\
\hline Dr. William Ellsworth & Dr. Elaine Padovani \\
\hline Chief of Branch of Seismology & Manager, Extemal Research Program \\
\hline U.S. Geological Survey & U.S. Geological Survey \\
\hline Menlo Park, Califomia & Reston, Virginia \\
\hline Dr. John Filson & Dr. David Simpson \\
\hline $\begin{array}{l}\text { Chief of Office of Earthquakes } \\
\text { Volcanoes, and Engineering }\end{array}$ & $\begin{array}{l}\text { Lamont Doherty Geological } \\
\text { Observatory }\end{array}$ \\
\hline U.S. Geological Survey & Columbia University \\
\hline Reston Virginia & Palisades, New York \\
\hline Dr. Thomas Hanks & Prof. Robert Smith \\
\hline Chief of Branch of & University of Utah \\
\hline Seismology and Geology & Salt Lake City, Utah \\
\hline \multicolumn{2}{|l|}{ U.S. Geological Survey } \\
\hline Menlo Park, Califomia & Dr. Wayne Thatcher \\
\hline & Chief of Branch of Tectonophysics \\
\hline & U.S. Geological Survey \\
\hline & Menlo Park, California \\
\hline
\end{tabular}

\section{CONFIGURATION AND USES OF EXISTING SEISMIC NETWORKS}

\section{Current Regional Networks}

From maps of earthquake activity in the contiguous United States (fig. 1), it is clear that seismic activity is distributed throughout the Nation. Alaska, Hawaii, and Puerto Rico also have high rates of seismic activity (the magnitude 9.2 1964 Alaskan earthquake is the largest known U.S. earthquake and the second largest in the world in this century). In order to understand this widespread earthquake activity, approximately 1,600 permanent seismographic stations are maintained throughout the United States by regional networks. Table 2 and figure 2 summarize the geographic loca- 


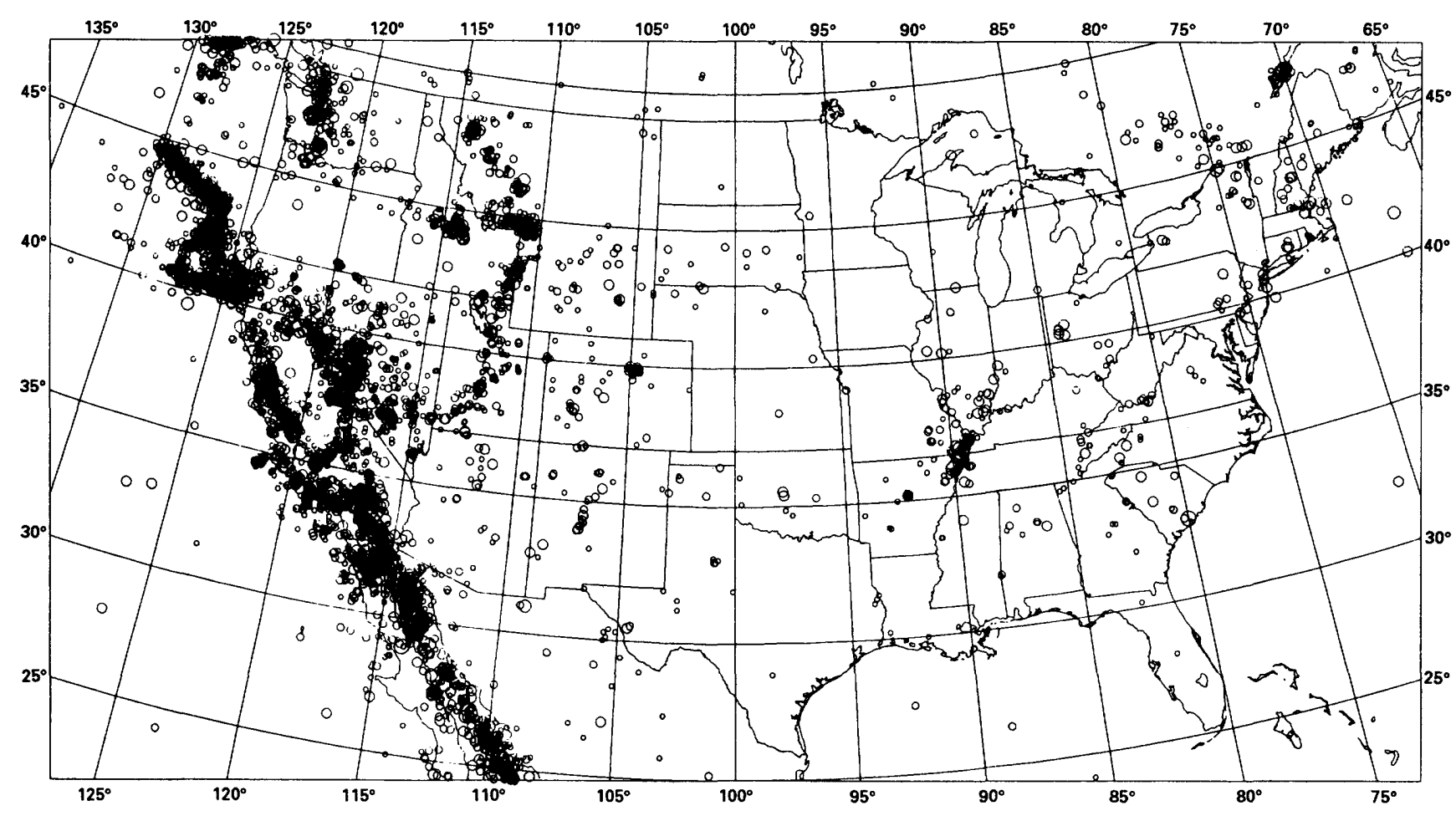

Figure 1. Seismicity within contiguous United States. All historical earthquakes with shaking intensity of at least VII ( $M$ approx 5.5), all earthquakes of magnitude of at least 5.0 since 1925 , all earthquakes of at least magnitude 4.0 since 1962 , and all earthquakes of at least magnitude 3.5 since 1975 are plotted (largest to smallest circles, respectively) (courtesy of E.R. Engdahl).

tion and operating organization for the largest of these regional networks (compiled from Simpson and Ellsworth, 1985). There is great diversity in the size of these networks, in the volume of data that is processed, in the nature of the operating facility, and in the funding sources. Although there are some notable exceptions, most of the stations consist of shortperiod vertical seismometers whose analog signals are continuously telemetered via voice-grade frequency-modulated (FM) telephone or radio links to a central recording site. In most instances, the incoming signals are digitized (typically at 100 samples per second) and processed on minicomputers. Although processing hardware and software varies considerably, all of the processing systems are designed to record only when several stations simultaneously detect signals above a threshold. Detected events are then analyzed to pick the times of seismic arrivals, locate the source of the seismic energy, and then catalog and archive the data on magnetic tape. The number of earthquakes recorded by these networks varies from less than 100 per year in much of the Eastern United States to more than 15,000 per year for the large California networks. Since the primary mission of regional networks is to monitor regional earthquake activity, many regional networks do not attempt to consistently record signals from distant earthquakes (teleseisms), although $P$-waves from larger teleseisms often trigger event detectors and are hence well recorded. Stations in the regional networks of
California are shown in figure 3 , and a compilation of earthquakes located with these networks for the period 1980 through 1986 is shown in figure 4 (D.P. Hill, written commun., 1987).

\section{Uses of Current Regional Networks}

Regional seismic networks are a fundamental multipurpose tool of observational seismology. Although commonly perceived as simply a tool for earthquake "surveillance" or "monitoring," existing seismic networks provide data and information for a host of uses:

-Public safety and emergency management

-Quantification of hazards and risk associated with both natural and human-triggered earthquakes

-Surveillance of underground nuclear explosion

-Investigation of earthquake mechanics and dynamics

-Investigation of seismic wave propagation

-Investigation of seismotectonic processes

-Earthquake forecasting and prediction research

-Probing the internal structure of the Earth

Importantly, seismic networks are also key facilities for the graduate education and training of this country's professional seismologists, and they provide direct outlets for public information and for expert assistance to public policy makers, planners, designers, and safety officials. 
Table 2. Existing U.S. regional seismic networks

\begin{tabular}{lc}
\hline Network & $\begin{array}{c}\text { Number of } \\
\text { Stations }\end{array}$ \\
\hline
\end{tabular}

Northeastem U.S. seismic networks Lamont Doherty (Columbia University)

Weston Observatory (Boston College)

Woodward Clyde Consultants Others

Total

Southeastern U.S. seismic networks Center for Earthquake Research (Memphis State University) Georgia Institute of Technology

University of South Carolina (also USGS)

Virginia Tech

Tennessee Valley Authority

Others

Total

Central U.S. seismic networks

St. Louis University

Oklahoma Geophysical Observatory

University of Michigan

Others

Total

Great Basin, Intermountain, and Rocky Mountain networks University of Utah

University of Nevada, Reno

U.S. Geological Survey Southem Nevada (Denver, CO) Others

Total

California seismic networks

USGS Central and Northem Calif.

USGS - California Institute of Tech. Southern Calif.

University of California, Berkeley

University of Southem Califomia

Others

Total

Northwestem U.S. seismic networks

University of Washington-USGS Network

North American Rockwell

Alaskan seismic networks

U.S. Geological Survey (Menlo Park, CA)

University of Alaska

Lamont Doherty (Columbia University)

Alaska Tsunami Warning Center

CIRIES (Boulder, CO)

Total

Hawaii seismic networks

Hawaiian Volcano Observatory (USGS)

Pacific Tsunami Waming Center (NOAA)

Total

Hanks (1985, 1987) published two informative summaries that reflect, in considerable part, the broad scope of current network seismology (see also Simpson and Ellsworth,
1985). They deal respectively with (1) the current scientific status of earthquake-related studies under the National Earthquake Hazards Reduction Program, and (2) seismology in the period 1983-1986. We elaborate on some of the uses of current seismic networks in the following two subsections, broadly labeled "Earthquake physics and hazard analysis" and "Structure of the Earth."

\section{Earthquake Physics and Hazard Analysis}

The majority of existing seismic networks in the United States relate fundamentally to understanding and mitigating the danger of damaging earthquakes. This involves anything and everything amenable to seismological observation-from the mechanics and dynamics of an earthquake source to the ground motions produced at any site from transmitted seismic waves. Describing the "anything and everything" that network seismologists investigate is beyond our scope. However, one way to outline much of that body of effort is to consider the aspects of a modern earthquake hazard analysis. Numerous interrelated pieces of information from network seismology become involved in the process.

To begin with, an earthquake hazard is a physical phenomenon with potentially adverse effects associated with an earthquake - for example, ground shaking, ground failure, surface faulting, tectonic deformation, inundation. In a rigorous seismic hazard analysis (for example, Electric Power Research Institute, 1987; Savy and others, 1986), quantitative models of earthquake behavior and effects are specified so that the level of hazard, such as the likely non-exceedance value of ground motion, can be computed for one or more sites for some exposure time, usually using a probabilistic approach.

The flowchart shown in figure 5 outlines the basic elements of a seismic hazard analysis for the hazard of ground motion. The sequence of necessary procedures is shown by steps 1 through 5 in the left-hand column; interrelated aspects of observational seismology are shown in the right-hand column.

Earthquake catalogs (step 1, fig. 5) are a basic starting point of earthquake seismology. Although the historical earthquake record is approximately 400 and 150 years in the Eastern and Western United States, respectively, good instrumental monitoring in many regions dates from only the 1970's (Simpson and Ellsworth, 1985). At a time when studies of prehistoric earthquakes attract attention (for example Allen, 1986), it seems worth emphasizing that earthquake catalogs are essential for estimating seismic hazard for earthquakes below the threshold of surface faulting (for example, the 2 May $1983 M 6.5$ Coalinga earthquake or the 1 October 1987 M 5.9 Whittier Narrows earthquake). Along the Wasatch Front, Utah, such earthquakes $(M 6.0-6.5)$ are the largest contributor to probabilistic ground shaking hazard for exposure periods of 50 years or less (Arabasz and others, 1987). In the central and Eastern United States, historical surface ruptures are virtually absent and information on prehis- 


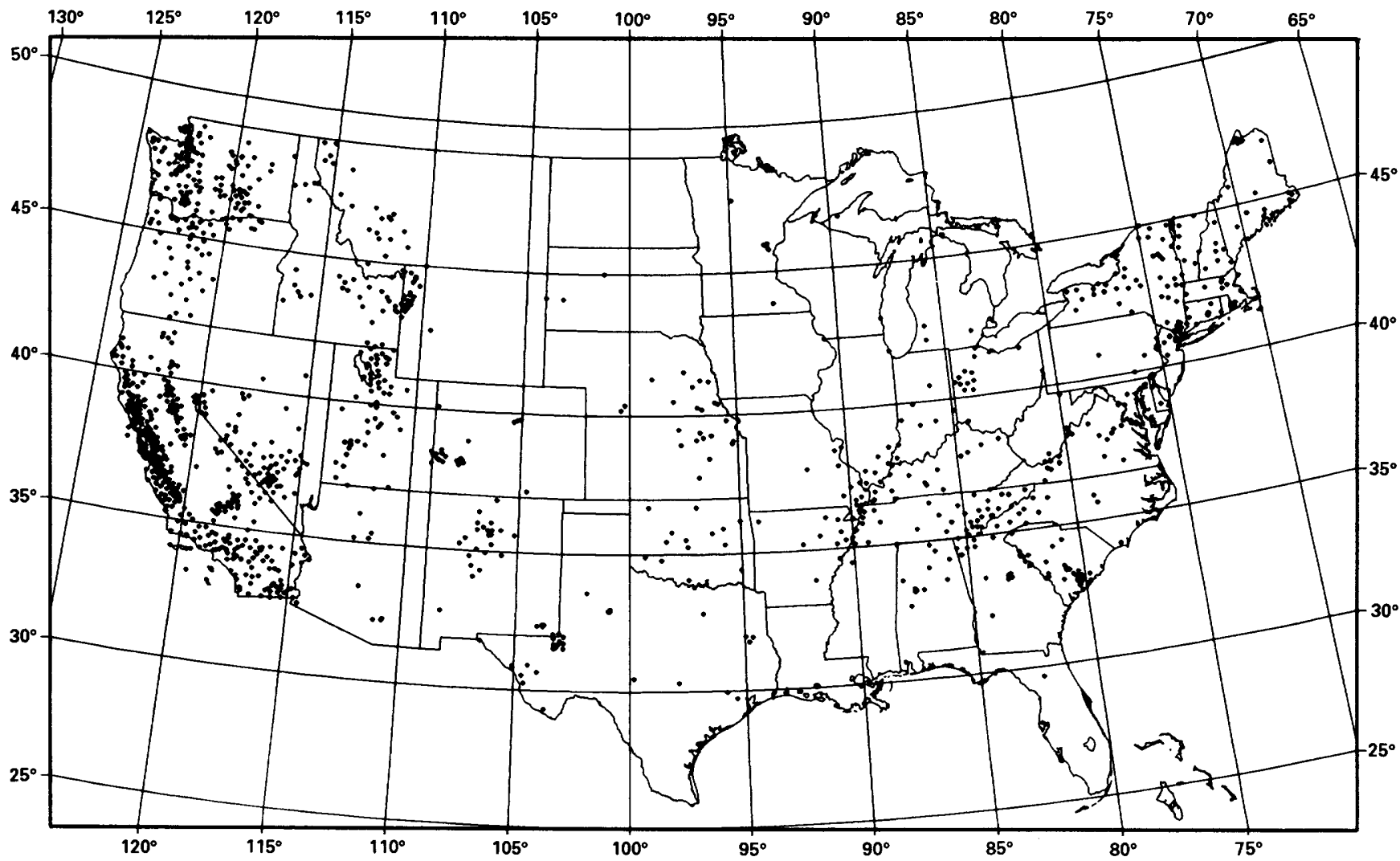

Figure 2. Seismograph stations operated by regional networks in the contiguous United States (map prepared by the National Earthquake Information Center). This compilation reflects station locations in the early 1980's, and although the current configuration of regional networks is similar, there are discrepancies between this map and the configuration of regional networks in 1988. A listing of the operators of regional networks is given in table 2.

toric earthquakes is sparse. Therefore, the historical and instrumental earthquake record is of great importance in assessing the potential sources of future earthquakes. In regions away from the active plate boundaries of western North America, the numbers of total earthquakes for any time period are significantly fewer than near the boundary. In the seismic regions interior to the plate, modern instrumental data become particularly important in the statistical processing of earthquake catalogs to estimate reliable seismicity parameters (step 4, fig. 5; see Veneziano and Van Dyck, 1986).

The characterization of seismotectonic framework (step 2, fig. 5) encompasses extensive efforts of network seismologists and gets to the heart of understanding earthquake behavior in diverse tectonic regions. The definition and geometric depiction of seismic source zones (step 3, fig. 5) is intimately related. Precise mechanisms and associated source parameters, stress state and strain rate, models for crustal structure, the location and geometry of active faults, and the fault mechanics and operative tectonic processes within a given region must all be investigated. We refer the reader to Allen (1986) and Hill (1987) for more comprehensive review papers.

Increasingly elegant techniques have become available to network seismologists for seismotectonic studies. Four ex- amples (and representative citations) are: (1) cross-spectral analysis of waveforms for high-resolution earthquake locations (Pechmann and Kanamori, 1982; Ito, 1985); (2) inversion of focal mechanisms to obtain the stress field (Angelier, 1987; Michael, 1987); (3) determination of rupture characteristics of earthquakes from ground-motion data using the waveforms of adjacent small earthquakes as empirical Green's functions (O'Neill, 1984; Frankel and others, 1986), and (4) the mapping of seismic slip distributions on a single fault plane to investigate details of the earthquake generation process (Bakun and others, 1986). Despite such advances, there emphatically remain first-order problems throughout much of the United States in associating observed seismicity with specific geologic structures-and in confidently identifying the sources of future moderate-to-large earthquakes. Examples in the Pacific Northwest, the intermountain west, and eastern North America (including the problematic source of the 1886 Charleston, South Carolina, earthquake) were reviewed by Hill (1987).

Earthquake physics, based on network observations, becomes an important part of the modeling of ground-shaking hazard (step 5, fig. 5) in the specification of the source spectrum, its scaling with earthquake size, and effects on wave propagation and attenuation. Earthquake physics also governs 


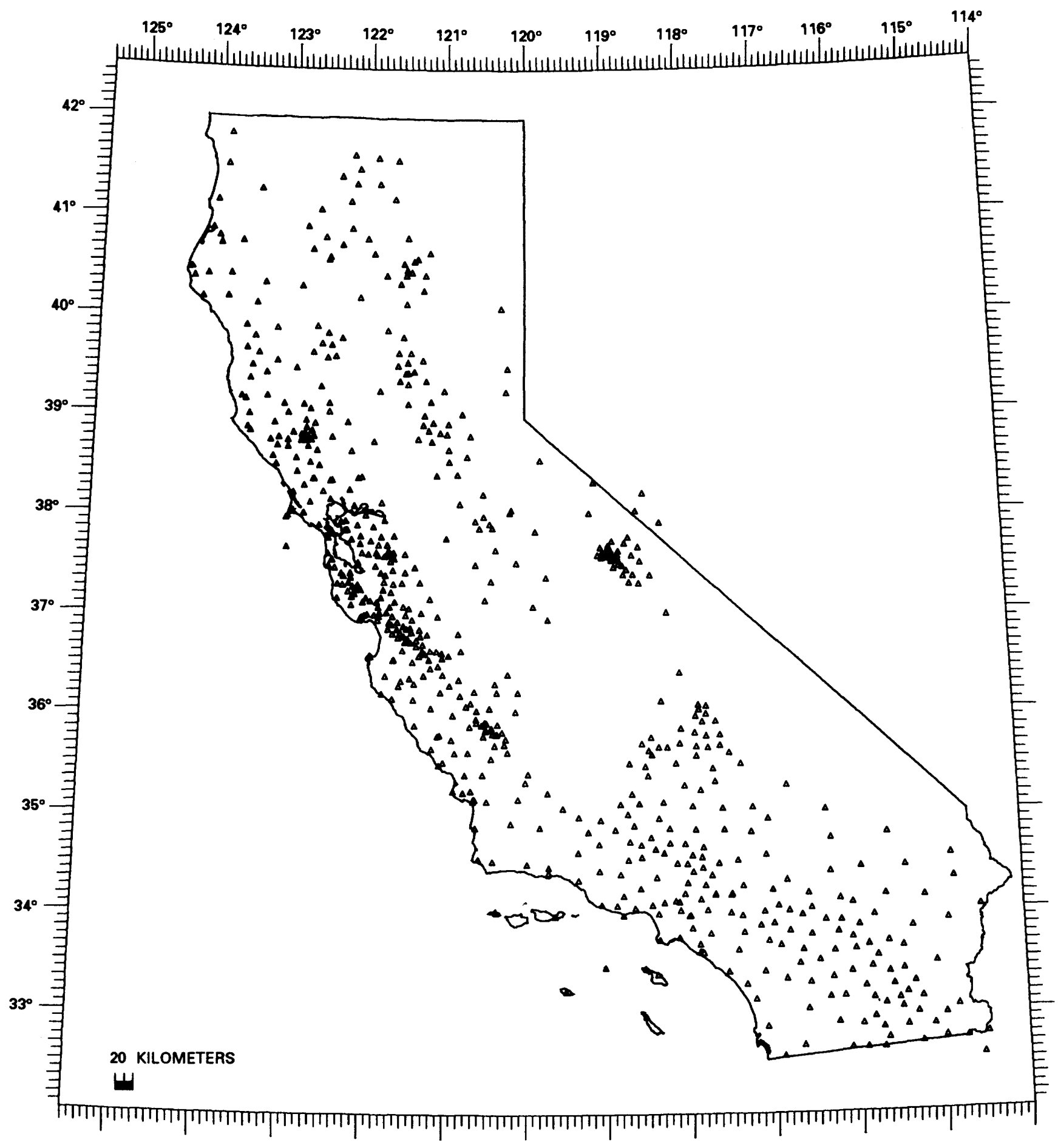

Figure 3. Major California regional network stations.

the assessment of maximum magnitude (step 4, fig. 5), although empirical approaches are more generally adopted. An important part of the hazard analysis is the recurrence modeling (step 4, fig. 5), which involves specifying time and size distributions of earthquakes for the identified seismic source zones. The so-called Poisson-exponential model is common- ly assumed in which earthquake occurrences are postulated to follow a memoryless Poisson process in time and a truncated exponential distribution in size. The associated parameters depend fundamentally upon earthquake catalogs. If the place and time of an earthquake can be predicted, however, probabilistic estimates of hazard become drastically altered. 


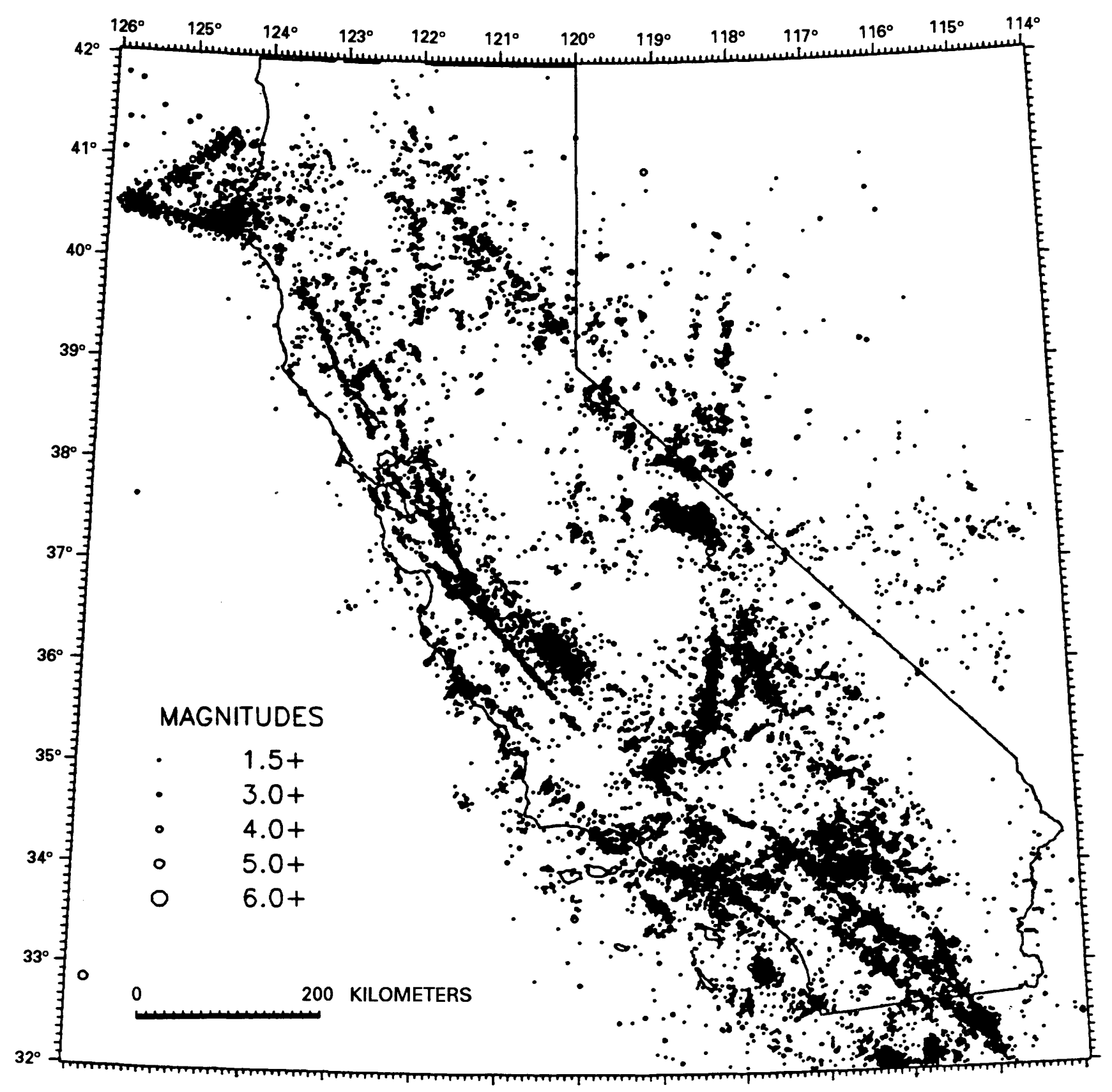

Figure 4. Seismicity throughout California and western Nevada for the period 1980-1986 (D.P. Hill, written commun., 1987).

Bakun (1987) provided a perspective on the current status of progress toward earthquake prediction, including description of a specific prediction by the U.S. Geological Survey (USGS) for the occurrence of a characteristic magnitude 6 earthquake on the Parkfield section of the San Andreas fault in $1988 \pm 5$ years. Patterns of earthquake occurrence documented from global, regional, and local earthquake monitoring provide viable approaches (with different degrees of general acceptance) for a probabilistic approach to earthquake prediction on different time scales. These include (1) recognition of seismic gaps along plate boundaries, (2) the seismic quiescence hypothesis that proposes a decrease in seismicity before some larger earthquakes, (3) repetition of similar or characteristic earthquakes along definable fault segments, and (4) recognizable slip deficits along parts of well-monitored, seismically active faults.

Recently, an integrated assessment of the probability of occurrence of major earthquakes along the San Andreas fault during the next 30 years (fig. 6) was released by the USGSsponsored Working Group on California Earthquake Probabilities (1988). The potential for future damaging earthquakes on each segment of the fault was derived through 


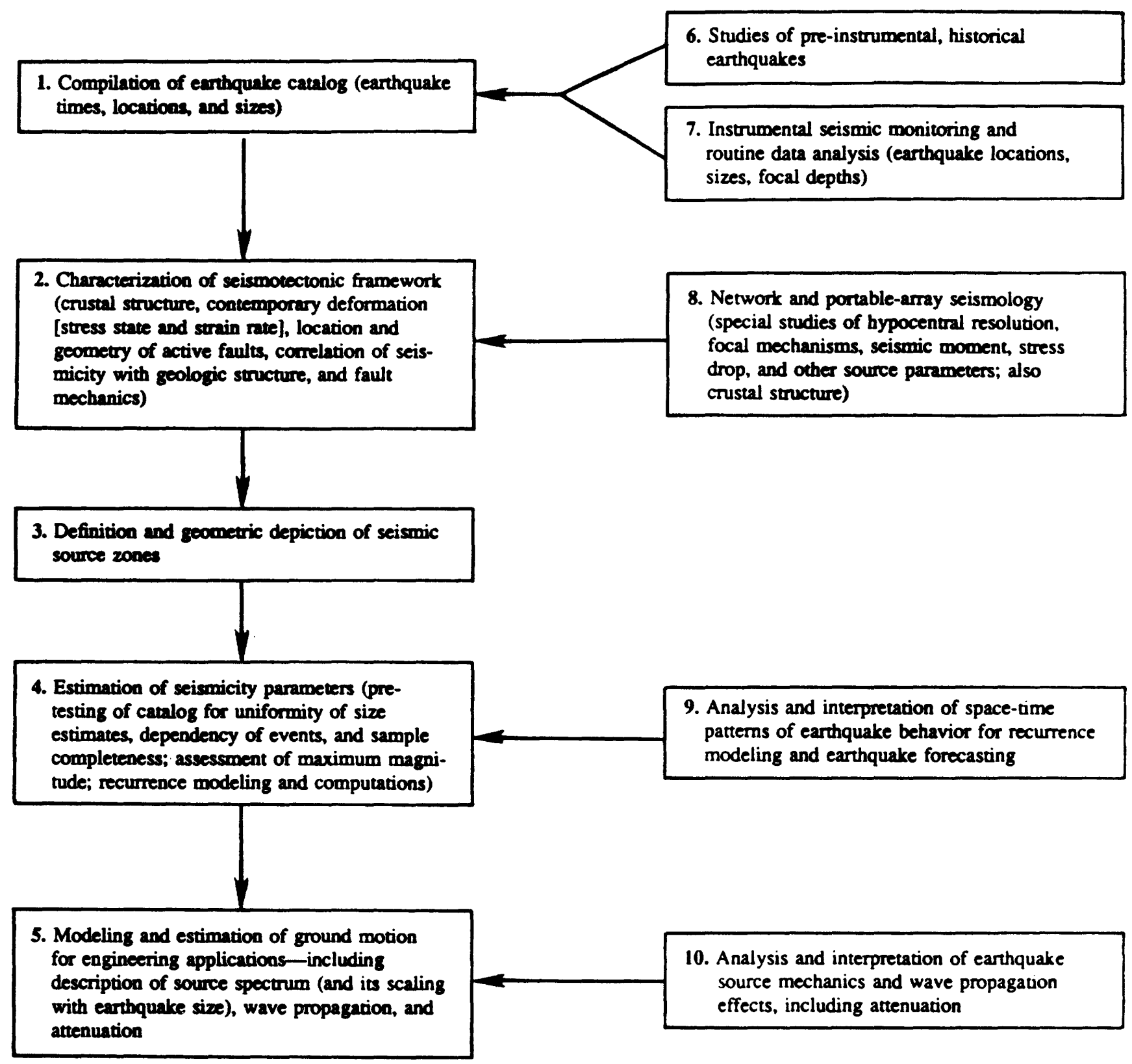

Figure 5. Steps in a formalized hazard analysis (left column) and interrelated aspects of observational seismology (right column). This example (from Arabasz and others, 1987) is for the Wasatch Front, Utah, region; a similar flowchart for California would involve more elaborate elements in the right column.

the synthesis of instrumental and historical seismic records, geologic studies of prehistoric events, and geodesy through the application of the same probabilistic approach employed at Parkfield and supported by worldwide observations (Nishenko and Buland, 1987). The report identifies the southern third of the San Andreas fault, including segments posing the highest risk to the major metropolitan regions of southern California, as having an aggregate probability of 60 percent for a $M 7.5$ to 8 earthquake by the year 2018. Just as the regional seismic data base has already played a critical role in defining the hazard, it has the potential to significantly reduce the risk posed by the anticipated earthquakes (see later discussion on applications of seismic networks).

\section{Structure of the Earth}

Since the 1960's there have been many applications of seismic arrays for analysis of detailed Earth structure. The principal advantages offered by an array are (1) that dense station distribution allows for direct measurement of the azimuths of approaching wavefronts and slopes of travel time curves, $\mathrm{d} t / \mathrm{d} \Delta$, which are directly used in earthquake locations 


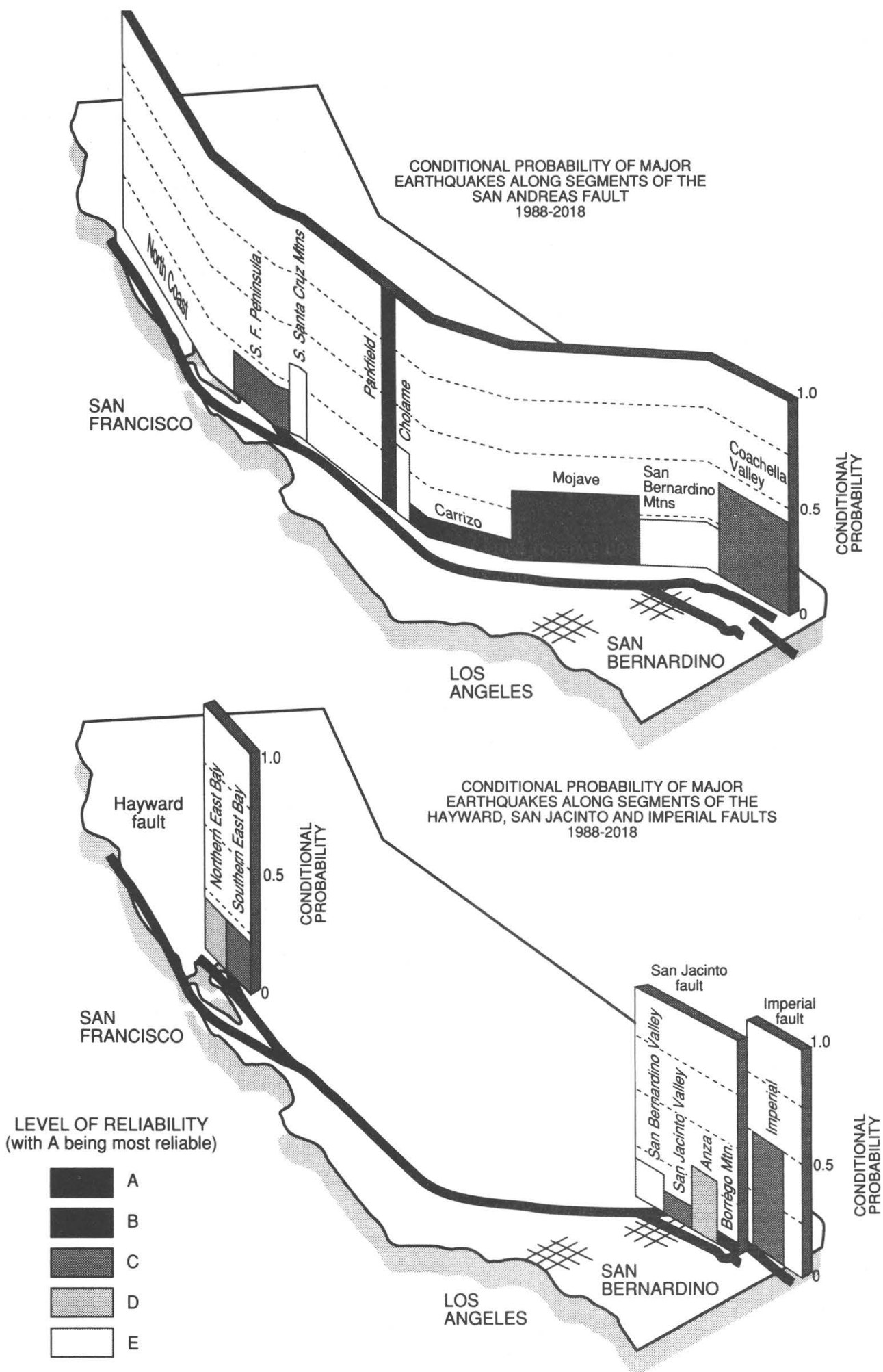

Figure 6. Conditional probabilities of the occurrence of major earthquakes on the San Andreas, Imperial, San Jacinto, and Hayward fault systems for the 30-year period from 1988 to 2018 (Working Group on California Earthquake Probabilities, 1988) 
and earth structure inversions, and (2) that signal-to-noise enhancement can be achieved by stacking closely spaced observations. Many specialized arrays such as LASA and NORSAR have been deployed with regular geometries and standardized instrumentation; however, regional networks have proved equally useful as large "arrays" despite their irregular geometries and variable instrumentation.

Array diagrams for regional networks and arrays (fig. 7) are a way to indicate earthquake location capabilities of each array relative to a global network of stations (Powell, 1976). The CIT regional network (Southern California Seismic Network) shows remarkably small mislocation vectors, which is a consequence of its large aperture and high station density. Systematic analysis of the regional mislocation vectors has been adapted to a variety of studies, including analysis of mantle velocity heterogeneity near the earthquake source, deep in the mantle, and in the upper mantle and crust beneath the regional network. The data are acquired in a passive mode as the regional networks are operating to accomplish their regional monitoring functions, but many additional array processing capabilities can potentially be implemented for regional networks. Examples would include routine beam forming for enhanced detection of seismicity in global seismic gaps, aftershock zones, or nuclear test sites. Such applications have been sparse largely due to limitations imposed by cumbersome data management systems and by the limited frequency bandwidth and dynamic range of existing regional networks.

The dense spatial coverage provided by regional networks has been directly exploited in many studies of crustal velocity structure to map the crust at geologically meaningful scales. In one example of detailed imaging of lateral variations in shallow crustal velocity structure (Hearn and Clayton, 1986a), obtained by use of stations and local seismicity in southern California (fig. 8), the crustal velocity variations are strongly associated with surface tectonic features such as the San Andreas fault. Similar analysis of lateral variations in uppermost mantle structure based on the $P_{\mathrm{n}}$ phase also reveals striking spatial heterogeneity, as shown in figure 9 (Hearn and Clayton, 1986b). Given that regional seismic networks are intrinsically located in interesting tectonic environments (for example, similar models have been obtained using regional networks near New Madrid, Missouri, and Puget Sound, Washington), it is always of interest to obtain such detailed crustal models in order to understand the underlying physical processes causing the seismic activity. The data for such analysis are a direct by-product of the seismic monitoring function of networks.

In addition to using local earthquakes to investigate shallow crustal structure, regional networks accumulate teleseismic travel times and waveforms that allow deeper mantle structure to be studied. A spectacular example is seen in figure 10 (Humphreys and others, 1984), showing a high-velocity tabular root that extends several hundred kilometers into the mantle beneath the Transverse Ranges of southern California.
New sophisticated tomographic inversion techniques have been developed to reliably resolve such structure from regional network data, and practical experience has shown that upper mantle heterogeneity is ubiquitous. This has many implications for the dynamics and chemical evolution of the crust and upper mantle. Regional network data have been used to produce three-dimensional images of velocity structure beneath southern California, northern California, New England, Washington, and the New Madrid seismic zone.

Accurate measurements of travel times and wave slowness by regional networks have played a major role in improving our detailed knowledge of upper and lower mantle radial and lateral variations. Figure 11 (Walck, 1984) shows the high resolution of travel time and ray-parameter measurements that can be attained using regional network data (in this case from the Southern California Seismic Network). The critical identification of secondary arrivals is abetted by the dense station distribution, as shown in figure 12, where data from several events are combined to develop a profile for the ray paths beneath the Gulf of California (Walck, 1984).

\section{Current Strong-Motion Instrumentation}

The term "strong motion" is used in the engineering and seismological communities to mean ground motions that are sufficiently large to be capable of causing damage, and "strong-motion instruments" are seismographs (usually accelerometers) that can record these large motions without overdriving the seismograph. Presently, a large number of Federal, State, and local governmental agencies, corporations, public utilities, and universities operate and maintain about 3,000 strong-motion instruments in the United States (National Research Council, 1987; table 3, figures 13 and 14). Each organization installs instruments to satisfy its own particular needs, and about 40 percent of the instruments are private and yield data not available for research. In general, the primary goal of the instrumentation is to gather data for engineering purposes. The majority of these instruments are installed within or on structures ranging in size from one-story fire stations, schools, and post offices to high-rise buildings, dams, bridges, storage tanks, and power plants. Few of these instruments are installed in free-field or ground sites, which typically consist of an accelerograph housed within a small fiberglass hut resting upon a concrete pad 1 meter square.

Although some digital accelerographs have been installed within the last few years, the vast majority of strong-motion instruments are analog and record their signals on moving photographic film. For a large structure in which many acceleration sensors are deployed throughout the structure, the signals from all sensors are conveyed to a central multichannel recorder that records all channels simultaneously on photographic film. For smaller structures and for free-field sites, the most commonly used accelerograph is a self-contained unit that records three orthogonal components of ac- 

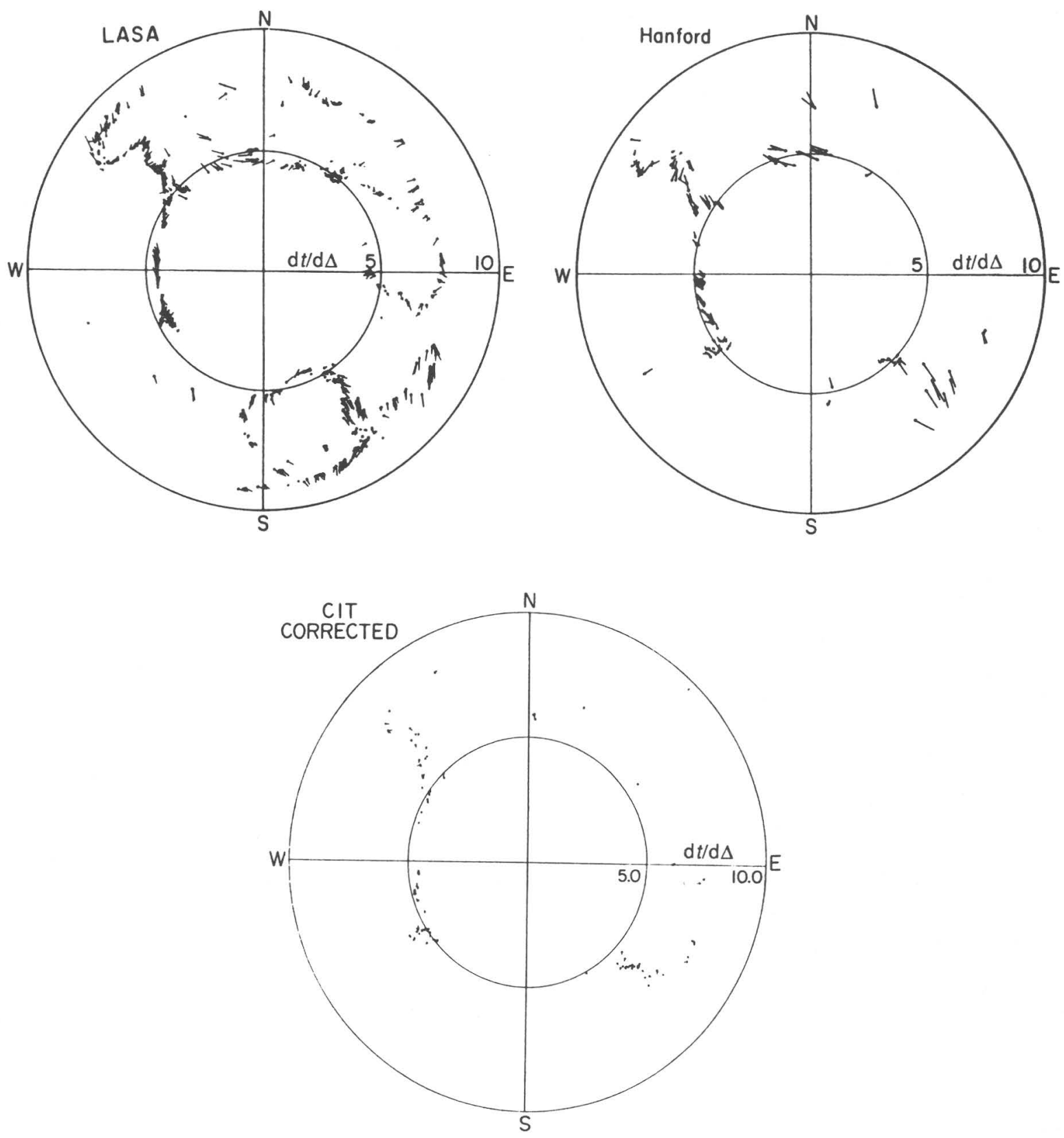

Figure 7. Mislocation vectors from Large Aperture Seismic Array (LASA) in Montana (discontinued in the 1970's), regional network in eastern Washington (Hanford), and southern California (CIT) regional network. Tail of each vector represents azimuth and incidence angle of a planar $P$ wave from a teleseismic earthquake as observed at these networks, and the head represents azimuth and incidence angles expected from known locations of earthquakes and standard earth model (Powell, 1976). Apparent velocity, $d t / d \Delta$, in seconds per degree.

celeration on a 70-mm photographic film strip. All of these accelerograph systems are "triggered" units, which sit dormant until detecting a ground acceleration that exceeds a preset threshold (usually $0.01 \mathrm{~g}$ on the vertical component). Once the threshold is exceeded, there is a short interval (about $0.1 \mathrm{~s})$ during which the instrument's film transport accelerates to its desired operating speed. Because of the triggering and the delay of the film transport, these accelerographs cannot record the initial $P$-wave motions of the earthquake or any preevent ground noise. In addition, many of these instruments have no external time reference, so that absolute wave arrival times cannot be determined, and in cases of multiple 

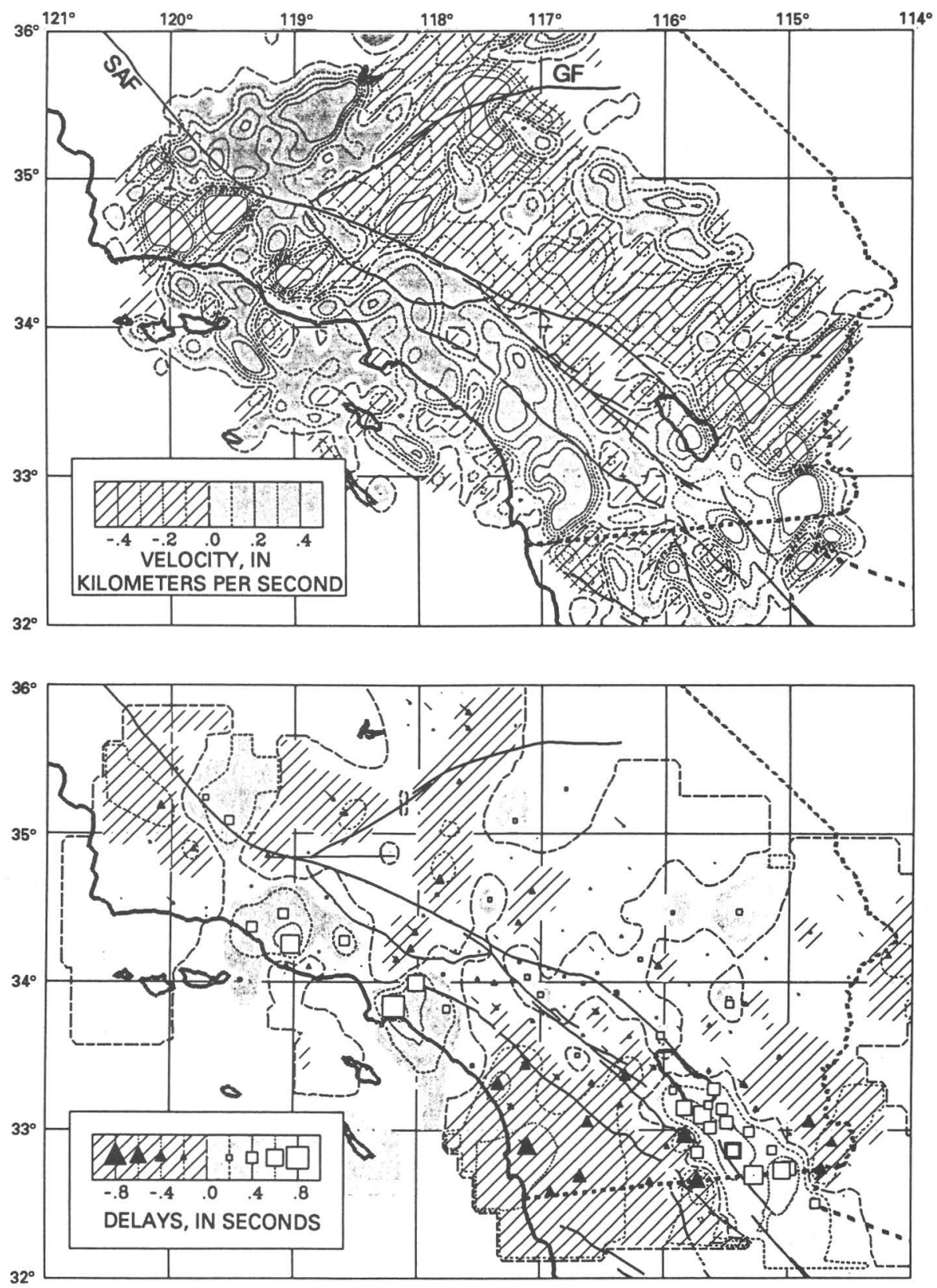

Figure 8. $P_{\mathrm{g}}$ velocity variation (top map) in southern California as inferred from tomographic inversion of $P_{\mathrm{g}}$-wave travel times from local earthquakes recorded on the Southern California Seismic Network. $P_{g}$ velocities are representative of the average crustal $\boldsymbol{P}$-wave velocity. Hachured region indicates relatively low velocities and shaded regions are relatively fast. A strong correlation between $P_{g}$ velocities and major geologic discontinuities such as the San Andreas fault (SAF) and Garlock fault (GF) can be seen. Station delays (bottom map) for corresponding study. Hachured areas show regions of early arrivals. Late arrivals (shaded areas) are associated with Los Angeles and Ventura basins and Salton trough (Hearn and Clayton, 1986a).

earthquakes (such as aftershocks) the lack of an external time reference prevents unambiguous identification of a recorded event. Because a rather strong signal $(0.01 \mathrm{~g})$ is required to trigger these accelerographs, these instruments detect relative- ly few events; they are usually only triggered by very local events of about $M 4.5$ or larger, or by larger more distant events. In many cases a strong-motion instrument will trigger on only the main event of a sequence. 

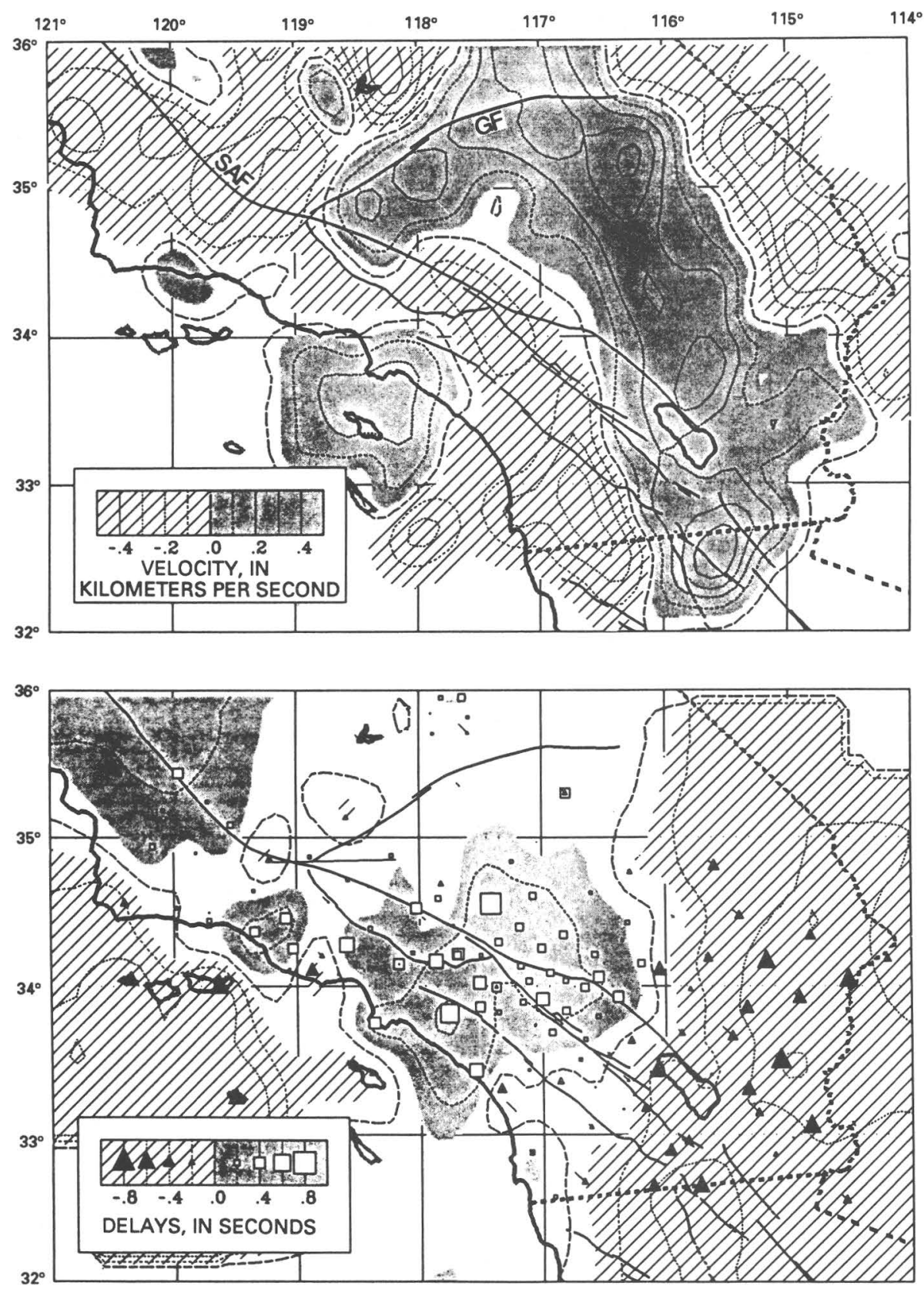

Figure 9. $P_{\mathrm{n}}$ velocity variation (top map) in southern California as inferred from tomographic inversion of $\boldsymbol{P}_{\mathrm{n}}$-wave travel times from earthquakes recorded on Southern California Seismic Network. $\boldsymbol{P}_{\mathrm{n}}$ velocities representative of uppermost mantle beneath southern California. Hachured regions indicate relatively low velocities; shaded regions are relatively fast. $P_{n}$ velocities are generally higher on North American plate, east of San Andreas fault (SAF), than on Pacific plate, west of San Andreas fault. Contour plot (bottom map) shows station delays. Hachured areas indicate regions of relatively early arrivals. Largest delays (shaded areas) are associated with sedimentary basins, and early arrivals are associated with thin crust (Hearn and Clayton, 1986b). GF, Garlock fault.

Most accelerograms recorded on photographic film are processed using a fairly standard procedure. The first step is the decision of which recordings are sufficiently interesting from an engineering standpoint to merit digitization; general- ly only those recordings having accelerations larger than 0.05 $g$ are digitized. Thus, the detection threshold for digitized data is around $M 5$. The digitization is performed by an automated trace-following system supplemented by hand digitization of 

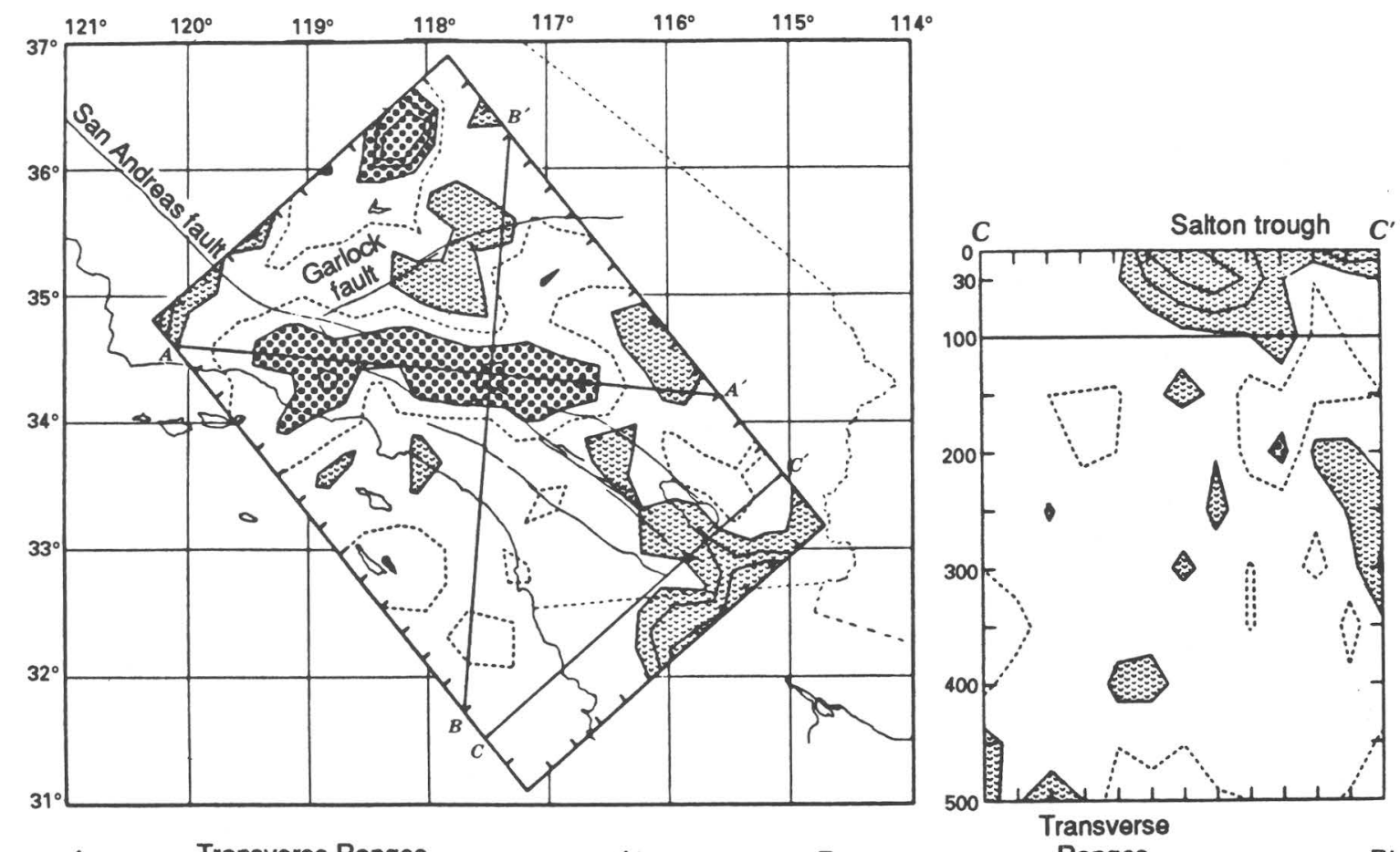

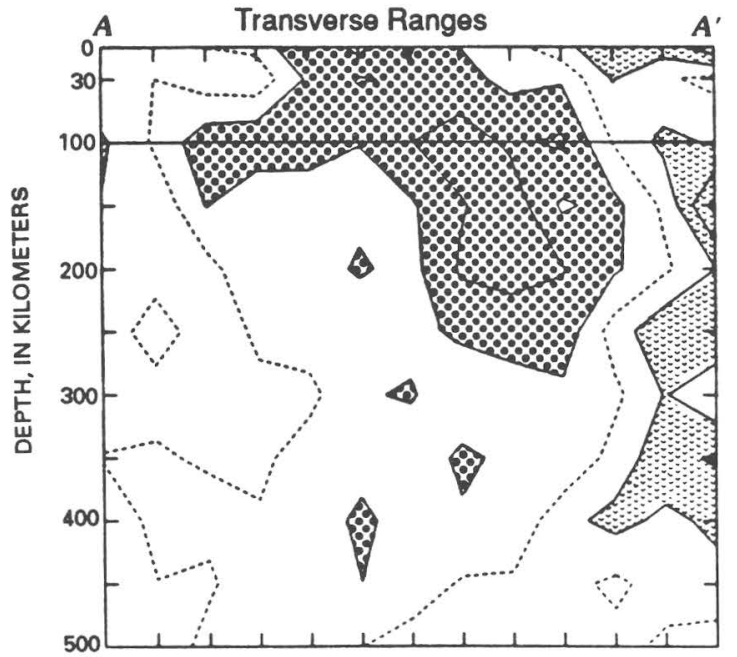

Figure 10. Three-dimensional upper-mantle $P$-wave velocity structure beneath southern California as inferred from tomographic inversion of teleseismic $\boldsymbol{P}$ delays derived from Southern California Seismic Network. In upper left panel, horizontal section at depth of $100 \mathrm{~km}$ is superimposed on location map of southern California. Locations are shown for three cross sections $\left(A-A^{\prime}, B-B^{\prime}\right.$, $\left.C-C^{\prime}\right)$ displayed in other panels. Vertical and horizontal scales are identical. Contour interval is 1.5 percent velocity variations, with high-velocity regions indicated by dotted

portions of the record where accelerations are large and the automated system cannot follow the traces properly. The digital acceleration data are then corrected for the instrument response and integrated to yield ground velocity and ground

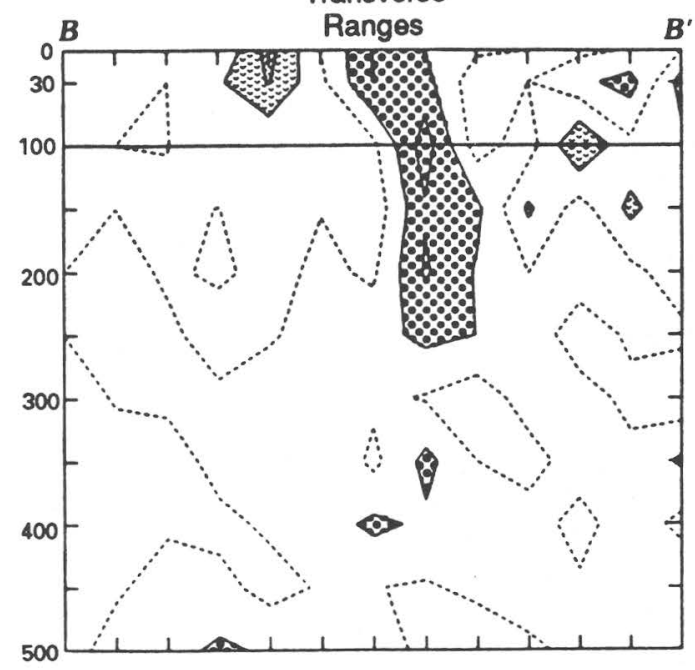

areas, and low-velocity regions indicated by chevron pattern. Zero contour is dashed. East-west-trending, tabular, high-velocity region beneath Transverse Ranges can be seen in cross sections $A-A^{\prime}$ and $B-B^{\prime}$. This slab of high-velocty material may represent downwelling in mantle beneath Transverse Ranges. Cross section $C-C^{\prime}$ perpendicular to Salton trough, reveals region of velocities that are 2 to 4 percent slow at depths extending to $100 \mathrm{~km}$ beneath this region of crustal extension (Humphreys and others, 1984).

displacement records. The effective bandwidth of the data is from about 0.1 or $0.2 \mathrm{~Hz}$ at low frequencies to about 25 to 50 $\mathrm{Hz}$ at high frequencies. The bandwidth is much less broad for small events due to the large amount of noise introduced into 
the data during digitization. The effective dynamic range of these systems is about $60 \mathrm{~dB}$.

\section{Limitations of Existing Networks}

The development of the current generation of regional networks within the United States began in the 1960's in response to the need to learn more about the distribution of seismicity within regions of recognized earthquake hazards. The most basic questions (such as, "Do earthquakes occur along recognizable fault planes?") had no answers at that time. Consequently, observational seismology was in a position to make rapid progress by adapting well-established seismological techniques of earthquake location and magnitude determination to local and regional scale problems. By the early 1970 's the design characteristics of the network systems were largely established. These now-antiquated technologies have continued to operate into the 1980's with only modest upgrading of their data analysis capabilities and without any improvements in the resulting data.

The characteristics of existing regional seismic and strong-motion networks have been very strongly influenced by the objectives attainable with then available technology. In the case of regional seismic networks, the primary objective has been the construction of a high spatial resolution catalog of earthquake activity within each network. It has thus been imperative to obtain numerous $P$-wave arrival times for as many earthquakes as can practically be observed. Economic considerations dictated the recording of high-frequency, vertical-component ground motions from many sites.

The actual ground motion history has largely been sacrificed in this mission. Because of the need for high sample rates, the only practical solution in the past has been to continuously telemeter analog data streams. Furthermore, the required high sample rates have made it difficult to store digital records from long-duration records such as those expected from teleseisms. The use of analog FM data telemetry has severely restricted the dynamic range (typically $40 \mathrm{~dB}$ ) of the seismic systems. Because the mission calls for the monitoring of small earthquake activity, gains are typically set high enough to resolve earth noise. Consequently, the signals are off scale for most of the significant earthquakes. Furthermore, small earthquakes are best detected and timed using high-frequency ground motions. Since there is typically high ground noise at periods near 6 seconds, there has been a conscious effort to record only frequencies higher than about $1 \mathrm{~Hz}$. The effective dynamic range of typical existing networks compared with expected seismic signals is shown in figure 15 . Clearly, much important ground-motion information is not currently recorded by the existing regional networks.

The need for continuous telemetry has also made the cost of telemetry a major consideration for the design of networks. In the present situation, the cost of telemetry increases linearly with the number of channels that are sent. The cost of telemetry, together with the limited dynamic range of the sys-
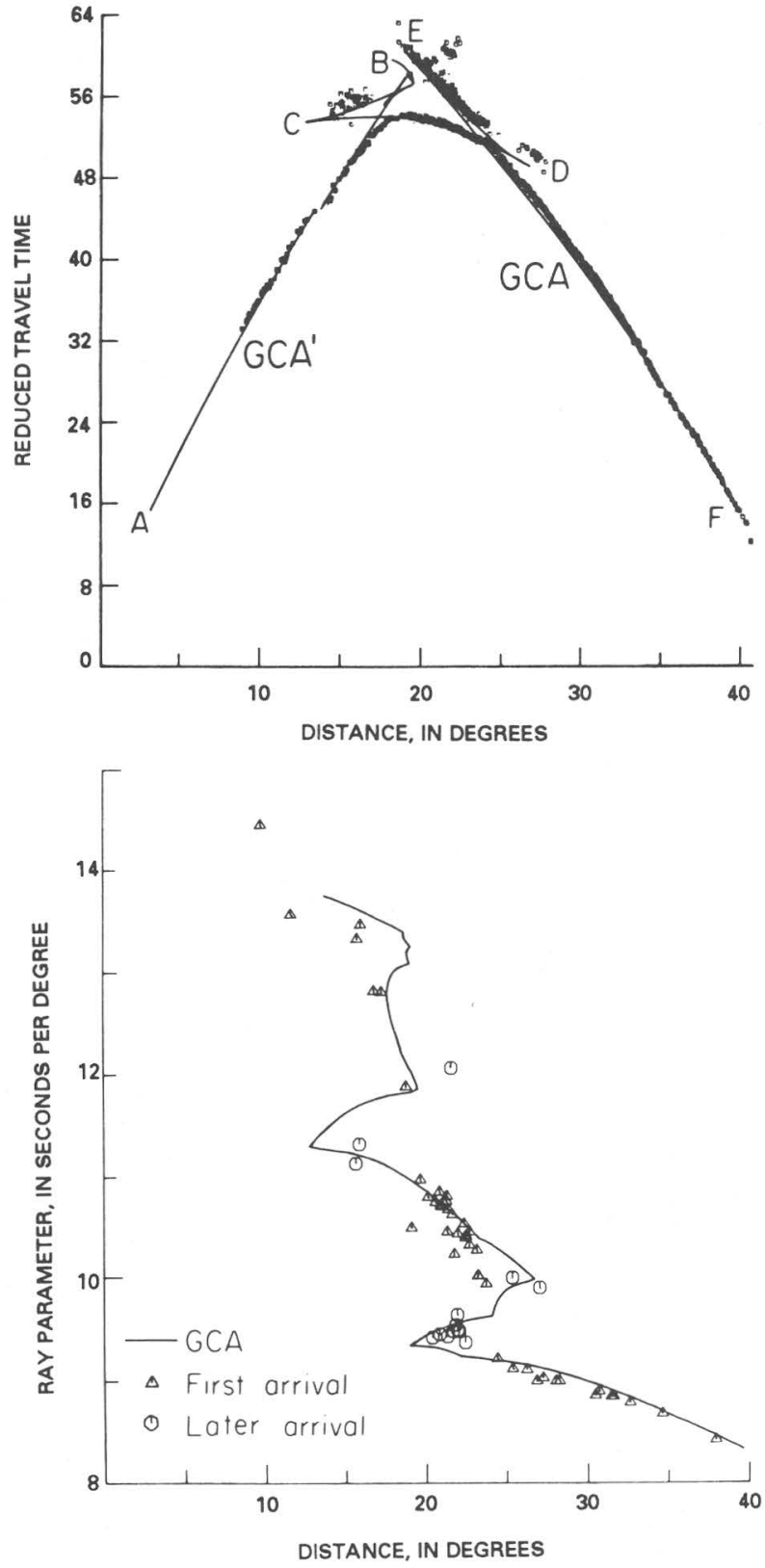

Figure 11. Reduced travel times (top plot) of $P$ waves traveling in upper mantle from earthquakes located at regional distances and recorded on Southern California Seismic Network. Triplications caused by velocity discontinuities in upper mantle are easily identified (travel-time branches $A B$, $\mathrm{CD}, \mathrm{EF}$ ). Ray parameters (bottom) measured from corresponding data together with those expected for a model of uppermantle $P$-wave velocities. See Walck (1984) for further discussion of Gulf of California region models GCA and GCA'.

tem, have largely contributed to the decision not to record horizontal components of ground motion at most sites. Unfortunately, this has led to very uncertain interpretation of shear-wave arrivals. 

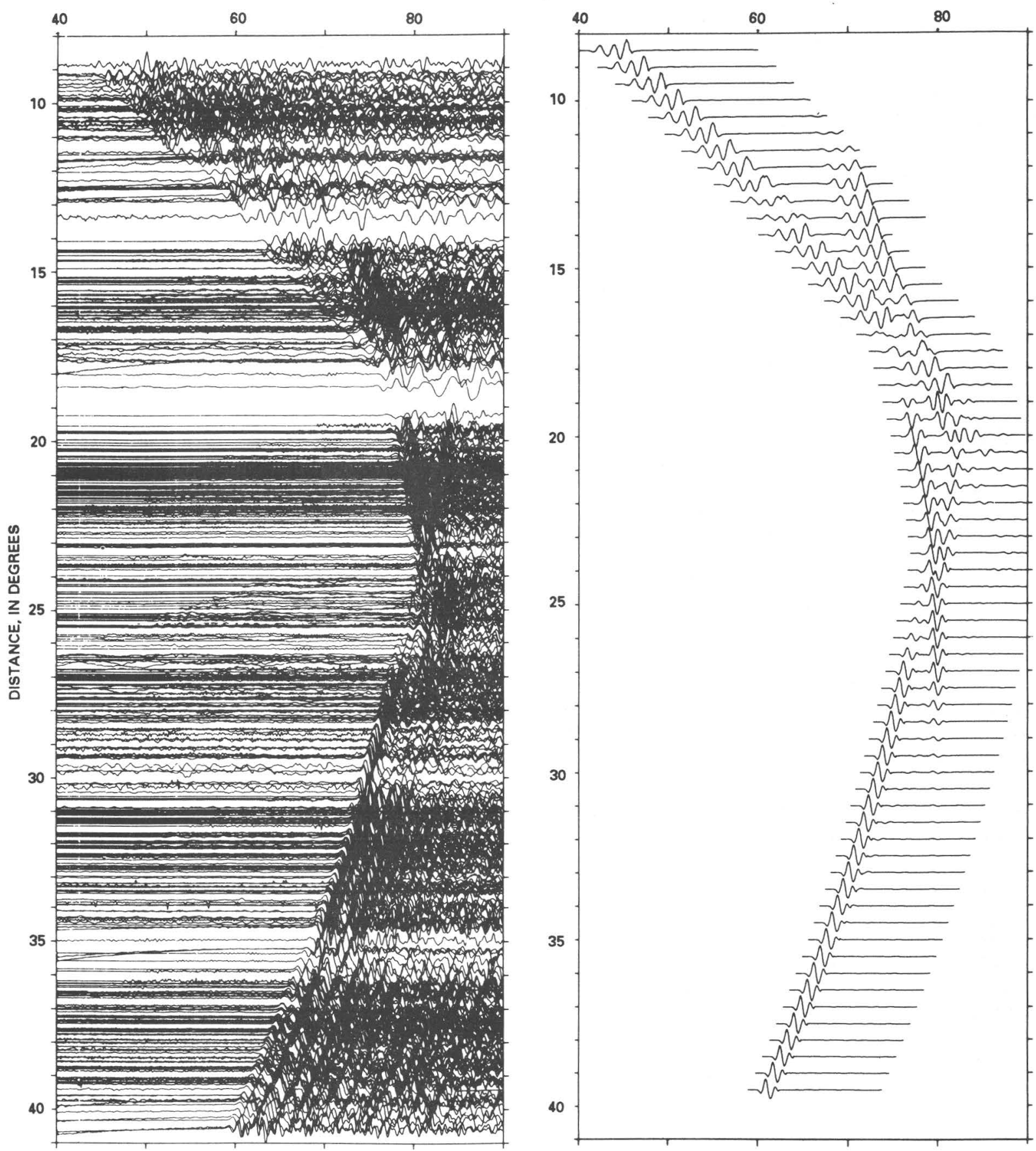

Figure 12. Data record section (left) for upper-mantle $P$-waves from 10 earthquakes spanning the distance from $9^{\circ}$ to $40^{\circ}$ and recorded on the Southern California Seismic Network. Mantle triplication phases are clearly visible. Synthetic record section (right) on the same scale (Walck, 1984).

Serious noise problems, including noise "glitches" in telephone and radio systems, are also associated with analog FM telemetry. Furthermore, in most networks the analog signals from many stations are transmitted on twisted pairs of wires to a single analog to digital converter (ADC). Inductive crossfeed between stations can sometimes be a serious problem that is difficult to recognize and which can lead to very serious errors in interpretation. These noise problems are 
Table 3. Summary of strong-motion instrumentation efforts in the United States

\begin{tabular}{lr}
\hline Organization & $\begin{array}{c}\text { Number } \\
\text { of instruments }\end{array}$ \\
\hline California Division of Mines and Geology & 500 \\
U.S. Army Corps of Engineers & 350 \\
U.S. Geological Survey & 275 \\
Pacific Gas and Electric Company & 91 \\
State of Washington & 90 \\
University of Southem California & 81 \\
U.S. Department of Energy & 80 \\
U.S. Bureau of Reclamation & 70 \\
U.S. Veterans Administration & 65 \\
Nuclear power plants & 62 \\
Califomia Department of Water Resources & 70 \\
University of Califomia, Los Angeles & 36 \\
Los Angeles Department of Water and Power & 35 \\
U.S. Navy & 35 \\
Federal Highway Administration & 30 \\
Metropolitan Water District of Southern California & 30 \\
Southem California Edison Company & 26 \\
Los Angeles Flood Control District & 25 \\
University of California, San Diego & 21 \\
Intemational Business Machines Company & 20 \\
Columbia University & 18 \\
Stanford University & 15 \\
California Institute of Technology & 15 \\
Washington Department of Transportation & 15 \\
Idaho National Engineering Laboratory & 15 \\
Lawrence Livermore National Laboratory & 15 \\
Buildings instrumented in cities using Uniform Building Code & 321 \\
Instruments installed by various organizations & 325 \\
The City of Los Angeles requires owners of large buildings to & \\
install and maintain strong-motion instruments. This is the & \\
largest uncoordinated collection of instruments & 500 \\
& \\
\hline & \\
& \\
&
\end{tabular}

not present in systems in which data are digitized at the station and then transmitted via error-detecting telemetry.

The large volume of data that must be managed in order to record many events at many stations and at high sample rates has necessitated the development of specialized computer hardware and software. Actual seismcgrams are stored on magnetic tapes, and it is usually an arduous task to retrieve subsets of the data for research. These high-rate data streams also make it difficult to stay current with data analysis during seismic crises, just when such analysis is most needed.

Although the monitoring of local seismic activity is a crucial one, the attainment of that goal has severely limited the usefulness of the data for many other areas of seismology. This has caused the study of regional network seismology to become intellectually isolated from other fields of seismology.

Strong-motion networks also have a relatively narrow, but very different, mission. Their primary function is to record three-component earthquake ground motions that could cause damage to facilities. They must operate on scale for shaking from relatively rare earthquakes that are large or close enough to cause damage. Continuous telemetry of these signals has been a very low priority since there are rarely any data to telemeter. Hence, it usually requires many days for strong-mo- tion records to become available. Furthermore, since the knowledge of absolute time is of little interest to the response of an engineered structure, there is usually little information about the absolute time of seismic arrivals during strong shaking. This often considerably complicates any fundamental physical interpretation of the cause of the ground shaking.

Because of the difference in their primary missions, highgain seismometers and strong-motion seismometers are very rarely collocated. As will be discussed later, this has several important implications: (1) Ground motions from small earthquakes are dominated by the effects of propagation through complex geologic structure. If these effects are understood from the study of recording of weak motions from small earthquakes, then they can be removed from the strong motions that occur during large earthquakes and the detailed nature of the seismic source can be ascertained. Therefore, it is difficult to separate the effects of rupture and wave propagation. (2) High-gain seismometers are rarely located in regions of intrinsically high noise, such as cities, or even basins. However, these are the areas having most inhabited structures. Important propagation effects (such as that which happened on 15 October 1985 in Mexico City) are usually not recognized until after a tragedy has occurred. (3) Perhaps the largest disadvantage of the configuration of present networks is the lack of interaction between earthquake engineers and earthquake seismologists.

\section{CONFIGURATION OF PROPOSED DIGITAL NATIONAL SEISMIC SYSTEM}

\section{The U.S. National Seismic Network}

The U.S. National Seismic Network (USNSN) is a new program being undertaken by the National Earthquake Information Center (NEIC) of the U.S. Geological Survey. Although a tentative plan has been developed to instrument the entire United States (see figure 16 for a preliminary distribution of stations), funding has only been obtained for the portion of the continental United States that is east of the Rocky Mountains as part of a joint project with the U.S. Nuclear Regulatory Commission (USNRC). The USNSN program is large and complex. The major elements are (1) the field system, (2) the telemetry system, (3) the central processing system, and (4) a data archival and distribution center.

The USNSN design goals reflect an attempt to satisfy a number of diverse requirements including national and global monitoring and research on a regional scale within the United States. However, the design goals have also been strongly influenced by known and suspected financial constraints in an attempt to ensure that the network can be completed and operated over the coming decades. Further, the design has been affected by the conscious management strategy of attempting to maximize functionality and minimize cost by the use of state-of-the-art technology without taking undue risks with emerging technologies. 


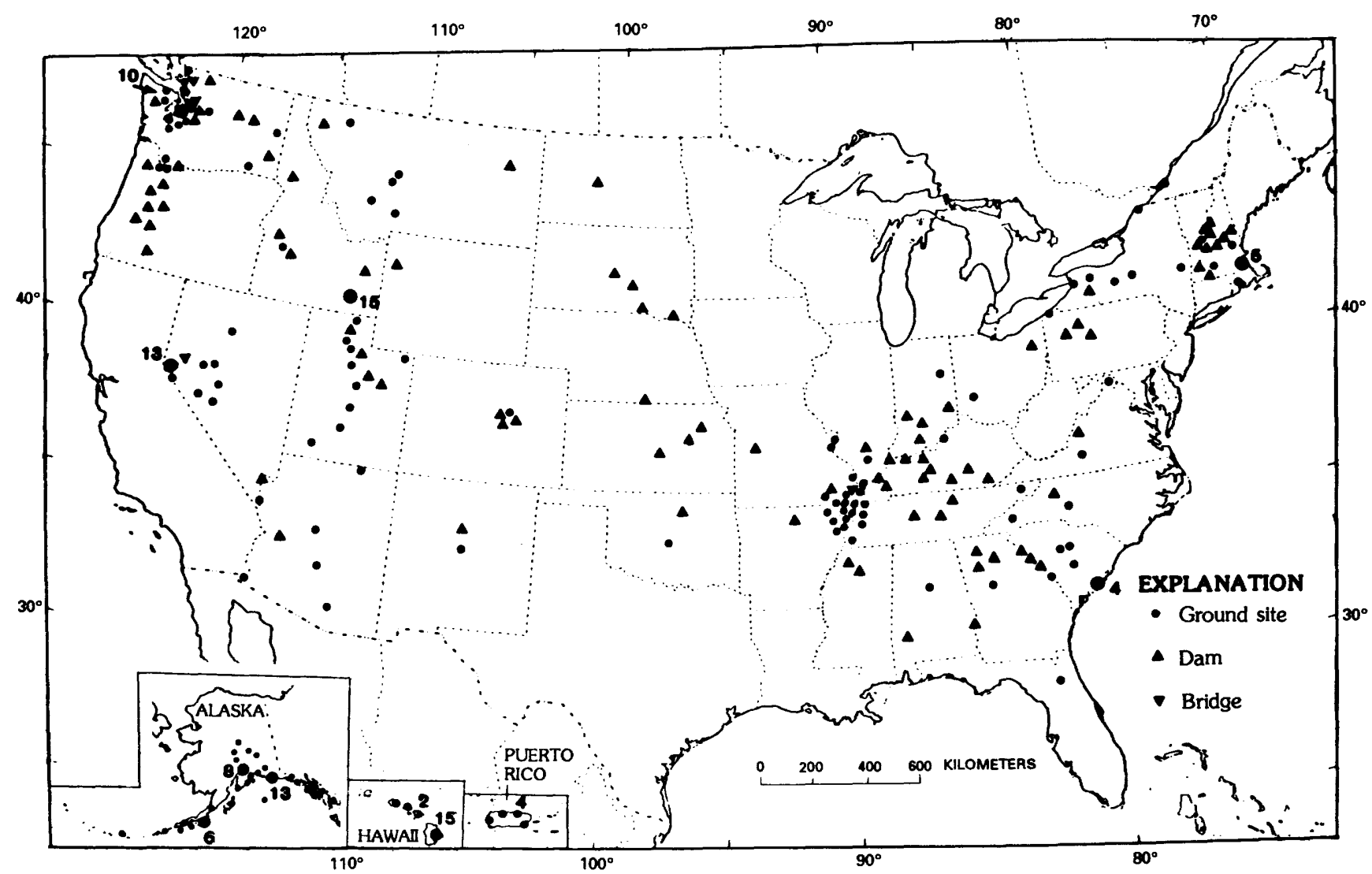

Figure 13. Known accelerographs in the United States outside of California as of April 30, 1981. Excludes commercial nuclearpowered electrical generating plants. Numbers indicate where more than one station is located.

The seismic monitoring design goals of the USNSN arise from the requirements of the National Earthquake Information Service (NEIS) Earthquake Early Alerting Service. These design goals tend to complement the capabilities of existing USGS and USNRC funded regional seismic networks that were described in previous sections. In fact, the NEIS currently depends on real-time data telemetered from a small subset of regional seismic networks for their Alert Service. The monitoring goals of the USNSN are (1) uniform coverage of the United States and (2) on-scale recording of all seismic phases of interest from all earthquakes of interest. Uniform coverage is defined as the ability to record any event of magnitude $\mathbf{2 . 5}$ or larger by at least five stations anywhere in the continental United States and any event of magnitude 3.5 or larger anywhere in Alaska, Hawaii, and Puerto Rico. Phases of interest for seismic monitoring are various compressional and shear wave groups within the frequency band 0.5 to 15.0 $\mathrm{Hz}$ and surface waves of 15 to $30 \mathrm{~s}$. To be of use in Alert Service monitoring, all data must be available within several minutes of real time.

The research design goals for the USNSN can be summarized as a requirement for three-component, broad-band, high-dynamic-range data. The network should record both body waves and surface waves from local, regional, and teleseismic sources. Although data streams that are triggered and record only during the arrival of significant phases are considered to provide a practical solution to data management problems, it is important to develop sophisticated triggers to allow flexibility in the types of research problems that can be investigated with this network.

In order to meet these monitoring and research design goals with available technology, the USNSN will consist of the following components (shown diagrammatically in figure 17). The required dynamic range, linearity, and bandwidth of the seismometers dictates the use of force balance sensors. Even using state-of-the-art seismometry, the desired dynamic range will require the use of two sets of seismometers (a highgain and a low-gain sensor for each component). In order to preserve this dynamic range, the seismometer outputs must be digitized onsite. This will be accomplished by means of stateof-the-art 24-bit (144 dB) analog to digital converters.

A station processor is required to perform the following functions: (1) acquire six channels of seismic data and up to eight channels of state-of-health data, (2) low-pass filter and decimate the six high-frequency (HF) channels to derive six broad-band (BB) channels, six long-period (LP) channels, and one short-period (SP) channel, (3) manage rotating buffers of pre-event data, (4) perform signal detection on the BB high- 


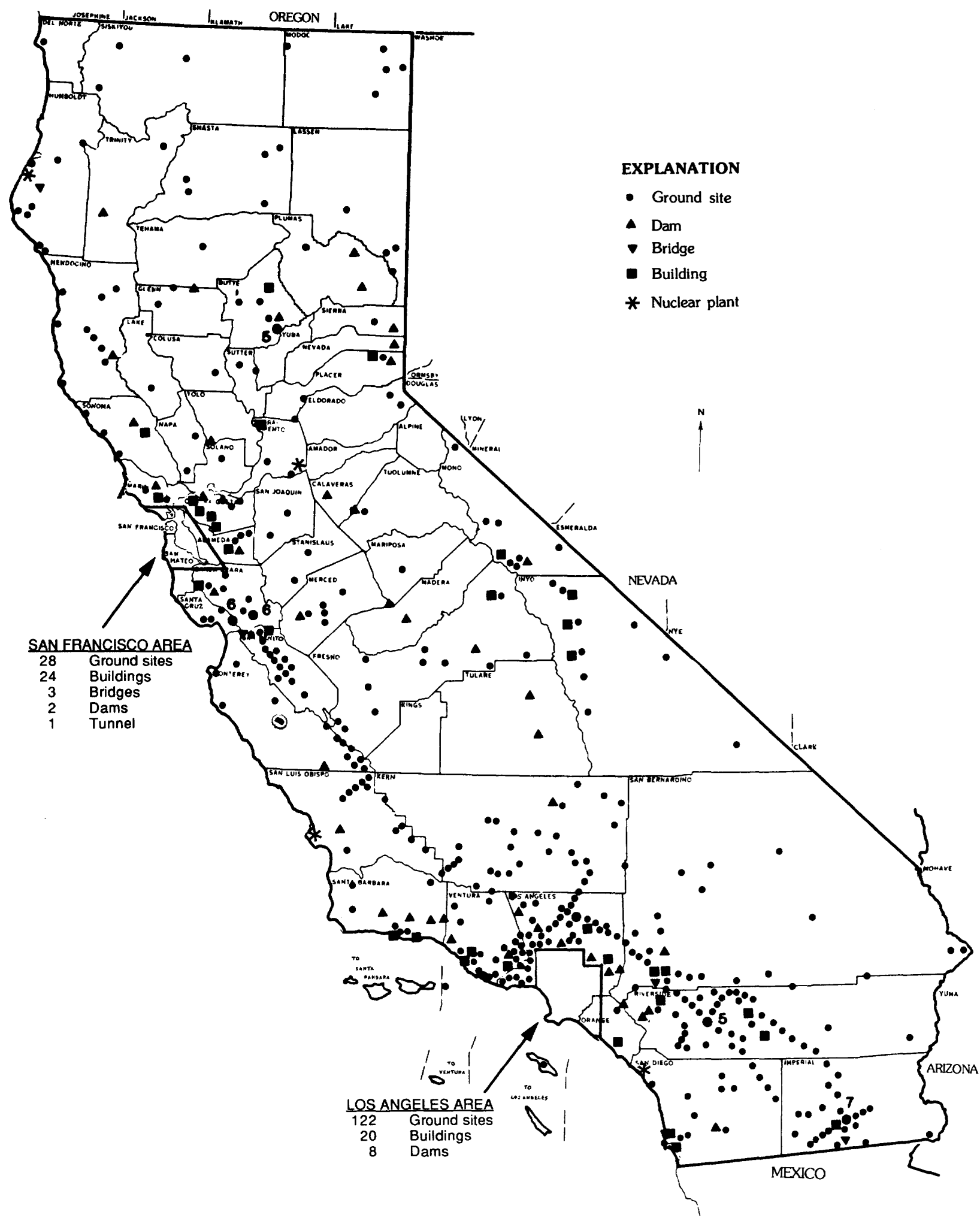

Figure 14. Known accelerographs in California as of April 30, 1981. Excludes instruments required by building codes. Numbers indicate where more than one station is located. 


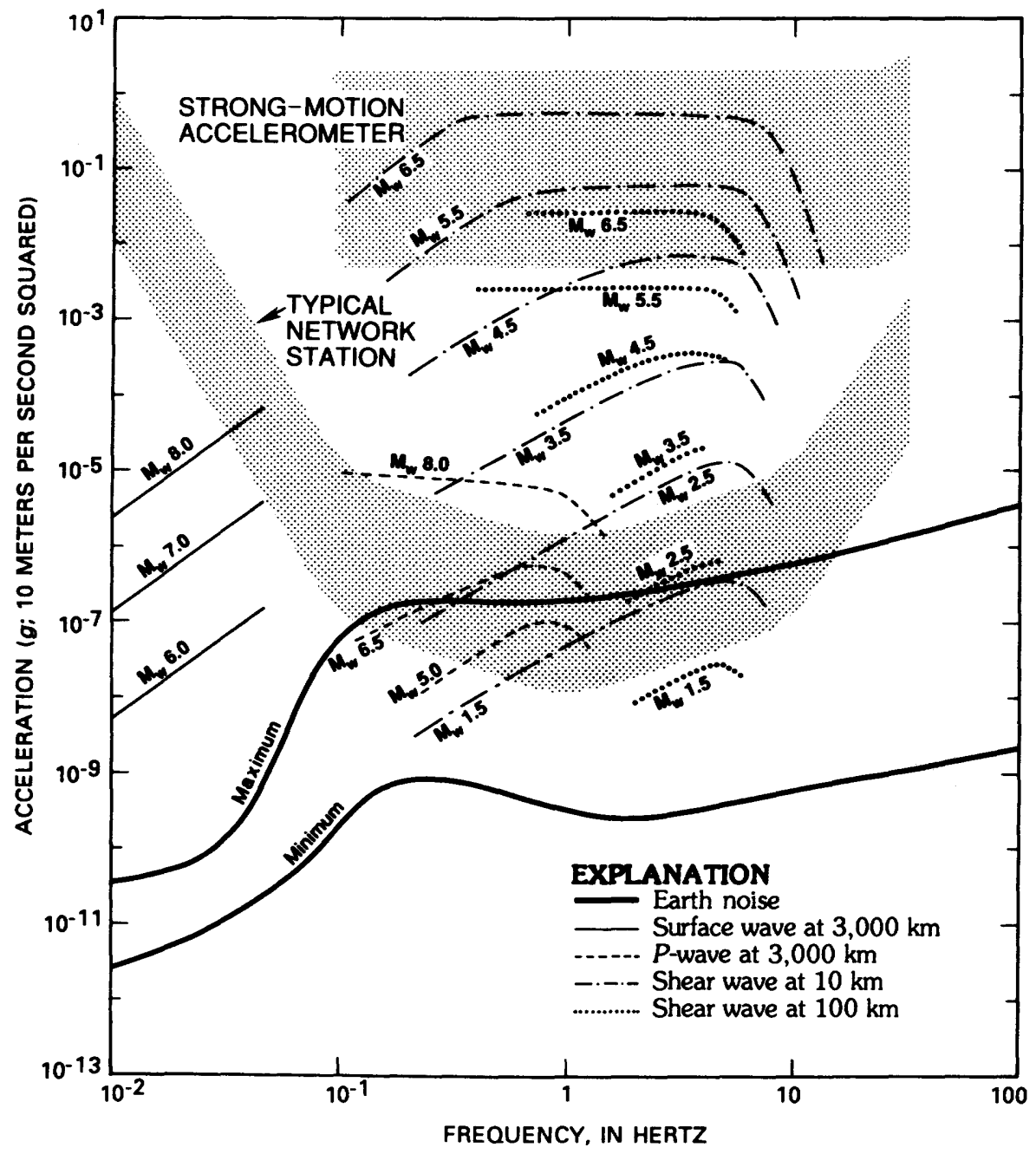

Figure 15. Dynamic range plotted against frequency for typical regional network station and typical strong-motion station as well as expected levels of ground motion for different seismic arrivals from earthquakes of different sizes and recorded at different distances.

gain vertical channel based on an integer fast-Fourier transform, (5) format and manage prioritized output queues of continuous and event data, (6) communicate with the satellite telemetry system, (7) acquire and maintain absolute time, (8) interpret and execute remote commands, and (9) provide calibration and control signals initiated by remote command.

$\mathrm{Ku}$ band (14-16 GHz), time division multiple access (TDMA), very small aperture telecommunications (VSAT) satellite telemetry technology has been chosen since no other system has been found to be nearly as cost effective. This approach requires a master station with a $4.5-7.0 \mathrm{~m}$ antenna at the NEIC to control the multiplexing of 56-96 kilobyte-persecond satellite channels and VSAT's with 1.2-3 m antennas and associated electronics at each field site. The system will have sufficient capacity to telemeter all data simultaneously in the event of a great earthquake in North America. Furthermore, the system will be capable of two-way communications, thereby greatly increasing the flexibility of future trigger algorithms and station maintenance. A modified VSAT X.25 protocol will provide error detection and correction, thereby providing a very low bit error rate. This will greatly simplify the processing at the station and the central recording site. In addition, the VSAT system will provide absolute time (broadcast periodically by the master station).

Two different scenarios are being considered for the physical installation of the sites. In either case, the seismometers will be mounted on a concrete pad in a shallow pit and covered by a partially buried fiberglass dome. The seismometers will be adequately coupled to the pad and adequately thermally insulated. In the first scenario, commercial electric power will be available at the field site. This power will be filtered through an uninterruptable power supply (UPS) and distributed by a custom DC regulation system to the seismometer filter and control electronics, the station 


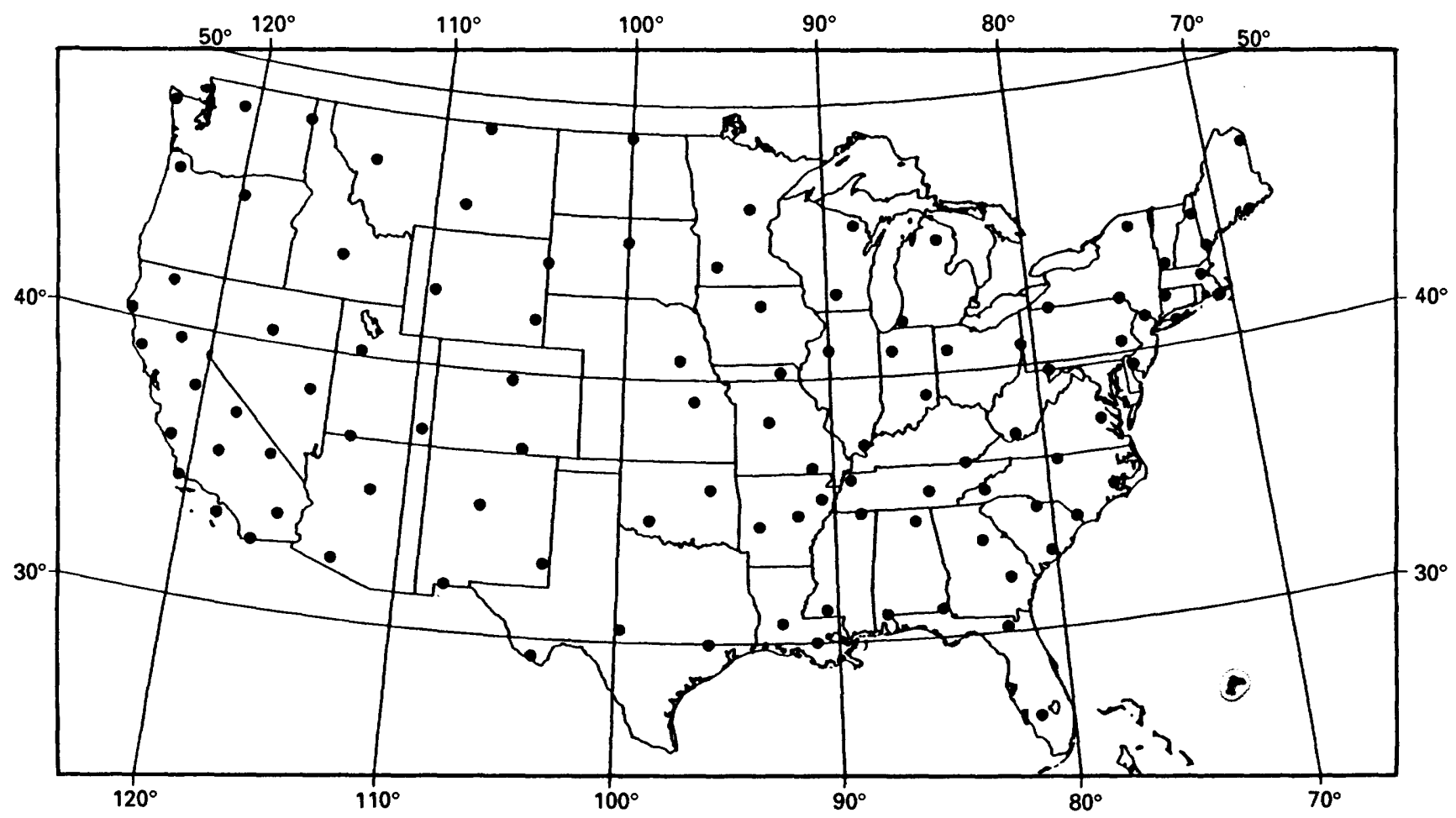

Figure 16. Proposed National Seismic Network stations in the contiguous United States. Additional stations are proposed for Alaska, Hawaii, and Puerto Rico. Only stations east of the Rocky Mountains in the contiguous United States are currently funded (from Massé and Buland, 1987).

processor, and the VSAT electronics which will all be housed in a separate, partially buried, vented enclosure. The VSAT antenna will be mounted on a standard kingpost set into a concrete pad. In order to minimize noise from cooling fans and wind coupled through the antenna, the seismometer will be removed from the VSAT hardware (using a hardwire cable) by as great a distance as is practical.

The second installation scenario is considered to be more desirable, but also more costly. In this case, commercial electric power will be available within a few kilometers of the field site, but not at the field site itself. The seismometer, seismometer electronics, and the station processor will be located at the field site and operated by batteries recharged by solar panels. As no fans will be required for the electronics, all equipment could be housed in a single vented enclosure. The VSAT electronics and antenna will be placed where commercial electric power and reasonable security are available. A 2,400-baud telemetry link will connect the seismometer and the VSAT sites. Although the latter scenario is somewhat more expensive, it provides the possibility of lower seismic noise, greater physical security, and greater lightning protection. If the VSAT electronics become available in a low-power configuration, it may be possible to eliminate the fans and commercial power at all sites. At sites where an adequate pre-existing borehole is available, provision is being made to mount the seismometer package in the borehole.

\section{Relationship Between Regional and National Seismic Networks}

Although the proposed 150-station National Seismic Network will provide exciting new waveform data on a national scale (only 60 stations are currently funded), it cannot perform the functions of the 1,600 stations currently in regional networks. In particular, the primary function of detecting and locating earthquakes cannot be accomplished at an acceptable level with only 150 stations nationwide. As an example, we show earthquakes located by the 75-station regional network operated by the University of Utah together with proposed sites for the National Seismic Network in figure 18. It is clear that the relatively low station density for the National Seismic Network would be inadequate to resolve the detailed patterns of seismicity seen with the existing regional network. As we discuss later, study of these seismicity patterns is vital for a better understanding of a wide variety of basic problems.

The relatively high station densities of existing regional networks are also vital for a wide range of other important seismological problems. These problems, listed in table 4, are discussed in detail in the sections on applications and research possibilities for a National Seismic System.

Even if sufficient station density were available in the National Seismic Network, regional networks would remain a focal point for research on important, but localized, 


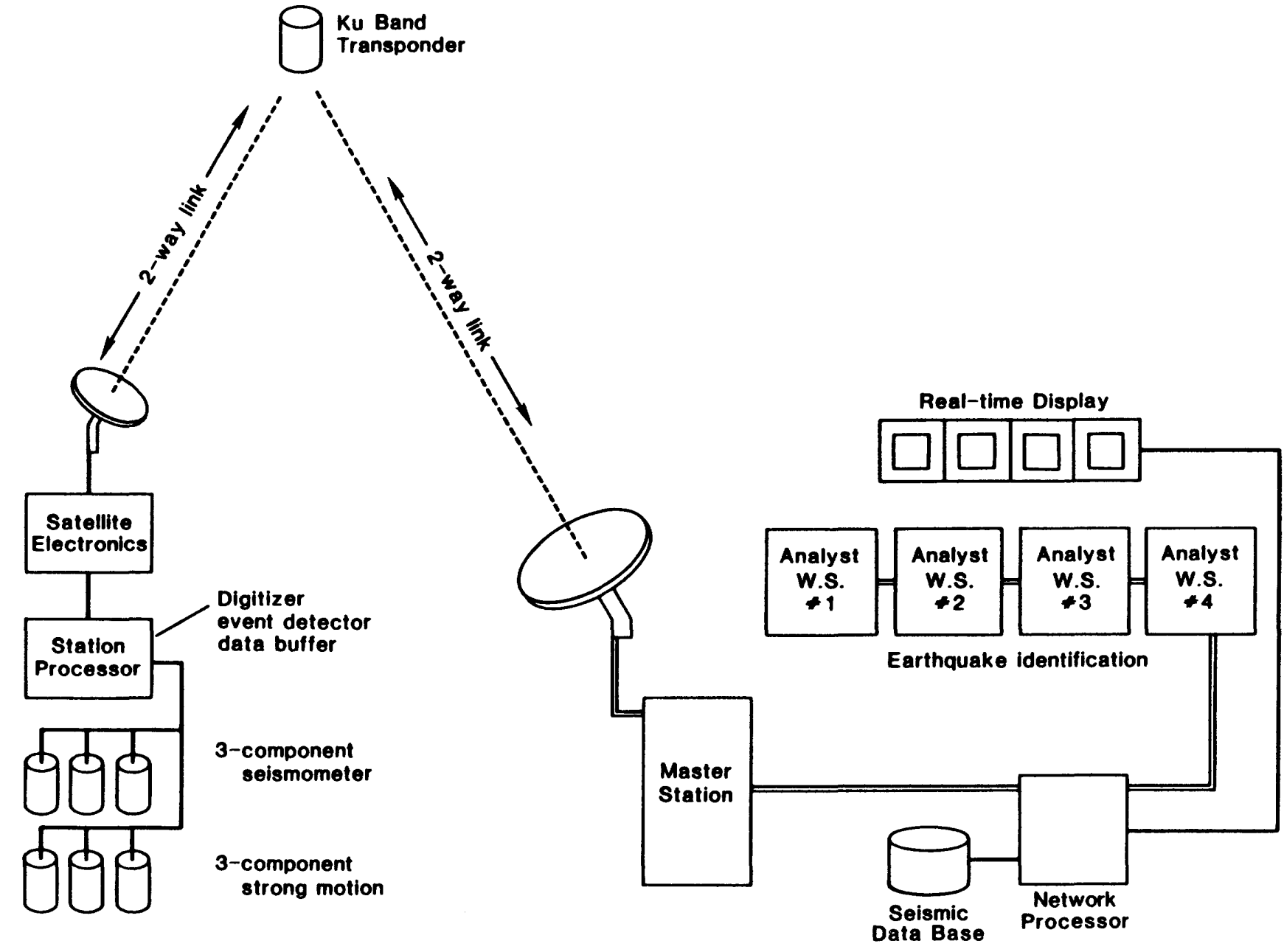

Figure 17. Schematic representation of National Seismic Network. Three-component, force-balance, broad-band seismometers (both high and low sensitivity) are digitally recorded at the station for a total dynamic range of approximately 10 decades (200 $\mathrm{dB}$ ). Significant seismic signals detected at the station processor are telemetered via satellite to the Master Station in Golden, Colorado, for analysis and archival.

earthquake and tectonic problems. Although the National Seismic Network is not designed to replace regional seismic networks, it provides an opportunity to dramatically improve the capabilities of regional networks. That is, the National Seismic Network provides regional networks with the technology for recording broad-band, high-dynamic-range, threecomponent seismic data in real time and with low telemetry costs. Furthermore, the National Seismic Network provides a communications network that will interconnect regional networks. Standardized data manipulation procedures will allow better access to these important data sets by all researchers.

\section{Need to Develop Digital Regional Networks}

We have demonstrated that the existing regional networks provide a vital function in the observation of seismic waves, and their continuing operation should have a high national priority. We have also demonstrated that the existing regional networks are severely limited by the outdated technology on which they are based. Therefore, the upgrading of existing networks to digitally telemeter high-dynamic-range, broadband seismic data is a long-range goal of high priority. Unfortunately, a coordinated plan to ensure that such a goal is met has not yet been formulated.

In the beginning of this decade, the seismological community recognized similar shortcomings in global seismic networks (principally the World-Wide Standardized Seismic Network, WWSSN) and in the field of dense portable networks. As a result, approximately 57 research institutions formed a nonprofit corporation, the Incorporated Research Institutes for Seismology (IRIS). IRIS has three principal goals: (1) develop a Global Seismic Network (GSN) of approximately 100 high-quality digital stations, (2) develop a portable network of approximately 1,000 portable digital seismic stations (Program for Array Seismic Studies of the Continental Lithosphere, PASSCAL), and (3) develop a Data Management Cen- 


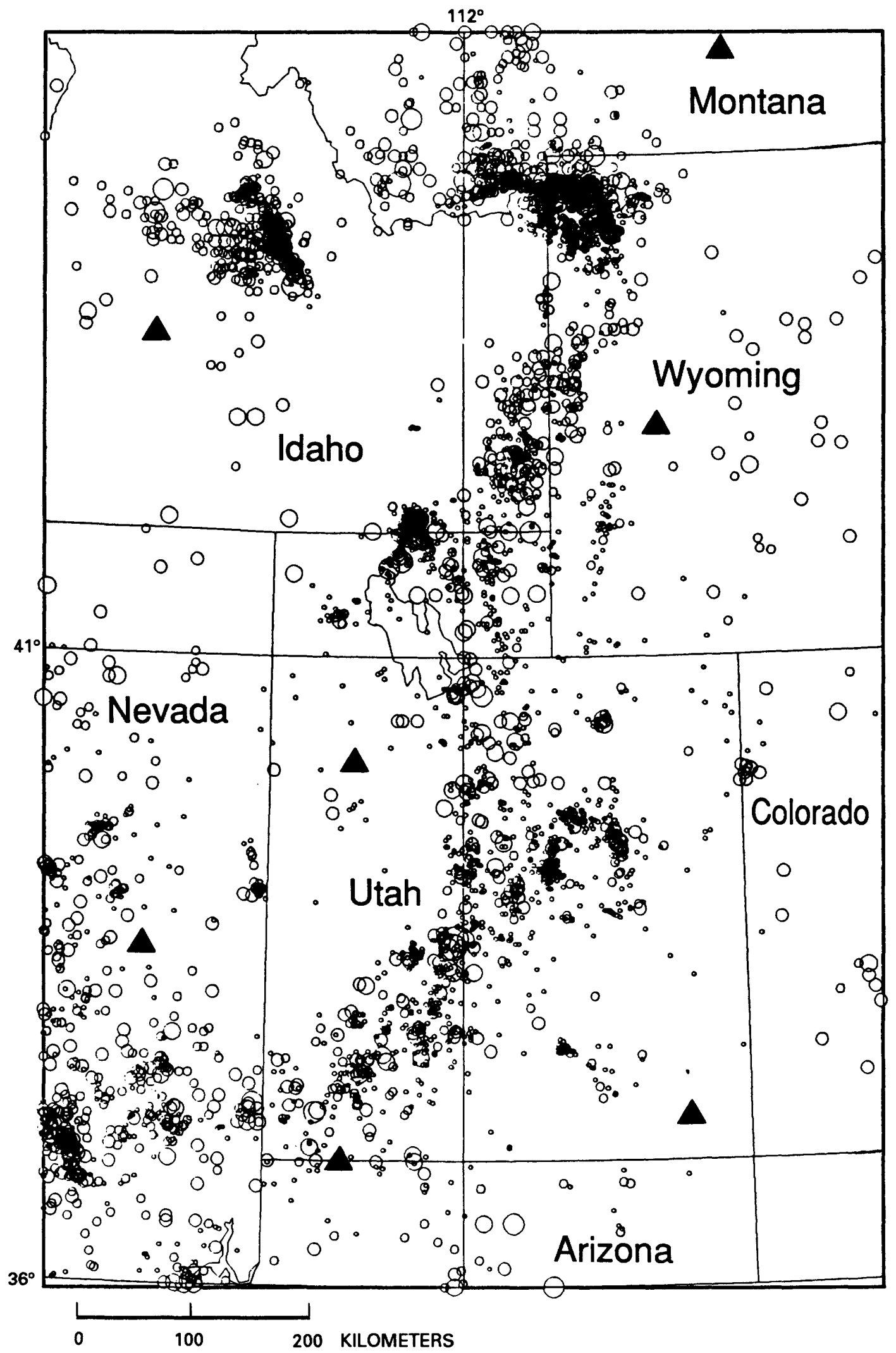

Figure 18. Seismicity of the intermountain region located using the 75-station regional network operated by the University of Utah. Earthquakes since 1962 and larger than magnitude 2.0 are plotted. Proposed station locations for the National Seismic Network (triangles) illustrate that the National Seismic Network is far too sparse to study detailed features of regional seismic activity (courtesy of R. Smith, R. Engdahl, and J. Dewey). 
Table 4. Problems requiring high station densities

- Detection of microearthquakes (magnitudes less than 2.5)

- Accurate determination of hypocentral locations.

- Accurate determination of earthquake rupture characteristics.

- Rapid determination of shaking distribution for significant earthquakes.

- Short-term warning of imminent strong shaking during significant earthquakes.

- Real-time tsunami warning.

- Volcano monitoring.

- Determination of path effects to better predict strong-motion characteristics at individual sites.

- Determination of velocity distributions of the crust and the Earth's interior.

ter (DMC) to store and disseminate the data from these networks. IRIS helps to coordinate activities within the United States to see that these important goals are met. However, it is important to recognize that these programs do not address the vital problems of developing regional networks. A national plan to deal with the issues of regional networks should be developed. It is not within the scope of this document to specify the way in which such a plan should be developed. However, it is clear that the formulation of such a plan should be a high priority of the U.S. seismological community.

\section{APPLICATIONS OF A NATIONAL SEISMIC SYSTEM}

\section{Estimation of Current Earthquake Risk}

When an earthquake occurs, the risk of a major earthquake occurring within a short period of time increases significantly because of the possibility that the first event is a foreshock. Seismologists have always become more wary in the first few days after an earthquake, but have not usually issued public statements because the chance of a false alarm in this situation is also high. In the last few years, however, more accurate estimates have been made of how the probability of a major earthquake increases following other seismic activity. In addition, both seismologists and emergency management personnel have recognized that an earthquake prediction should include not only time, place, and magnitude of the event but also the probability that the prediction is correct. These developments have allowed predictions of earthquake risk that are well above background but well below 50 percent probability to be issued and used. This has also increased the need for accurate information immediately after an earthquake. An example of the way that seismic risk increases dramatically after a potential foreshock is shown in figure 19. In this example, Jones (1985) shows that the probability per

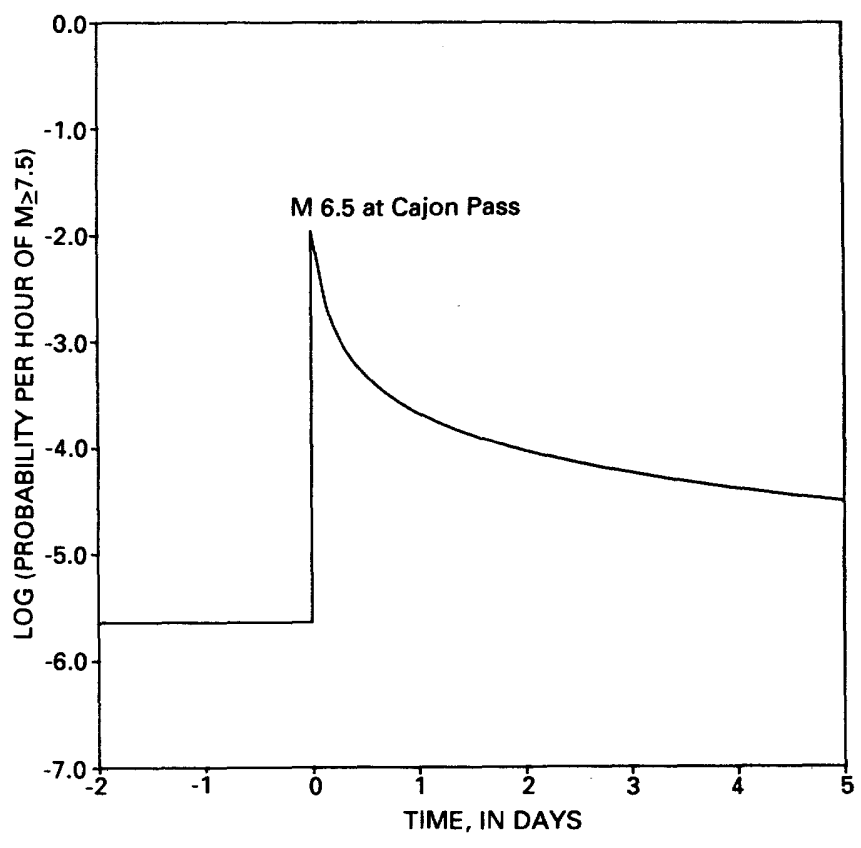

Figure 19. Probability per hour of a large $(M \geq 7.5)$ earthquake occurring on the Palmdale section of the southern San Andreas fault as a function of time when a M6.5 earthquake occurs at Cajon Pass (Jones, 1985).

hour of a large $(M \geq 7.5)$ earthquake occurring on the Palmdale section of the San Andreas fault is a function of time when a $M 6.5$ earthquake occurs on the segment.

On May 27, 1980, the Director of the U.S. Geological Survey issued a Hazards Watch for potentially damaging earthquake activity in the Long Valley region of eastern California in the wake of the occurrence of three magnitude 6 earthquakes two days earlier. This first public statement in the United States was followed by a fourth magnitude 6 event (Hill and others, 1985).

The next statement from the U.S. Geological Survey about an increase in the probability of a damaging earthquake was made in June 1985 (Golz, 1985). Three $M 4$ earthquakes in San Diego increased the probability of a damaging earthquake to 5 percent within five days. Limitations of the old regional network in southern California led to delays in determining the location and magnitudes of these smaller earthquakes. However, because of the location of these earthquakes directly under a city of 1 million people, the California State Office of Emergency Services was notified of the increased probability as soon as it was recognized, four hours after the start of the sequence. San Diego responded by putting disaster management personnel on alert, checking water supplies and moving fire engines outdoors, appropriate for a 5 percent chance of having an earthquake.

Plans are being made to issue a similar short-term warning if foreshocks precede the Parkfield earthquake (Bakun and others, 1986). Parkfield is a site on the San Andreas fault where moderate earthquakes ( $M$ approx 6 ) have occurred on 
the average once every 22 years. Because of this apparent repeatability, an intermediate-term prediction has been issued for another $M 6$ event by 1993. In preparing for this earthquake, the U.S. Geological Survey is working with the California Office of Emergency Services to develop response scenarios for possible changes in the Earth that might precede the Parkfield earthquake. In particular, USGS seismologists have determined the probabilities of the Parkfield earthquake occurring within three days after earthquake activity on the San Andreas fault (figure 20). These probabilities range from 1 to 2 percent for a $M 2$ earthquake to over 35 percent for a $M$ 4.5 event. These probabilities have been assigned to alert levels, such that during a level $A$ alert, the chance of the Parkfield earthquake occurring is greater than 35 percent; during a level $\mathrm{B}$ alert, the chance is 10 percent to 35 percent, and so forth. The Office of Emergency Services has developed appropriate response plans for each alert level (State of California, 1988). Thus when an alert is actually called, information can be quickly and efficiently exchanged and plans activated because all of the decisions for that alert level have already been made.

A crucial element of the Parkfield plans is real-time location of earthquakes. Studies have shown that the increase in probability after a potential foreshock is concentrated in the first few hours after the event; one quarter of all foreshocks occur within one hour of their mainshock. The foreshock to the last Parkfield earthquake occurred only 17 minutes before the mainshock. Thus an extensive network has been installed in the Parkfield area and new computer systems developed to produce locations and magnitude estimates for earthquakes in real time.

New computer systems would allow real-time assessments similar to those at Parkfield to be made in other regions as well. For instance, a moderate earthquake on the southern San Andreas fault, like the North Palm Springs earthquake of July 1986 , has been estimated to have a 10 percent chance of being followed by a $M 8$ great earthquake. However, six hours after such a moderate earthquake, the probability of a $M 8$ earthquake occurring is down to 5 percent; thus, quick response is essential. Although the chance of a false alarmthat the earthquake will not occur-is 90 percent, disaster planners have stated that a warning issued on this basis would be useful to them. Responses to such a warning could involve canceling vacations for emergency response personnel, moving fire engines outdoors, delaying toxic waste disposal operations, and many other steps.

Seismicity patterns on longer time scales than immediate foreshocks may also reflect changes in the earthquake hazard. As these are better understood, it will be possible to have earthquake risk maps that change with time, reflecting the probability of earthquakes over time scales of weeks and months. Significant seismic sequences that are potential foreshocks to hazardous earthquakes will continue to occur, and seismologists must be prepared to provide useful, timely information to mitigate potential hazards.

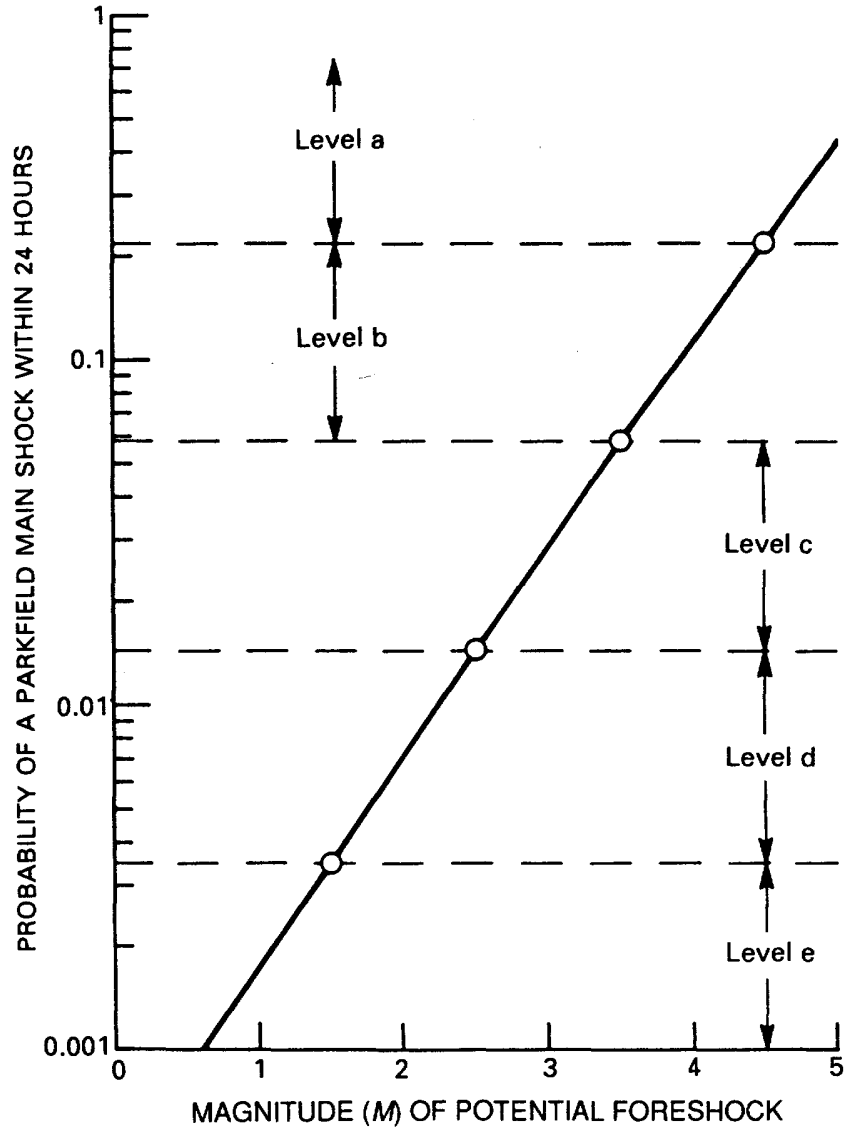

Figure 20. Probability of a characteristic Parkfield, California, earthquake in 24 hours following occurrence of potential foreshock of magnitude $M$. Levels a through e refer to alert levels as defined in Bakun and others (1986).

\section{Short-Term Warning of Imminent Ground Shaking}

In earthquakes of great fault length, substantial damage often occurs at great distances from the earthquake's epicenter. Because of the relatively slow speed of seismic waves, it is possible to electronically warn a region of imminent strong shaking as much as several tens of seconds before the onset of very strong shaking. Automated safety responses could be triggered by users after receiving estimates of the arrival time and strength of shaking expected at an individual site.

The great earthquake of 1857 that ruptured a $300-\mathrm{km}$-long segment of the San Andreas fault in southern California is an example of how a Seismic Computerized Alert Network (SCAN) could provide more than a minute of warning time before the occurrence of strong shaking in a heavily populated area. There is evidence that the rupture initiated in the vicinity of Parkfield, a small town $275 \mathrm{~km}$ northwest of metropolitan Los Angeles. It seems likely that the rupture propagated south toward the Los Angeles region at a velocity of about $3 \mathrm{~km} / \mathrm{s}$ or less, and the strongest shaking in the Los Angeles region probably occurred at least 100 seconds after the ground began to shake at Parkfield. 
In similar earthquakes, a SCAN could provide users with information during this time so that they could initiate certain safety precautions. The most suitable applications are those operations that come under computer control and can be safeguarded quickly. For example, a SCAN could initiate electrical isolation and protection of delicate computer systems, isolation of electric power grids to avoid widespread blackouts, protection of hazardous chemical systems and offshore oil facilities, closing of natural gas valves to minimize fire hazards, warning of nuclear power plants and national defense facilities, protection of emergency facilities such as hospitals and fire stations, and protection of fixed rail transportation systems. It may even be possible to provide protection to individuals in hazardous structures. For instance, structurally strong areas could be built in schoolrooms (such as a heavily reinforced table) to which students could rapidly evacuate.

Heaton (1985) discussed the basic principles and expected performance of a SCAN of the type shown schematically in figure 21 . Ground motions recorded by a dense array of broad-band, high dynamic range seismometers are digitally telemetered to a central processing site. The occurrence of a large earthquake is detected and the location, time of origin, amplitude, and reliability estimates are transmitted instantly to microcomputers operated by individual users. The user's computer then combines this information with that about the user's site (for example location and geologic conditions of the site) to estimate the arrival time and nature of motions expected at the site. Decisions already programmed into the user's computer are then made on the basis of this information and the appropriate action is taken.

The problem of false alarms is minimized by continuous updates regarding the size of the ground motions at differing stations in the seismometer array. If the user is close to the epicenter of a developing earthquake, then the user's processor will recognize that little time is available to receive further information and immediate action may be appropriate. However, if the user is far from the epicenter, then considerable time is available before shaking begins. This time may be used to receive further information about the size of the earthquake. In this way, users at large epicentral distances take action for only the large earthquakes that present a real hazard, and each user adjusts the decision-making process to the needs of the site. The use of the seismometer array for the routine research study of numerous small local earthquakes will help to ensure that the system is maintained in good working order.

The circumstances surrounding the great 1857 earthquake, a damaging earthquake in Los Angeles with a very distant epicenter, are optimal for the operation of a SCAN system. However, there are a number of examples where damage is more localized to the epicentral regions such as was the case for the 1971 San Fernando earthquake or the 1933 Long Beach earthquake. In these cases only several seconds of warning could be expected in heavily damaged areas. Heaton (1985) provided estimates of the probability distribution that a site which experiences a specified strength of shaking will also receive a given warning time. The distribution of warning time as a function of peak acceleration is shown in figure 22 . The contours give the probability that a user will receive at least a certain warning time in the event of at least a certain value of acceleration. The total area of southern California to receive a given peak acceleration or greater in a 100 -year period is shown to the right. This number may exceed the total area of southern California (about $3 \times 10^{5} \mathrm{~km}^{2}$ ) because many areas will experience low values of acceleration several times in a 100 -year period.

The expected warning time is long at both low $(<0.1 \mathrm{~g})$ and high $(>0.3 \mathrm{~g})$ values of acceleration, but the expected warning time is short for moderate $(0.1$ to $0.3 \mathrm{~g})$ values. Because small accelerations occur at large distances between site and fault, the warning time is large for small accelerations. In this model, accelerations of $0.2 \mathrm{~g}$ are most likely to occur close to the numerous moderate-size earthquakes, and hence the expected warning time is short. However, large accelerations result from large earthquakes of long rupture length. Thus areas that receive large accelerations can also expect to receive large warning times.

The 27 March 1964 Alaskan earthquake $\left(M_{w}, 9.2\right)$ is the largest earthquake documented in U.S. history and it is the second largest earthquake of this century. The fault rupture extended more than $600 \mathrm{~km}$ in length and had a width of more than $200 \mathrm{~km}$. Very strong shaking of unusually long duration (several minutes) occurred over a very large region, and devastating local tsunamis were generated (National Academy of Sciences, 1972). The strong shaking and giant tsunamis extensively damaged cities and transportation links within the regions of Prince William Sound, Kenai Peninsula, Kodiak Islands, and Cook Inlet. Because of the very large rupture dimensions, most of the region that was strongly shaken would hypothetically have received many tens of seconds of warning if a SCAN system had been operational. This giant earthquake was the result of thrusting of the North American continental plate over the Pacific Ocean plate, a process known as subduction. Similar subduction processes are known to occur along most of Alaska's southern coast and also along the entire length of the Aleutian Island chain.

The Cascadia subduction zone is a $1,200-\mathrm{km}$-long plate boundary in the Pacific Northwest along which the North American plate overthrusts the Gorda, Juan de Fuca, and Explorer oceanic plates. This plate boundary extends from northern California to Vancouver Island, British Columbia. Although there have not been large historic subduction earthquakes on this zone, recent studies indicate that very large subduction earthquakes (perhaps as large as $M_{\mathrm{w}}$ 9.5) may occur there (Heaton and Hartzell, 1987; Atwater, 1987). If subduction earthquakes occur on this zone, then relatively strong shaking can be expected over a large area of the Pacific Northwest, including the Puget Sound and Willamette Valley regions (Seattle and Portland). Because of the potential for 


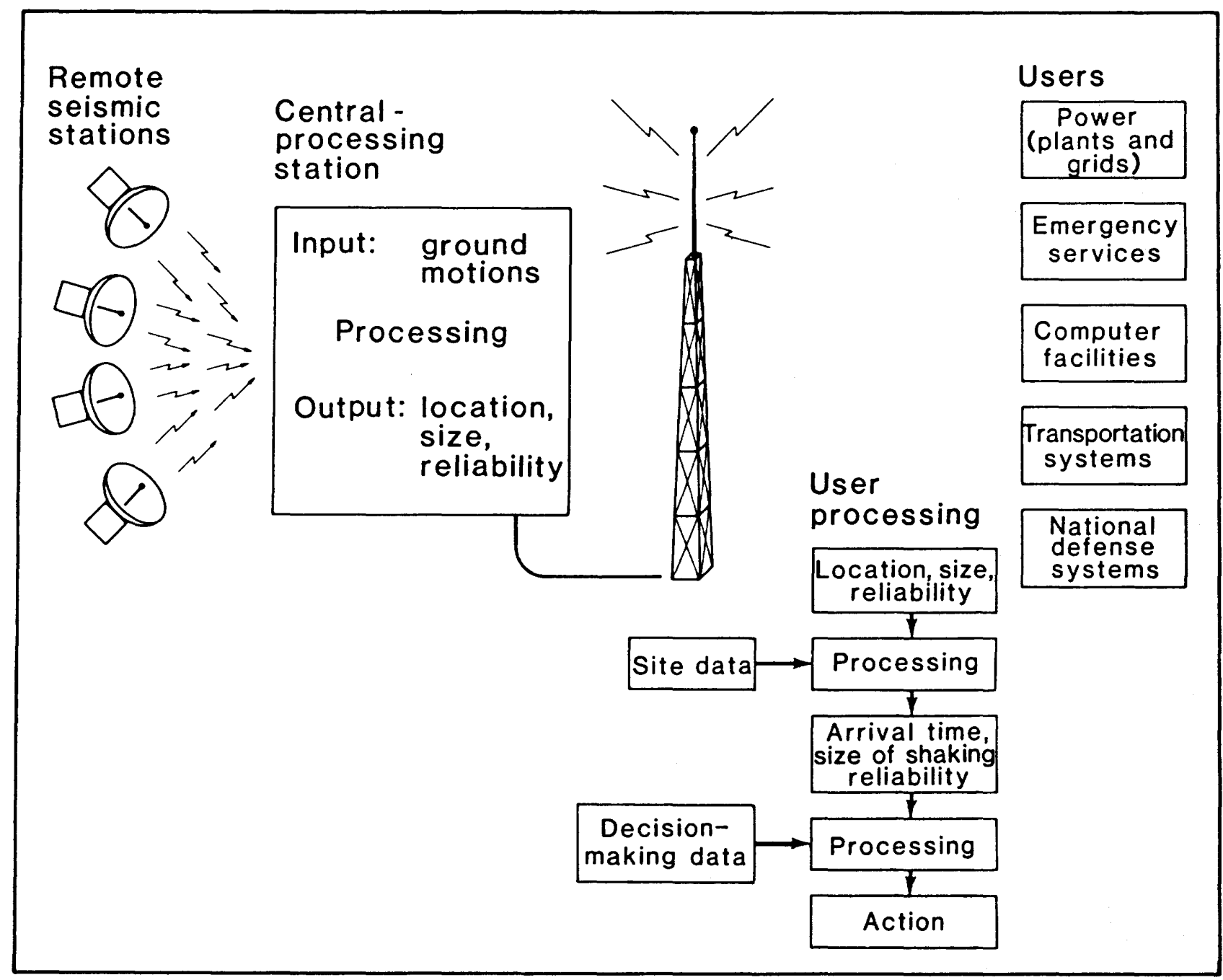

Figure 21. Conceptual design of a Seismic Computerized Alert Network (SCAN). The purpose of this system is to provide very short-term prediction of the arrival time and size of imminent strong shaking to areas at some distance from an earthquake's epicenter. The system relies on the relatively slow speed of seismic waves (approximately $3 \mathrm{~km} / \mathrm{s}$ ) compared with electronic communications. The system would also provide important emergency information immediately after a damaging earthquake (Heaton, 1985).

earthquakes of very large rupture dimensions, a SCAN system may provide many tens of seconds of waming in advance of very strong shaking for great subduction earthquakes in the Pacific Northwest.

Large historic earthquakes have also occurred in the United States that are far from known plate boundaries. Specifically, large earthquakes occurred in the central United States (New Madrid) in 1811 and 1812 and also in the southeastem United States (Charleston) in 1886. Although the mechanisms of these events are poorly understood, these events probably do not involve large rupture dimensions. Nevertheless, the felt areas of these earthquakes were larger than those for the largest California earthquakes (Nuttli and Zollweg, 1974). It is generally felt that the principal reason for this phenomenon is a lesser degree of attenuation of seismic waves east of the Rocky Mountains. Because rupture lengths of great earthquakes in the central and Eastern United States may be less than $50 \mathrm{~km}$, the regions of strongest shaking that lie adjacent to the rupture zone are not likely to receive large warning times. However, Rossi-Forel intensities of IX and VIII may have extended to distances of 100 and $200 \mathrm{~km}$, respectively, for the 1811 and 1812 New Madrid earthquakes. This means that a SCAN system could still provide a significant warning time for areas shaken strongly enough to cause great damage during great earthquakes in the central and Eastern United States.

\section{Rapid Estimation of Shaking Intensity}

Past experience has proved that there is always great confusion immediately following damaging earthquakes. Very heavy loads are put on communication lines at a time that they 


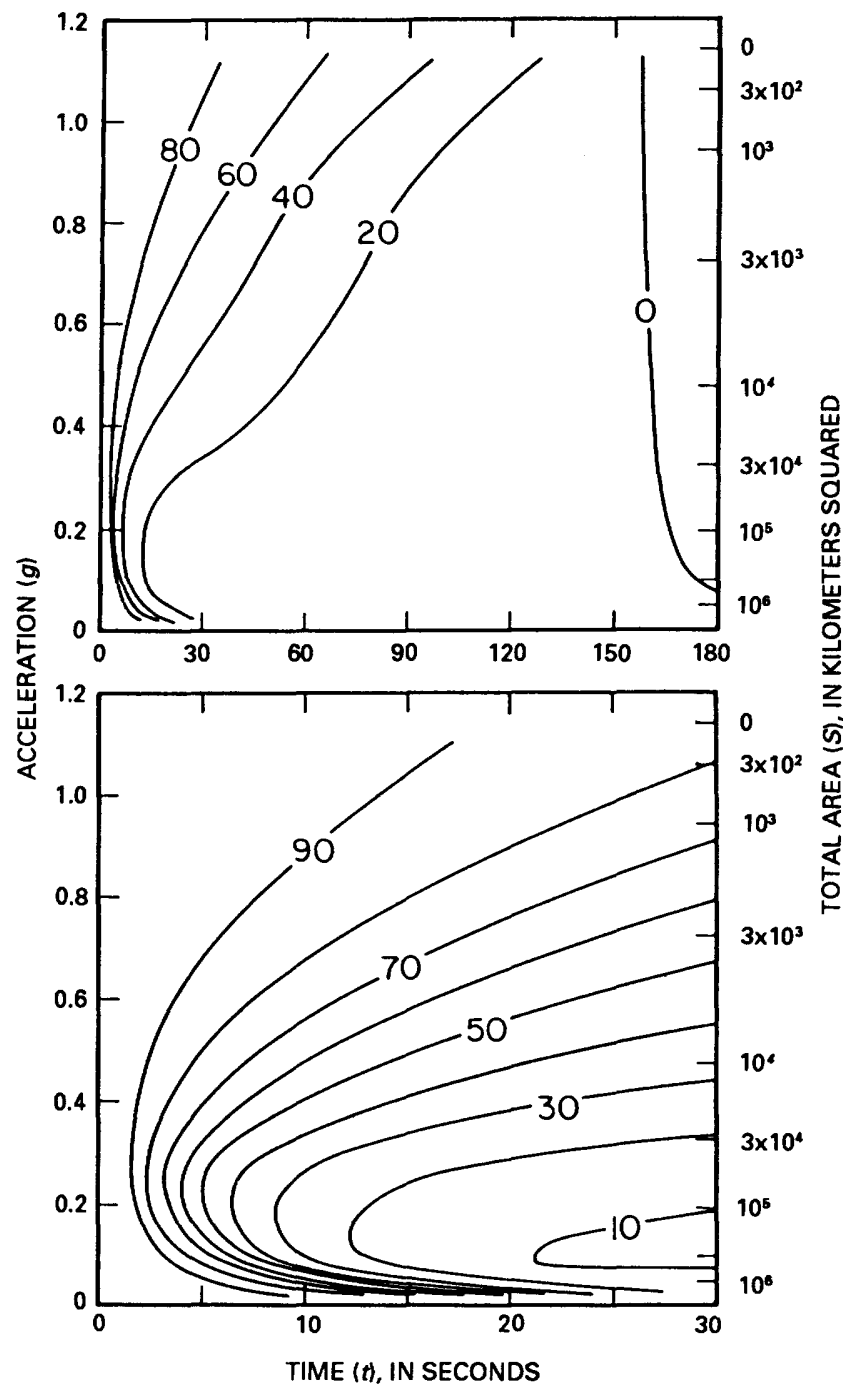

Figure 22. Theoretical calculation of distribution of warning times for SCAN system in southern California as a function of expected peak ground acceleration. Contours denote percent of area having peak acceleration of $g$ or greater that receives a warning time of $t$ or greater. $S$ is total area to receive a peak acceleration of $g$ or greater in a 100 -year period in southern California. Warning time is given relative to arrival time of maximum shaking. Bottom part of figure is same as top, but with an expanded time scale (Heaton, 1985).

may already be damaged during the earthquake. It is very difficult for emergency management professionals to rapidly assess the nature of the crisis. Unfortunately, seismologists have not always provided much assistance because most of their available records are completely off scale. However with a high dynamic range, digitally telemetered seismic network of the type that is necessary for a SCAN system, it would be possible for seismologists to provide a very rapid assessment of the severity of ground shaking for different regions.

The California State Office of Emergency Services is $g u r-$ rently developing plans for a southern California emergency response center that will be responsible for coordinating emergency services after a damaging earthquake. Recent earthquake disasters, such as those in Mexico City, have emphasized the importance of rapid rescue and relief activities. The cost of inadequate response can be many lives. In an area as extensive as southern California, it may be very time consuming for officials to assess the true nature of an earthquake disaster. Estimates of the strong shaking could be relayed directly to the State's emergency response center. These estimates will allow rapid assessment of the overall extent of the disaster. It may even be possible to automatically project earthquake damage based on this incoming data. For example, the Southern California Association of Governments is currently developing a geographic relational data base using census statistics. They plan to use this data base to model hypothetical earthquake disasters assuming several different earthquake scenarios. Included in the data base are such items as hospitals, lifelines, transportation links, hazardous facilities, and current distribution of population (how many people are away from their homes?). Once such a system is developed, it should be possible to input estimates of the actual shaking immediately after an earthquake in order to anticipate the most immediate emergencies.

Rapid estimation of earthquake damage is also of vital interest to many other organizations. For instance, our national defense system may receive severe damage during a large earthquake. Proper and timely reallocation of resources will depend on accurate estimates of the extent of the earthquake. This post-earthquake damage information is also of obvious value to the repair and protection of lifeline systems (aqueducts, electrical power grids, telecommunications, natural gas, and so on).

\section{Tsunami Warning}

Tsunamis are long-period (usually tens of minutes) ocean waves that are commonly generated by large earthquakes beneath the ocean. In general, the largest earthquakes are responsible for the largest tsunamis. Tsunamis are also sometimes generated by underwater volcanoes and perhaps by underwater landslides. Several devastating tsunamis that occurred in Hawaii $(1946,1960,1964)$ were actually generated by earthquakes several thousands of kilometers distant from Hawaii. In these instances, the tsunami waves, which travel less than $1,000 \mathrm{~km} / \mathrm{hr}$, took many hours to traverse the Pacific Ocean to Hawaii. Much of our present tsunami warning system is based on the premise that warning will be given for populated coastlines for tsunamis that are generated in remote and distant regions of the Pacific. However, very large tsunamis with runup heights in excess of $20 \mathrm{~m}$ have struck U.S. coastlines from nearby earthquakes in 1868 (Hawaii), 1946 (Aleutian Islands), 1958 (Alaska), and 1964 (Alaska). Tsunamis that occur in the region of the generating earthquake are referred to as local tsunamis. Local tsunamis can be particularly dangerous because they can be 


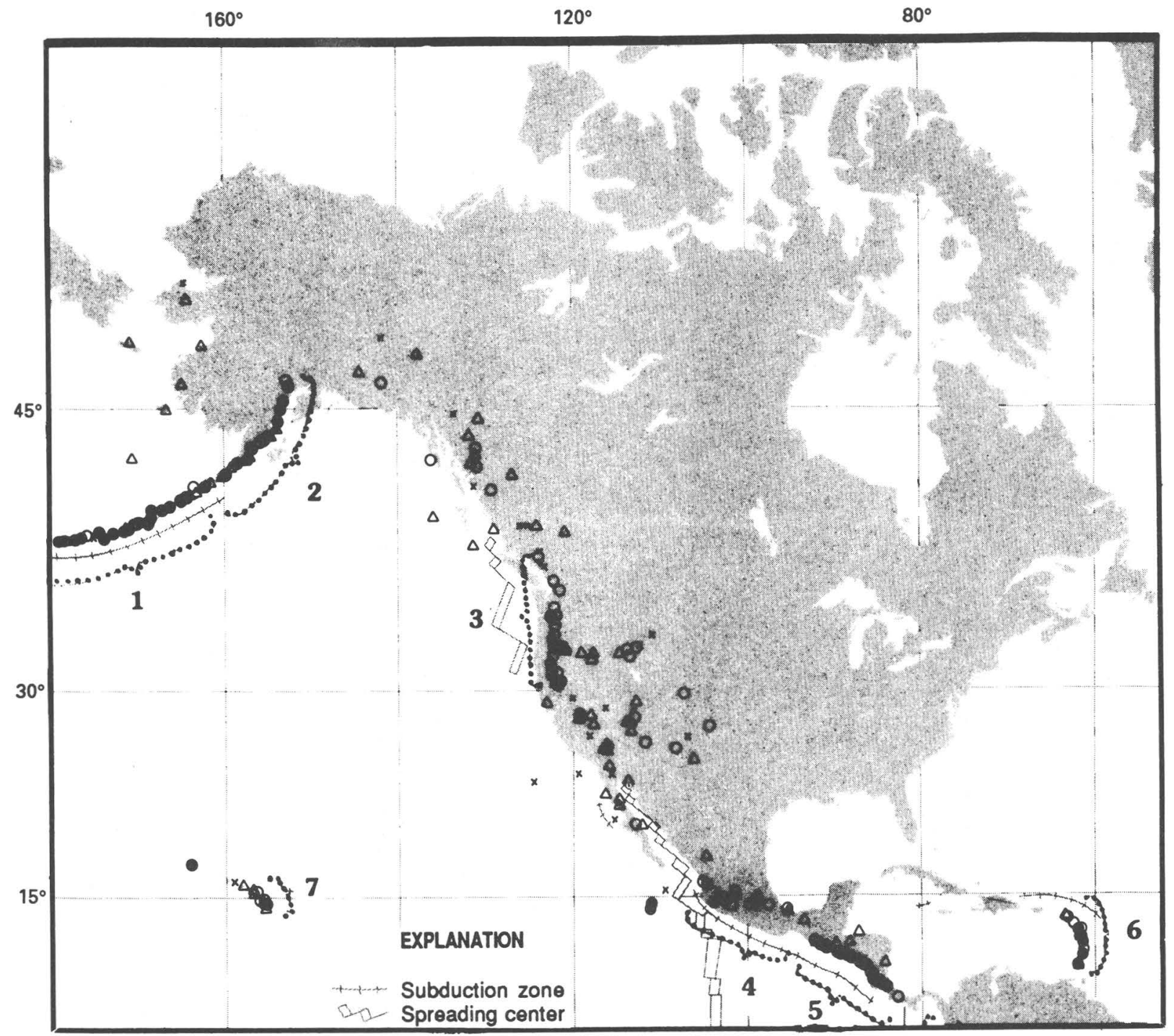

Figure 23. Locations of probable Holocene volcanism (last 10,000 years). Volcanoes with known eruptions since 1880 are shown by filled circles. Volcanoes with dated eruptions, but none since 1880 , are shown by open circles, and those with undated but probable Holocene eruptions are shown by triangles. Volcanoes with uncertain or only solfataric activity are shown by a small $\mathrm{x}$. Volcanic belts that are numbered correspond to table 5 (modified from Simkin and Siebert, 1984)

type that threaten high-rise buildings was also observed in the Los Angeles and San Fernando basins in the 1971 San Fernando earthquake. Figure 24 shows a profile of ground velocity records across these basins (Liu and Heaton, 1984). Individual sets of surface waves are developed within these basins, and these surface waves control the duration and peak amplitude of the longer period parts of the ground motion.

The effects of propagation of strong ground motions in complex geologic structures, such as basins, are usually included in earthquake design studies as a simple scalar site amplification factor whose value is determined by the local site condition (hard rock, intermediate, soil). Such a procedure cannot adequately characterize the phenomena that make
Table 5. Holocene volcanism of North America and Hawaii [from Simkin and Siebert (1984)]

\begin{tabular}{lccr}
\hline Belt name & $\begin{array}{c}\text { Length } \\
(\mathbf{k m})\end{array}$ & $\begin{array}{c}\text { Number of } \\
\text { Holocene } \\
\text { volcances }\end{array}$ & $\begin{array}{r}\text { Eruptions } \\
\text { since 1880 }\end{array}$ \\
\hline 1. Aleutians & 1,457 & 40 & 203 \\
2. Alaska Peninsula & 944 & 33 & 120 \\
3. Cascades & 1,152 & 38 & 141 \\
4. Mexico & 1,043 & 22 & 64 \\
5. Central America & 1,254 & 79 & 35 \\
6. West Indies & 632 & 17 & 59 \\
7. Hawaii & 174 & 6 & 114 \\
\hline
\end{tabular}


exceedingly large and because they may strike within 15 minutes of the causative earthquake. Although most of the coastal areas of the contiguous United States have not experienced historic devastating tsunamis, there is evidence that large tsunamis from great subduction earthquakes may present a severe problem in the Pacific Northwest (Heaton and Hartzell, 1987; Atwater, 1987). Furthermore, it is difficult to preclude the possibility of damaging tsunamis along any U.S. coastal region.

Kanamori (1985) presented a methodology for determining tsunami sizes from near-field ground motions that occur within the first several minutes of large coastal earthquakes. Furthermore, reasonably precise predictions of local tsunami runup heights are now feasible using complex models of sea waves in detailed models of seafloor bathymetry (Satake, 1987). However, on-scale measurements of long-period ground motions in the near-source region of large earthquakes must be available in real time in order to provide a working local tsunami warning system (Bernard and others, 1988). Clearly, regional networks with seismic instrumentation, communication, and real-time analysis systems of the type proposed for the National Seismic Network would be able to meet these needs.

\section{Volcano Monitoring}

On 20 March 1980 the regional seismic network operated by the University of Washington detected small earthquakes beneath usually quiet Mount St. Helens. Over the next two months, seismic activity increased dramatically as the volcano experienced several small phreatic (steam-blast) eruptions and the flank of the volcano bulged dramatically. Because of this precursory activity, thousands of lives were saved from the catastrophic eruption of 18 May 1980. Careful monitoring of seismicity in the Mount St. Helens region was a key tool for the prediction of numerous other eruptions over the next several years (Swanson and others, 1983). Seismic monitoring has also been a key tool in the prediction of numerous eruptions in Hawaii (Klein, 1984; Klein and others, 1987). Smith and Luedke (1984) estimate that there are approximately 75 volcanoes distributed in 11 Western States of the conterminous United States that have potential for future eruptions. In addition, there are 33 Holocene volcanoes on the Alaskan peninsula, 40 in the Aleutian Island chain, and six in the Hawaiian Islands (Simkin and Siebert, 1984). Regions of the United States that have a potential for future volcanic activity are shown on figure 23 and summarized in table 5 .

Not all large explosive eruptions are preceded by significant periods of precursory eruptive activity. Simkin and Siebert (1984) reported that of 205 of the largest documented eruptions, 92 occurred within a day of the onset of eruptive activity. No precursory eruptions were reported for the largest volcanic eruption this century, which occurred in 1912 at Alaska's Katmai volcano. However, earthquake activity was noted for several days before the main eruption (Bullard,
1962) and most (if not all) great volcanic eruptions are preceded by a significant seismicity precursor. "Harmonic tremor" or "volcanic tremor," which is characterized by a nearly continuous oscillation of the ground, seems to be a phenomenon that is particularly diagnostic of magmatic activity. As is the case with earthquake ground motions, the range of amplitudes of ground motion during harmonic tremor is very large. Because of the unusual nature of the seismic source for harmonic tremor, this phenomenon is best studied with three-component, broad-band instrumentation.

Because there are so many potentially active U.S. volcanoes that may have little in the way of precursory eruptions, the monitoring of seismic activity is of vital importance for U.S. volcano prediction. This monitoring requires relatively dense seismic networks throughout the Western United States, Alaska, and Hawaii. Furthermore, it is important to monitor seismicity from volcanic regions in near-real time. When visibility is limited (as it often is on large volcanoes), seismic monitoring can also be important for the recognition of significant eruptions that may trigger dangerous lahars (mudflows often triggered by the rapid melting of snow and ice) as occurred with tragic results in 1985 at Colombia's Ruiz volcano, killing over 20,000 people. In addition, even moderate-sized eruptions can send ash into the atmosphere that can be a serious hazard for aircraft.

Volcano monitoring is already an important task of existing regional seismic networks. The upgrading of these networks to include three-component, high-dynamic-range seismometers, and the development of systems to analyze seismicity in real time will greatly enhance the ability to recognize, understand, and respond to U.S. volcanic hazards.

\section{Prediction of Site Effects in Strong Ground Motions}

One of the most critical factors in the engineering of structures is anticipating the nature of the ground motions that may be experienced by the structure. Earthquake ground motions are determined by the nature of the seismic energy radiated by the source and also by the way in which the seismic energy propagates through the medium to the site. A complete physical description of this process is exceedingly complex, and the current practice in earthquake engineering is to simplify this problem by parameterizing the earthquake source by magnitude and the effects of propagation by distance between the earthquake and the site. Unfortunately, this parameterization can be tragically inadequate, as was the case for the 1985 Michoacan earthquake in which thousands lost their lives in Mexico City. Although Mexico City was over $350 \mathrm{~km}$ from this earthquake (the distance between Los Angeles and Las Vegas), there was heavy damage to earthquake-engineered structures caused by ground motions that were strongly amplified by the sedimentary structures beneath the city. Significant amplification of longer period ground motions of the 

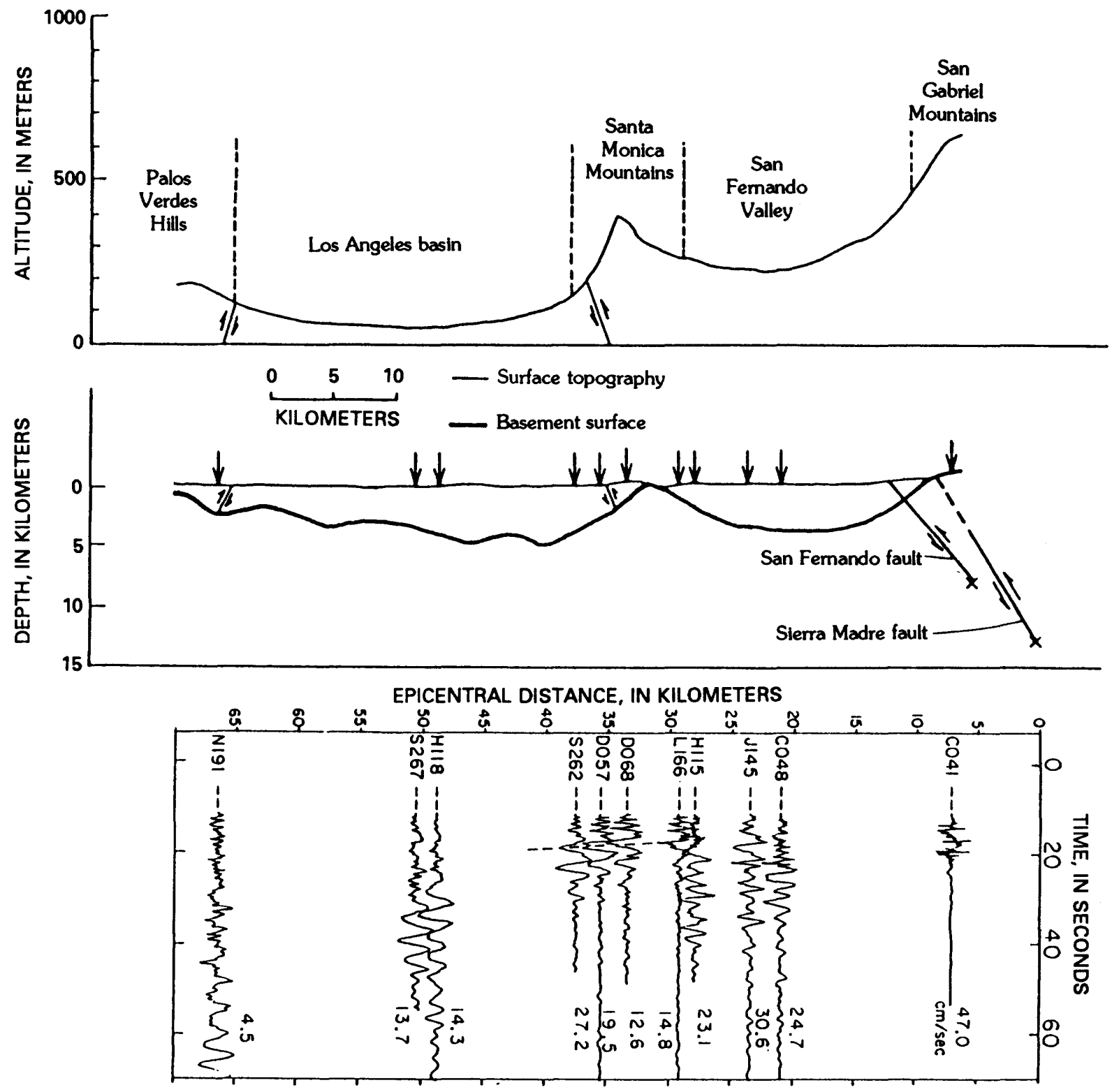

Figure 24. Transverse component of ground velocities recorded during the 9 February 1971 San Fernando, California, earthquake. Records are plotted as a function of epicentral distance along a profile (top) running south across the San Fernando Valley and the Los Angeles basin. Corresponding free-surface and basement-surface profiles are shown in the center. Dashed lines in records (bottom) indicate probable phase arrival of surface waves. Note that the apparent surface waves seen within the basins do not appear to propagate across the Santa Monica Mountains (from Liu and Heaton, 1984).

sites at equal distance from the same earthquake experience very different ground motions. Response spectra from $M 6.5$ strike-slip earthquakes that were observed at a distance of 50 $\mathrm{km}$ are shown in figure 25 . It is clear that simply knowing distance, magnitude, and soil condition still leaves an order of magnitude uncertainty in the estimation of ground motions.

Fortunately, we needn't wait to record destructive ground motions at a site before we can anticipate dangerous amplification effects. Since wave propagation in earthquakes is by and large a linear process, we can infer the effects of propagation by the study of weak ground motions from numerous smaller earthquakes. By studying these smaller motions from a variety of sources, we can understand which effects are stable with respect to the geometry of the source and the site. Ground motions recorded by a digital telemetered network will be ideally suited for these types of studies. In order to increase station coverage to get an even more detailed understanding of the variations of ground motion with site location, the array would be temporarily supplemented with portable stations that will be occupied only long enough to record data from several sources which could even be artificial sources (quarry blasts, Nevada test site, and so forth). 


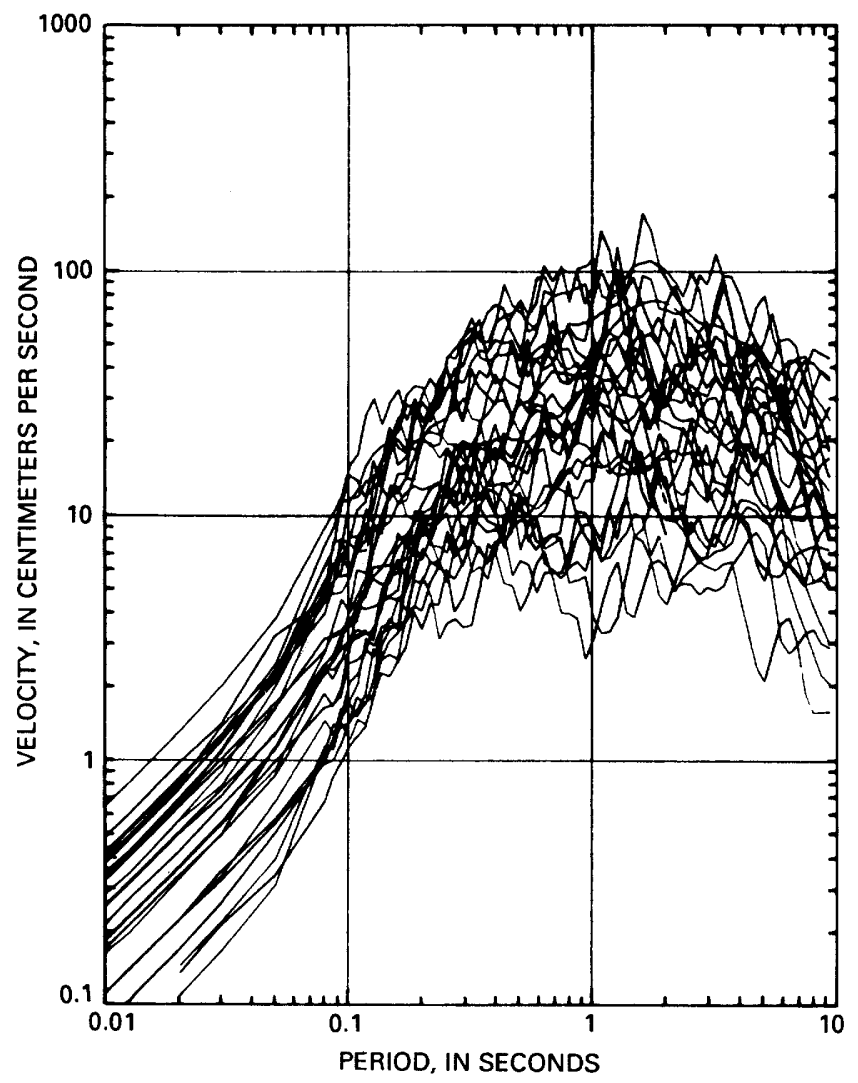

Figure 25. Response spectra (3 percent damped) for horizontal components of 15 records from strike-slip earthquakes, scaled to a distance of $50 \mathrm{~km}$ and a magnitude of 6.5 (from Heaton and others, 1986). Such scatter is typical of ground motions recorded at a given distance and magnitude.

\section{RESEARCH POSSIBILITIES OF THREE- COMPONENT DIGITAL REGIONAL NETWORKS}

The approximately 1,600 seismic stations in existing U.S. regional networks have the potential to form the world's largest and densest seismic array. This array could be used for highly innovative studies of earthquakes, the structure of our continent, and the structure and dynamics of the Earth. Unfortunately, the limited capabilities of the instrumentation in these arrays and the lack of standardization have severely limited the scope of research problems that have utilized regional array data. We now briefly summarize some of the research problems that will be analyzed using data from regional networks of modern three-component digital instruments.

\section{Earthquake Studies}

Earthquakes are the result of sudden changes in elastic strain within the Earth. Elastic strains within the Earth may be caused by several mechanisms that include the overall shifting of the Earth's plates (by far the most important), the migra- tion of magma to the Earth's surface, readjustments to load on the Earth's surface (rebound of mountains due to erosion or glaciers), and injection or withdrawal of fluids. We can infer that some of these processes are occurring throughout the Earth. The Earth is constantly deforming, and sometimes this deformation is accompanied by earthquakes. However, most of the deformation within the Earth occurs slowly and steadily without earthquakes. When and where does deformation occur through unstable slip (earthquakes)? We wish to be able to better predict how large earthquakes will be and how often they will occur. We seek a better understanding of the fundamental physics of deformation in the Earth.

\section{Seismicity Patterns}

Perhaps the key motivation for constructing the existing regional seismic networks is the study of patterns of small earthquake occurrence. This is a very large subject with many volumes of literature, and only a few points can be made here. Seismic activity in California for 1980 through 1986 is shown in figure 4 (D.P. Hill, written commun., 1987). Data from more than 600 stations in three regional networks were combined to construct this figure. A number of major seismic lineations can be seen, and the majority of these coincide with recognized active faults. Some seismicity lineations occur in broad zones for which there is not an identifiable surface expression. One of the most striking features of this seismicity is the paucity of small earthquakes along the stretches of the San Andreas fault that experienced great earthquakes in 1857 and 1906. Stretches of the fault that are slipping steadily (creep) experienced the highest rate of small earthquake activity. Study of spatial patterns of small earthquakes helps to delineate changes in the physical properties of faults. These physical properties determine the size and frequency with which large earthquakes will occur. Bakun (1980) studied spatial seismicity patterns on the Calaveras fault of central California and identified a segment of the fault that was ultimately the source of the $M_{\mathrm{L}} 6.2,24$ April 1984, Morgan Hill earthquake. An example of the nature of the detailed seismicity patterns that can be seen in the vicinity of the Morgan Hill earthquake is shown in figure 26.

The study of distributions of seismicity is also very important in other parts of the United States. Seismicity defines the geometry of subduction zones in the Pacific Northwest, Alaska, Aleutian Islands, and the Commonwealth of Puerto

Figure 26. Stereoscopic views of locations and fault plane orientations for aftershocks of the $M$ 6.2 1984 Morgan Hill earthquake (Oppenheimer and others, 1988). Each fault-plane solution is represented by a circle centered on a hypocenter and oriented in a preferred plane of slip. The line through the diameter is parallel to the slip vector. $A$, View from directly above showing surface fault traces. $B$, Oblique view from south. $C$, Oblique view from southeast along strike of Calaveras fault. Figure can be viewed with any standard stereoscope. 

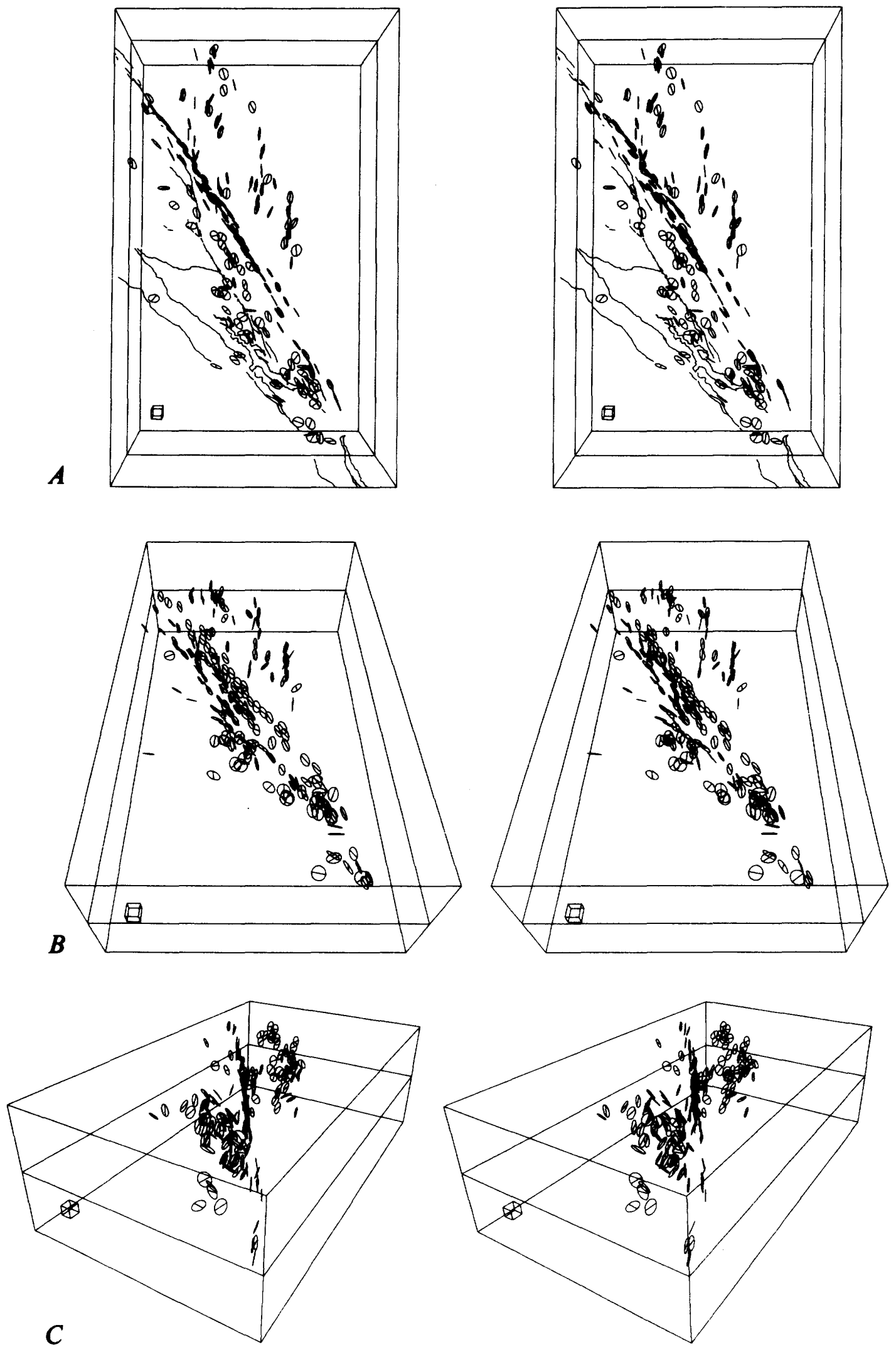
Rico. Seismicity patterns also help to define seismic gaps that may experience large earthquakes. Although there have been very large historic earthquakes in the Eastern United States, surface traces of the causative faults have not yet been identified. Nevertheless, the distribution of small earthquakes in the eastern United States allows the identification of lineations and zones of activity. Seismic activity in the central United States located with the regional network that is operated by St. Louis University is shown in figure 27. This was the source region of three very large earthquakes in 1811 and 1812 (Nuttli, 1973). Although very little has been known about the source of these earthquakes, modern seismicity in the region reveals a well-defined pattern of lineations that are thought to define the extent of the faults that were responsible for these important earthquakes. The distribution of seismicity is also the key tool for mapping the magma systems in active volcanoes. A cross section of seismicity beneath Hawaii's Kilauea Volcano (fig. 28; Klein and others, 1987) reveals a striking $40-\mathrm{km}$-deep pipe of seismicity that is believed to trace the magma supply system through the lithosphere.

Large earthquakes along subduction zones occur deep within the Earth and are almost never accompanied by recognizable surface rupture. Furthermore, many important shallow crustal earthquakes, such as those that occur in California, do not cause surface rupture. Recent examples are the $M 6.5$, 2 May 1983, Coalinga earthquake, the $M 6.2,24$ April 1984, Morgan Hill earthquake, and the $M$ 5.6, 8 July 1986, North Palm Springs earthquake. The spatial distribution of aftershocks from such earthquakes is the most important tool for defining the geometry and extent of the rupture surface for many earthquakes. Data from regional networks are essential for the study of aftershock distributions, and the absence of this information can result in fundamental misunderstandings of the nature of specific earthquakes.

Important patterns in the temporal distribution of earthquakes have also been observed. The occurrence of foreshocks and aftershocks are the most obvious examples of temporal patterns. The temporal distribution of foreshocks and aftershocks appears to vary regionally, and this variation seems to correlate with the tectonic environment. For example, swarms and multiple earthquakes (several mainshocks) often occur in extensional environments. In addition, Tajima and Kanamori (1985) reported that the temporal expansion of spatial distributions of aftershocks is small for subduction zones that are mostly locked, and the aftershock expansion is large for subduction zones that are slipping without large earthquakes. There are also indications that the average rate of seismicity may vary systematically with time for a given region. For instance, Ellsworth and others (1981) reported that seismic activity in central California was considerably higher in the half century preceding the great 1906 earthquake than in the half century following it. There are also several examples in which significant southern California earthquakes have been preceded by weeks to years of higher seismicity (Heaton, 1987). In addition, there is evidence that some earthquakes are preceded by months to years of seismic quiescence (Wyss and Habermann, 1988).

The existing U.S. regional seismic networks were designed primarily as a tool for the study of seismicity patterns, and in the last 10 years they have enabled a quantum leap in the knowledge of seismicity. However, even seismicity studies suffer from the limited capabilities of the existing networks. Limitations of the existing data have severely restricted the information available in these studies. Earthquake locations and magnitudes are generally well determined, particularly for the numerous small-magnitude events, as are focal mechanism solutions for most of the larger magnitude events. However, other essential physical measures of the earthquakes, such as moment tensor solutions, stress drop, and source dimension, are absent from virtually all catalogs and thus severely restrict the types of research that can be performed.

Most regional network stations record only the vertical component of ground motion, and therefore $S$-wave arrivals cannot be reliably recognized in many instances. These $S$ phases are of great value in the determination of hypocentral depth, a parameter of great significance to our understanding of earthquake physics. Furthermore, the limited dynamic range of the existing networks makes it very difficult to recognize significant events that may occur during crisis periods when the network is already off scale from events that have just occurred. Determination of earthquake size or magnitude is also an important problem that is limited by the capabilities of existing networks. Magnitudes are generally determined in a relative way with respect to a particular type and configuration of instruments. However, the configuration of any network changes in time, and it is difficult to know if an earthquake assigned a particular magnitude decades ago would still be given that same magnitude today or in the future. Problems of this type are eliminated by modern digital seismometers since they essentially record absolute levels of ground motion given in standard units. The use of three-component, high-dynamic-range seismometers in regional seismic networks promises to bring another quantum leap in our understanding of the spatial and temporal patterns of earthquake occurrence.

\section{Source Characteristics}

Ideally, the goal of seismic source studies is to achieve a sufficient knowledge of the physics of earthquake rupture so that the detailed rupture behavior of future earthquakes could be predicted in advance given knowledge of the Earth's mechanical properties and geological structure. To achieve this goal it is necessary to learn the state of stress within the Earth and the distribution of strong and weak zones within the Earth. In addition, we must be able to model the process of spontaneous rupture that occurs in heterogeneous regions.

While the gross kinematic aspects of earthquake sources are fairly well understood, their behavior is poorly known on 


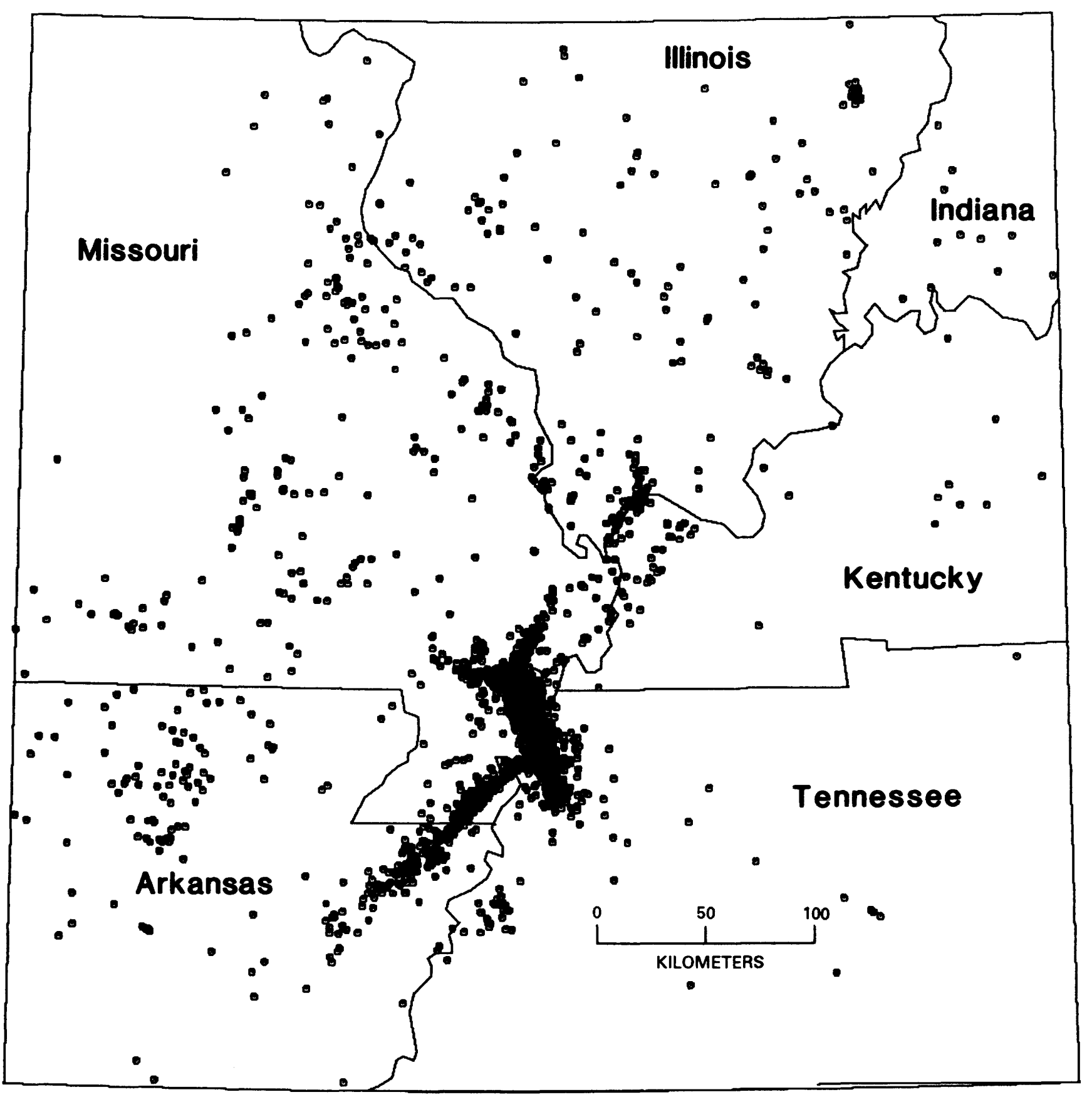

Figure 27. Seismicity in the central United States, 1974 through 1987 (2,900 events), located by seismic networks operated by St. Louis University, Memphis State University, the University of Kentucky, and the University of Michigan. A series of three very large earthquakes occurred in this region in 1811 and 1812 (Nuttli, 1973), and a repeat of similar events could result in catastrophic consequences (unpublished map courtesy of Robert Herrmann, St. Louis University).

time scales short compared to the total source duration and on distance scales short compared to the source extent. From an observational standpoint it is very important to analyze a large number of earthquakes in order to characterize the amount of nonuniformity in the distribution of slip on faults and the de- gree of irregularity with which rupture propagates along faults. Once these irregularities are observed, we must attempt to determine the irregular stress conditions and fault strength distributions that would result in the observed rupture behavior. In particular, recent advances have been made in the field of 


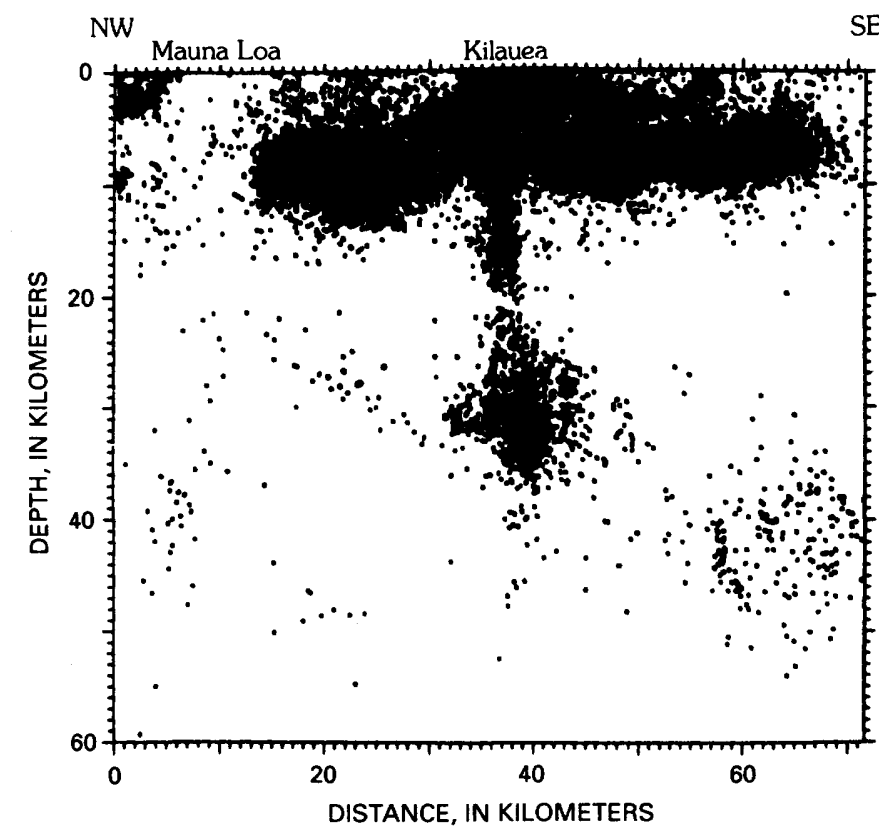

Figure 28. East-west cross section of seismicity through Kilauea Volcano, Hawaii, from the surface to the deepest seismicity at $60 \mathrm{~km}$. Earthquakes, for the time period 1970 to 1983, appear to define the conduit through which magma ascends beneath Kilauea Volcano (Klein and others, 1987).

rock mechanics in the understanding of the mechanical properties of faults through state-variable friction laws. Using these laws, the material properties of faults can be characterized by two position-dependent material properties and a position- and time-dependent state variable. These parameters govern the quasistatic and dynamic behavior of faults, and are related to other properties such as end-zone length. By observing rupture behavior in earthquakes, it may be possible to infer the values of these parameters at depth on real faults.

A second poorly understood characteristic of earthquake sources is their geometry at depth and its relation to the dynamics of rupture and the resulting ground motions. Surface faulting is often observed to consist of a complex group of en echelon cracks, often with associated Riedel shears. Mapped faults are known to have bends and jogs, which have, in some cases, appeared to affect the process of rupture on the fault. It is very important to attempt to deduce the geometry of faulting at depth from the radiated motions, both to learn the geometry of the fault itself and to understand how rupture actually propagates when complicated zones of weakness are present and offer potential avenues for slip. Such information may ultimately be used to predict the characteristics of future earthquakes and their associated ground motions given a known fault geometry.

Numerical modeling of ground motion is the primary tool for studying seismic sources. Ground-motion data are inverted to discover the slip history as a function of time and space during earthquakes. Of course it is essential to under- stand and account for the effects of wave propagation on the recorded ground motions. These propagation effects are best studied using ground motions from small earthquakes that have relatively simple rupture histories. By studying the way that ground motions vary with source location and fault orientation, we can account for these effects when modeling ground motions from significant earthquakes. In order to accomplish this, we need three components of ground motion data that are spatially well distributed in regions that may produce significant earthquakes. High dynamic range is of very great importance since we require ground motions from very small and very large earthquakes that are recorded at the same site. Unfortunately, sensitive seismometers and strong-motion accelerometers have very rarely been collocated. Furthermore, the fact that current seismic networks record only the vertical component of motion over a very limited frequency band and amplitude range has severely limited their usefulness in seismic source studies.

An example of the way that ground motions recorded on dense regional networks can be used to study earthquake rupture is shown in figure 29 (Mendoza and Hartzell, 1988). The slip distribution on the Calaveras fault that best models strong ground motions observed during the 1984 Morgan Hill earthquake (Hartzell and Heaton, 1986) is shown together with the aftershock distribution (Cockerham and Eaton, 1987) determined using the USGS central Califomia regional seismic network. It appears that the slip is highly heterogeneous and that the regions of high slip are characterized by a relative paucity of aftershocks. This same feature has been inferred in several other instances (Mendoza and Hartzell, 1988).

\section{Strong-Motion Attenuation}

Engineering design decisions are based partly on expected peak values of ground motion (acceleration, velocity, displacement) for the maximum expected earthquake at a given distance. The process used to estimate these values relies on strong-motion attenuation curves with distance. These curves are usually obtained from regression analysis of existing measurements of ground motion. Difficulties often arise, however, from the limited nature of the strong ground motion data set. It seems apparent that there are regional differences in these attenuation laws. For instance, strong ground motion in the Eastern and central United States seems to decay less rapidly with distance than in the southwestern United States. Although there is a fairly extensive strong-motion data set for the southwestern United States, there are few records for other parts of the country. However, ground-motion data from small earthquakes can be used to study the distance attenuation laws that would be expected during large earthquakes. Regional networks equipped to record broadband high-dynamic-range three-component ground motions could be used to obtain very reliable estimates of distance attenuation laws to predict strong shaking. 


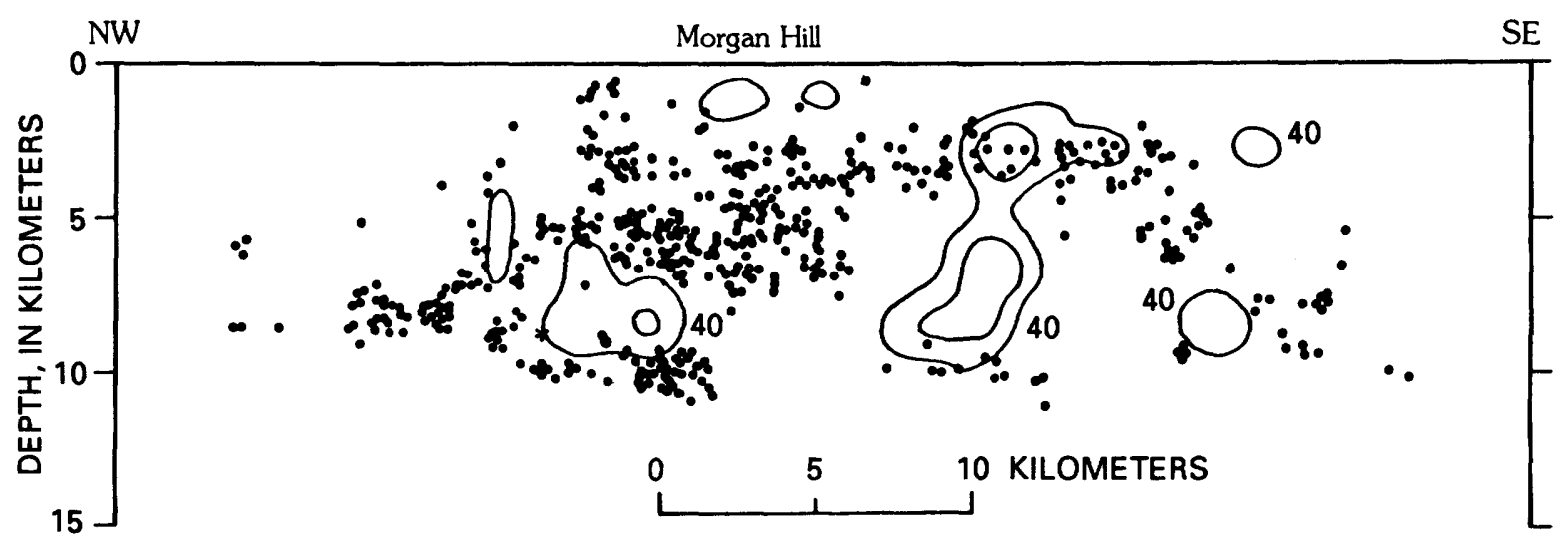

Figure 29. Aftershock distribution (dots) of 1984 Morgan Hill earthquake (from Cockerham and Eaton, 1987) coplotted with slip distribution that Hartzell and Heaton (1986) deduced from modeling strong ground motion (contours at $40-\mathrm{cm}$ intervals). In this sequence (and several others) it appears that aftershock activity occurs mainly outside area of major coseismic slip (from Mendoza and Hartzell, 1988).

\section{Strong-Motion Simulation}

In the last section we discussed a commonly used method for estimating the ground motion of an earthquake at a given distance and magnitude. However, even if the distance and magnitude are known, there is large uncertainty in the determination of ground motions that will result. To illustrate, we show response spectra from horizontal ground motions recorded at distances near $50 \mathrm{~km}$ from shallow, crustal, strikeslip earthquakes of about magnitude 6.5 in figure 25 . The largest ground motion is over 10 times larger than the smallest, and it is obvious that a wide variety of ground motions have occurred at a distance of about $50 \mathrm{~km}$ from M 6.5 strikeslip earthquakes. Wave propagation through geologically complex structures is one of the major reasons for the large observed scatter. In a previous section, we described how records from small earthquakes can be used to remove the effects of wave propagation from records of large earthquakes. In a similar manner, the records from small earthquakes can be used to simulate the nature of strong shaking to be expected when large earthquakes occur. That is, records from small earthquakes can be used as empirical Green's functions, and these Green's functions can be summed to simulate the shaking in the vicinity of the seismic station (Hartzell, 1978; Kanamori, 1979). If stations are located within metropolitan areas or near critical facilities, then important effects due to wave propagation can be anticipated.

\section{Earth Structure and Wave Propagation}

In our earlier discussion of the uses of existing networks, we pointed to numerous important studies of Earth structure that were made possible by the existence of regional networks. Most of these studies would have been impossible with sparse or temporary networks. In most instances and because of the nature of the data, these studies only use $P$-wave arrival times to infer large-scale variations in seismic velocities. However, the availability of broad-band three-component data from regional networks will greatly expand the nature of studies into the structure of the Earth and the manner in which waves travel through complex geologic structure. In particular, it will be possible to continuously observe the development in long-period waveforms as they sweep across entire regions. It will be possible to deterministically study the nature of and reasons for scatter in wave amplitudes that have been noted, but poorly understood. We now give some examples of the types of problems that will be studied with high-quality regional networks.

\section{Shear Waves}

The availability of three-component waveforms will dramatically improve the ability to study shear waves. Shear waves are typically very poorly recorded on vertical seismometers, and $S$-wave arrival times can be in serious error when only a vertical-component seismogram is used for analysis. Furthermore, interactions between $P$ waves and vertically polarized $S$ waves ( $S V$ waves) often complicates the interpretation of shear waves, and it is usually best to rotate motions into radial and tangential components so that tangential-component shear waves ( $S H$ waves) can be studied separately. This type of analysis is not possible with existing regional networks, but would be routine with high-quality three-component data.

Shear waves provide information about the Earth's interior that is independent from $P$ waves. Since they do not propagate through fluids, the search for travel paths along which shear waves are missing (or attenuated) is an important tool for mapping the subsurface extent of magma bodies. Furthermore, low shear-wave velocities are often inferred for zones of high tectonic slip rates, the presence of petroleum deposits, and the presence of geothermal resources. The use of shear-wave information promises to open a new class of problems in the exploration of the Earth's interior. 


\section{Surface Waves}

Surface waves are another class of seismic waves that are important for understanding the properties of the crust and uppermost mantle. They are also of interest because they may be an important factor in the seismic hazard of longer period structures (tall buildings, bridges, and so on). Although surface waves can have any period, they are generally important at periods of greater than 1 second. They are usually classified according to the polarization of the motions they produce, either transverse polarization ( $\mathrm{SH}$-type Love waves) or radialvertical ( $P$-SV-type Rayleigh waves). At large earthquake distances, these are usually the largest arrivals seen on a seismograph, and they contain important information about the average properties of the crust. Three-component data are essential for the identification and study of surface waves. Furthermore, the fact that these are relatively long-period waves means that they are usually not well recorded by existing short-period regional networks.

\section{Understanding the Coda}

The seismic coda has been the focus of considerable interest because it is thought that material properties of the Earth's lithosphere can be inferred from the coda, and because temporal variations in codas over periods of days to years may precede large earthquakes. The seismic coda, which is the part of the seismogram following the $S$ wave, is generally thought to consist of body and surface waves scattered off material heterogeneities in the Earth's structure (Aki and Chouet, 1975). If the coda consists primarily of single scattered waves, then the energy in the coda samples a large volume of the lithosphere, and thus the characteristics of the coda may be sensitive to the large-scale properties of the crust. Many researchers have measured the temporal decay rate of the seismic coda in various frequency bands. These observations have been widely characterized using a measurement called coda- $Q\left(Q_{c}\right)$, which has been observed to increase with frequency. Similarly, some researchers (for example, Jin and Aki, 1986; Novelo-Casanova and others, 1985) have observed temporal variations in coda- $Q$ before large earthquakes. It has been hypothesized that variations in average crustal seismic velocity would be relevant to earthquake prediction (Poupinet and others, 1985). Also, the spectrum of the coda has been used to infer the earthquake source spectrum and the site response of the seismic station (Phillips and Aki, 1986).

Despite all these proposed uses of the seismic coda and $Q_{\text {c }}$, there is still no general agreement on what property of the crust is measured by $Q_{c}$, on the volume of the lithosphere sampled by the coda, on the relative proportion of single- and multiple-scattered energy in the coda, and on the relative importance of near-surface heterogeneity on the time domain and frequency domain characteristics of the coda. One common interpretation of the coda is that it consists of energy that is singly back scattered from the lithosphere (Aki and Chouet, 1975). However, there are alternative models, such as the multiple-scattering energy-flux model of Frankel and Wennerberg (1987). In the single-scattering model, $Q_{\mathrm{c}}$ represents the total transmission $Q$ of the medium, including both the effects of scattering and anelastic attenuation, whereas in the multiple-scattering model, $Q_{\mathrm{c}}$ is at best a measure of only anelastic attenuation. Considerable disagreement exists on the portion of the lithosphere that is sampled by the coda. Levander and Hill (1985) have shown that a considerable portion of the coda energy may consist of surface waves, converted from body waves, that are trapped within the heterogeneous low-velocity region within a few kilometers of the Earth's surface. Spudich and Bostwick (1987) showed that the early part of the coda was dominated by multiply scattered waves reverberating within a few kilometers of the seismic station. If the coda is dominated by waves that sample only the near-surface zone, then Earth properties inferred from the coda will be biased toward their values near the surface of the Earth, and temporal changes in the coda may be related to near-surface fluctuations such as water table changes, rather than to temporal changes throughout the lithosphere. If the coda does not sample the entire lithosphere uniformly, then the widely observed frequency dependence of $Q_{c}$ may not indicate a true frequency dependence of anelastic attenuation in the crust, but rather may result from different frequency components of the coda preferentially sampling different depth regions of a lithosphere in which anelastic attenuation is a function of depth.

Consequently, it is necessary to determine the type of waves composing the coda, the importance of multiple scattering, and the volume of the Earth that these waves sample. We need to learn the relative importance of scattering attenuation and anelastic attenuation. Moreover, we need to learn the frequency dependence and spatial variation of these Earth properties. Careful study of broad-band waveforms recorded at a large number of sites from a large variety of seismic sources will be the key to unraveling the physics of seismic coda.

\section{Deep Structure of Basins and Mountains}

Achieving better resolution of the structural makeup and physical properties of the deeper parts of the continental crust in the United States has become one of the major goals in the U.S. seismological community (Panel on Seismological Studies of the Continental Lithosphere, 1984; IRIS, 1984; Mooney, 1987). Regions of basins and mountains are key targets whose subsurface study is motivated by their typical association with earthquake processes, their economic potential (for instance, hydrocarbon and other mineral deposits), and the fundamental need for new, high-quality data to evaluate competing hypotheses about their origin and evolution.

As outlined in the 10-year program plan for seismic studies of the continental lithosphere (IRIS, 1984), outstanding research problems are both topical and geographical. Topical studies relating to crustal structure include, for example: the geometry and nature of intracrustal discontinuities 
and lateral heterogeneities in velocity structure; the subsurface geometry of structures such as faults, domes, batholiths, and volcanoes; and information relevant to understanding processes associated with basin formation and extension, continental terrane accretion, detachment tectonics, magmatic intrusion, and volcanism. Mooney (1987) summarized by geographical region both (1) the nature of important problems relating to crustal structure and (2) recent and current investigations.

Three-component digital seismic networks will significantly enhance imaging of tectonically important regions-even though controlled-source studies (near-vertical-incidence reflection and refraction/wide-angle reflection; see Mooney, 1987) will continue to be primary investigative tools. The analysis of seismic waves from local and distant earthquakes complements, and indeed provides well-known advantages over, the use of artificial seismic sources for probing crustal structure. Earthquake sources are impulsive, occur at depth, generate higher levels of energy over a broader frequency range, and radiate shear-wave energy. Compared to short-term experiments, seismic networks provide the advantage of continuous, long-term recording for sampling earthquake sources. The broader regional coverage of seismic networks may also be advantageous, although some tomographic applications require close spatial sampling that realistically will only be achieved with dense temporary arrays of digital seismographs.

The inversion of travel times of earthquake body waves is a well-established tool for imaging the three-dimensional velocity structure beneath a seismic array. For studying crustal-level structure, station spacing and the availability of horizontal-component recordings (for $S$-wave velocity structure) are important constraints. Some examples of the successful inversion of $P$-wave travel times for crustal structure using local earthquakes recorded by existing vertical-component seismic networks are given by Walk and Clayton (1987), Hearn and Clayton (1986a,b), and Kissling and others (1984). Networks of three-component seismographs would allow similar resolution of $S$-wave velocity structure.

Owens and others (1987) demonstrated the power of a single three-component digital station for resolving local crustal structure from earthquake sources. Using a teleseismicwaveform-inversion technique, they derived a detailed vertical shear-velocity structure for the crust beneath the receiver site using converted waves of the $P$-to- $S$ type. Scherbaum (1987) described another single-station inversion method for subsurface impedance structure from locally recorded $S H$ waves. Regional earthquake phases that propagate in the crust are known to be sensitive to lateral changes in crustal structure (Campillo, 1987) and offer yet another potential way of mapping crustal structure with three-component digital networks.

High-resolution three-dimensional inversion of local crustal structure will unquestionably be pursued with temporary dense arrays of IRIS/PASSCAL-type instruments, in the best cases combining the recording of both earthquakes and controlled sources (IRIS, 1984). Three-component digital seismic networks, with their temporal continuity and regional extent, will contribute to resolving subsurface crustal features through refined source definition of seismically active structures at depth, through inversion of both travel times and waveforms for $P$ - and $S$-wave velocity structure, and through complementary interaction with controlled-source studies.

\section{Structure of the Earth's Interior}

Uniform, broad-band, high-dynamic-range instrumentation will enable far more complete resolution of deep Earth structure. In the future, the capabilities of regional networks will become even more important for the analysis of the structure of the Earth's mantle and core. These studies promise to provide the underpinnings for detailed models of the dynamics of plate tectonics, the evolution of the Earth, and origin of the Earth's magnetic field. In particular, density variations together with variations in the Earth's viscosity are the basic engine of plate tectonics. If these variations in the Earth's interior properties can be mapped, then we will have a much deeper understanding of plate tectonics. The use of data from regional networks will give an unprecedented look at the detailed structure not only beneath North America, but also along the travel path between North America and seismic sources located throughout the globe. Detailed studies of the nature of the Earth's interior discontinuities, such as the coremantle boundary or discontinuities in the upper mantle, will be feasible. There are even suggestions that the currents of fluid iron within the Earth's core may be observable with seismological studies. If this is true, then very detailed observations will be necessary. Since these currents may also change over time scales of years, dense permanent seismic networks (such as those in regional networks) are desirable for such studies.

For simplicity, the Earth is usually considered to be elastically isotropic. Detailed studies, however, usually indicate the presence of anisotropy, often on the order of 5 percent. This effect is comparable to variations caused by changes in temperature and mineralogy. Anisotropy shows up as azimuthally dependent velocities, $S$-wave splitting (different time shift for different $S$-wave polarities), and discrepancies between Love and Rayleigh wave observations. Although anisotropy can be considered as an irritating complication, it contains important information about mineralogy, flow, and stress. Time-dependent anisotropy has even been proposed as a possible earthquake precursor. Since the most important diagnoses of anisotropy are $S$-wave splitting and LoveRayleigh inversion, one requires broad-band, three-component seismic data. Since anisotropy may not be a second-order effect, the failure to recognize it may result in serious errors in our interpretation of the Earth's interior structure.

The anelastic properties of the Earth's interior are also of great importance for understanding its overall dynamics. 
However, it is difficult to study anelastic attenuation of seismic waves because it is intertwined with geometric spreading, focusing, and defocusing. Because of this, studies of the Earth's elastic and anelastic properties go hand in hand. The study of anelasticity requires spectral studies which, in turn, require high dynamic range and broad-band data. Highquality modern three-component instruments are essential. Anelasticity sheds light on the physical properties of the crust, mantle and core, the temperature, and the state of stress (dislocation density). Anelasticity also causes the elastic properties, including the seismic velocities, to be frequency dependent. This information is required in detailed modeling of the Earth's structure.

\section{Nuclear Discrimination}

Artificial explosions are commonly observed on existing regional seismic networks. These explosions are commonly quarry blasts observed at distances less than several hundred kilometers, but many of these explosions are the result of testing of nuclear weapons. There has been considerable study of the problem of detecting and recognizing nuclear explosions throughout the world. Although earthquakes and explosions both generate $P, S$, and Rayleigh waves, explosive sources are fundamentally different from earthquake sources. One of the most important differences is the relatively short process time of an explosion compared with an earthquake. Furthermore, the spatial amplitude pattern (radiation pattern) is completely different for explosions and earthquakes. The high station density of regional networks makes them ideal for detecting both regional and teleseismic explosions. In particular, stacking of signals to detect waves coming from regions of particular interest (such as known test sites) can significantly improve signal-to-noise ratios. Because of their limited bandwidth, current regional networks are not particularly well suited for explosion discrimination problems. However, regional networks with enhanced instrumentation will be well suited for studying explosions.

\section{CONCLUSIONS}

There are approximately 1,600 permanent stations in existing U.S. regional seismic networks. These networks were constructed with the primary function of locating the earthquake activity of different regions of the United States, and they are well suited for this task. Because of the now-antiquated telemetry and data-logging technology that was available during their development 20 years ago, existing regional networks only record the vertical component of motion over a very restricted range of amplitudes and frequencies. This severely restricts the role of regional networks.

Modern seismic and telecommunications systems have the capability of measuring all three components of ground motion with amplitudes ranging from ambient ground noise to the strongest shaking experienced during earthquakes and over a very broad band of frequencies. This new generation of instrumentation has the potential to revolutionize the role of regional networks. Regional networks should play a vital role in emergency response activities during and after significant earthquakes. Furthermore, enhanced regional networks would vastly improve the national capability to study earthquake physics, strong ground motions, the structure of the crust, and the structure and dynamics of the Earth's interior. The formulation of a national plan to develop new digital highdynamic-range, broad-band regional seismic networks should be given a high priority.

\section{REFERENCES CITED}

Aki, Keiiti, and Chouet, B.A., 1975, Origin of coda waves: Source, attenuation, and scattering effects: Journal of Geophysical Research, v. 80, p. 3322-3342.

Allen, C.R., 1986, Seismological and paleoseismological techniques of research in active tectonics, in Active tectonics: Washington, National Academy Press, p. 148-154.

Angelier, J., 1984, Tectonic analysis of fault slip data sets: Journal of Geophysical Research, v. 89, p. 5835-5848.

Arabasz, W.J., Pechmann, J.C., and Brown, E.D., 1987, Observational seismology and the evaluation of earthquake hazards and risk in the Wasatch Front area, Utah, in Gori, P.L., and Hays, W.W., eds., Assessment of regional earthquake hazards and risk along the Wasatch Front, Utah: U.S. Geological Survey Open-File Report 87-585, p. D1-D58..

Atwater, B.F., 1987, Evidence for great Holocene earthquakes along the outer coast of Washington State: Science, v. 236, p. 942 944.

Bakun, W.H., 1980, Seismic activity on the southern Calaveras fault in central California: Seismological Society of America Bulletin, v. 70, p. 1181-1197.

1987, Future earthquakes: Reviews of Geophysics, v. 25, p. 1135-1138.

Bakun, W.H., Bredehoeft, J.D., Burford, R.O., Ellsworth, W.L., Johnston, M.J.S., Jones, Lucile, Lindh, A.G., Mortensen, C.E., Roeloffs, E.A., Schulz, S., Segall, Paul, and Thatcher, Wayne, 1986, Parkfield earthquake prediction scenarios and response plans: U.S. Geological Survey Open-File Report 86-365, 64 p.

Bakun, W.H., King, G.C.P., and Cockerham, R.S., 1986, Seismic slip, aseismic slip, and the mechanics of repeating earthquakes on the Calaveras fault, California, in Earthquake source mechanics (Maurice Ewing Series, vol. 6): Washington, D.C., American Geophysical Union, p. 195-207.

Bernard, E.N., Behn, R.R., Hebenstreit, G.T., Gonzales, F.I., Krumpe, P.F., Lander, J.F., Lorca, E., McManamon, P.M., and Milburn, H.B., 1988, On mitigating rapid onset natural disasters: Project THRUST: Eos, v. 69, no. 24.

Bullard, F.M., 1962, Volcanoes of the Earth, Austin, University of Texas Press, 579 p.

Campillo, Michel, 1987, Lg wave propagation in a laterally varying crust and the distribution of the apparent quality factor in central France: Journal of Geophysical Research, v. 92, p. 12,604 12,614 .

Cockerham, R.S., and Eaton, J.P., 1987, The earthquake and its aftershocks, April 24 through September 30, 1984, in Hoose, S.N., 
ed., The Morgan Hill, California, earthquake of April 24, 1984, U.S. Geological Survey Bulletin 1639, p. 15-28.

Electric Power Research Institute, 1987, Seismic hazard methodology for the central and eastem United States, volume 1: Methodology: Palo Alto, California, EPRI Technical Report NP-4726 (revised), 197 p.

Ellsworth, W.L., Lindh, A.G., Prescott, W.H., and Herd D.G., 1981, The 1906 San Francisco earthquake and the seismic cycle, in Simpson, D.W., and Richards, P.G., eds., Earthquake prediction, an international review: Washington D.C., American Geophysical Union, p. 126-140.

Frankel, A.D., Fletcher, J.B., Vernon, F., Haar, L., Berger, Jon, Hanks, T.C., and Brune J.N., 1986, Rupture characteristics of $M_{L} \approx 3$ earthquakes near Anza, southem California: Journal of Geophysical Research, v. 91, p. 12,633-12,650.

Frankel, A.D., and Wennerberg, L.G., 1987, Energy flux model of seismic coda: Separation of scattering and intrinsic attenuation: Seismological Society of America Bulletin, v. 77, p. 1223-1251.

Golz, J., 1985, The Parkfield and San Diego earthquake predictions: a chronology: Special Report by the Southern California Earthquake Preparedness Project, Los Angeles, 23 p.

Hanks, T.C., 1985, The National Earthquake Hazards Reduction Program-Scientific status: U.S. Geological Survey Bulletin 1659,40 p.

1987, Seismology in the United States, 1983-1986: Reviews of Geophysics, v. 25, p. 1131-1133.

Hartzell, S.H., 1978, Earthquake aftershocks as Green's functions: Geophysical Research Letters, v. 5, p. 1-4.

Hartzell, S.H., and Heaton, T.H., 1986, Rupture history of the 1984 Morgan Hill, California, earthquake from the inversion of strong motion records: Seismological Society of America Bulletin, v. 76, p. 1553-1583.

Hearn, T.M., and Clayton, R.W., 1986a, Lateral velocity variations in southern California. I. Results for the upper crust from $P_{\mathbf{s}_{\mathbf{g}}}$ waves: Seismological Society of America Bulletin, v. 76, p. 495-509.

- 1986b, Lateral velocity variations in southem California. II. Results for the lower crust from $P_{\mathrm{n}}$ waves: Seismological Society of America Bulletin, v. 76, p. 511-520.

Heaton, T.H., 1985, A model for a seismic computerized alert network: Science, v. 228, p. 987-990.

1987, Anomalous seismicity in the San Diego coastal region, in Aki, Keiiti, and Stuart, W.D., eds., Proceedings of Workshop XXXVII, Physical and Observational Basis for IntermediateTerm Earthquake Prediction: U.S. Geological Survey OpenFile Report 87-591, p. 667-681.

Heaton, T.H., and Hartzell, S.H., 1987, Seismic hazards on the Cascadia Subduction Zone: Science, v. 236, p. 162-168.

Heaton, T.H., Tajima, F.C., and Mori, A., 1986, Estimating ground motions using recorded accelerograms: Surveys in Geophysics, v. 8 , p. $25-83$.

Hill, D.P., 1987, Seismotectonics: Reviews of Geophysics, v. 25, p. 1139-1148.

Hill, D.P., Wallace, R.E., Cockerham, R.E., 1985, Review of evidence on the potential for major earthquakes and volcanism in the Long Valley region of eastern California: Earthquake Prediction Research, v. 3, p. 571-594.

Humphreys, Eugene, Clayton, R.W., and Hager, B.H., 1984, A tomographic image of mantle structure beneath southern California: Geophysical Research Letters, v. 11, p. 625-627.
IRIS, 1984, Program for array seismic studies of the continental lithosphere (PASSCAL), report: Incorporated Research Institutions for Seismology, Washington, D.C., 169 p.

Ito, A., 1985, High resolution relative hypocenters of similar earthquakes by cross-spectral analysis method: Journal of Physics of Earth, v. 33, p. 279-294.

Jin, A., and Aki, Keiiti, 1986, Temporal changes in coda- $Q$ before the Tangshan earthquake of 1976 and the Haicheng earthquake of 1975: Journal of Geophysical Research, v. 91, p. 665-673.

Jones, L.M., 1985, Foreshocks and time-dependent earthquake hazard assessment in southem California: Seismological Society of America Bulletin, v. 75, p. 1669-1679.

Kanamori, Hiroo, 1979, A semi-empirical approach to prediction of long-period ground motions from great earthquakes: Seismological Society of America Bulletin, p. 1654-1670.

1985, A numerical experiment on seismic tsunami warning network for Alaska and the Aleutians, in Murty, T.S., and Rapatz, W.J., eds., Proceedings of the International Tsunami Symposium of the International Union of Geodesy and Geodynamics: Institute of Ocean Sciences, p. 30-39.

Kissling, E.H., Ellsworth, W.L., Cockerham, R.S., 1984, Threedimensional structure of the Long Valley caldera, California, region by geotomography, in Proceedings of Workshop XIX, Active Tectonics and Magmatic Processes Beneath Long Valley Caldera, Eastem California, vol. I: U.S. Geological Survey Open-File Report 84-939, p. 188-220.

Klein, F.W., 1984, Eruption forecasting at Kilauea Volcano, Hawaii: Journal of Geophysical Research, v. 89, p. 3059-3073.

Klein, F.W., Koyanagi, R.Y., Nakata, J.S., Tanigawa, W.R., 1987, The seismicity of Kilauea's magma system, in Decker, R.W., Wright, T.L., and Stauffer, P.H., eds., Volcanism in Hawaii, volume 2, Structure, dynamics, history of investigations of Hawaiian volcanism: U.S. Geological Survey Professional Paper 1350, p. 1019-1188.

Levander, A.R., and Hill, N.R., 1985, P-SV resonances in irregular low-velocity surface layers: Seismological Society of America Bulletin, v. 75, p. 847-864.

Liu, H.L., and Heaton, T.H., 1984, Array analysis of the ground velocities and accelerations from the 1971 San Fernando, California, earthquake: Seismological Society of America Bulletin, v. 74, p. 1961-1968.

Massé, Robert, and Buland, R.P., 1987, United States National Seismic Network: Report from the National Earthquake Information Center: Golden, Colorado, U.S. Geological Survey, 12 p.

Mendoza, C., and Hartzell, S.H., 1988, Aftershock patterns and mainshock faulting: Seismological Society of America Bulletin, v. 78, p. 1438-1449.

Michael, A.J., 1987, Use of focal mechanisms to determine stress: A central study: Journal of Geophysical Research, v. 92, p. 357368.

Mooney, W.D., 1987, Seismology of the continental crust and upper mantle: Reviews of Geophysics, v. 25, p. 1168-1176.

National Academy of Sciences, 1972, The Great Alaska earthquake of 1984, seismology and geodesy: Washington, D.C., Committee on Alaska Earthquakes, 596 p.

National Research Council (1987). Recommendations for the strong motion program in the United States: Washington, D.C., National Academy Press.

Nishenko, S.P., and Buland, R., 1987, A generic recurrence interval distribution for earthquake forecasting: Seismological Society 
of America Bulletin, v. 77, p. 1382-1399.

Novelo-Casanova, D., Berg, E., Hsu, V., and Helsley, E., 1985, Timespace variations of seismic $S$-wave coda attenuation $\left(Q_{c}-1\right)$ and magnitude distribution (b-value) for the Petatlan earthquake: Geophysical Research Letters, v. 12, p. 789-792.

Nuttli, O.W., 1973, The Mississippi Valley earthquakes of 1811 and 1812; Intensities, ground motion, and magnitudes: Seismological Society of America Bulletin, v. 63, p. 227-248.

O'Neill, M.E., 1984, Source dimensions and stress drops of small earthquakes near Parkfield, California: Seismological Society of America Bulletin, v. 74, p. $27-40$.

Oppenheimer, D.H., Reasenberg, P.A., and Simpson, R.W., 1988, Fault plane solutions for the 1984 Morgan Hill, California, earthquake sequence: Evidence for the state of stress on the Calaveras fault: Journal of Geophysical Research, v. 93, p. 9007-9026.

Owens, T.J., Taylor, S.R., and Zandt, G., 1987, Crustal structure at regional seismic test network stations determined from inversion of broadband teleseismic $P$ waveforms: Seismological Society of America Bulletin, v. 77, p. 631-662.

Panel on Seismological Studies of the Continental Lithosphere, 1984, Seismological studies of the continental lithosphere: Washington, D.C., National Academy Press, Board on Earth Sciences Report, 144 p.

Pechmann, J.C., and Kanamori, Hiroo, 1982, Waveforms and spectra of preshocks and aftershocks of the 1979 Imperial Valley, California, earthquake: Evidence for fault heterogeneity?: Journal of Geophysical Research, v. 87, p. 10,579-10,1597.

Phillips, W.S., and Aki, Keiiti, 1986, Site amplification of coda waves from local earthquakes in central Califomia: Seismological Society of America Bulletin, v. 76, p. 627-648.

Poupinet, Georges, Frechet, J., Ellsworth, W.L., Fremont, M., and Glangeaud, F., 1985, Doublet analysis: Improved accuracy for earthquake prediction studies: Earthquake Prediction Research, v. 1, p. 147-159.

Powell, C.A., 1976, Mantle heterogeneity: Evidence from large seismic arrays: Princeton, N.J., Princeton University, Ph.D. thesis, $326 \mathrm{p}$.

Satake, Kenji, 1987, Seismological Studies of the 1983 Japan Sea earthquake tsunami: University of Tokyo, Ph.D. thesis, 149 p.

Savy, J.B., Bernreuter, D.L., and Mensing, R.W., 1986, Seismic hazard characterization for the eastern United States: Nuclear Safety, v. 27, p. 476-487.

Scherbaum, Frank, 1987, Seismic imaging of the site response using microearthquake recordings, Part I. Method: Seismological
Society Society of America Bulletin, v. 77, p. 1905-1923.

Simkin, Tom, and Siebert, L., 1984, Explosive eruptions in space and time: durations, intervals, and a comparison of the world's active volcanic belts, in Studies in geophysics-Explosive volcanism: Inception, evolution and hazards: Washington, D.C., National Academy Press, Geophysics Study Committee of the National Research Council, p. 110-121.

Simpson, D.W., and Ellsworth, W.L., convenors, 1985, Symposium and workshop, regional seismographic networks, past-presentfuture, Proceedings of a symposium and workshop, Knoxville, Tenn., October 1985, U.S. Geological Survey Open-File Report, in press.

Smith, R.L., and Leudke, R.G., 1984, Potentially active volcanic lineaments belts, in Studies in geophysics-Explosive volcanism: Inception, evolution and hazards: Washington, D.C., National Academy Press, Geophysics Study Committee of the National Research Council, p. 47-66.

Spudich, P.K., and Bostwick, T., 1987, Studies of the seismic coda using an earthquake cluster as a buried seismograph array: Journal of Geophysical Research, v. 92, p. 10,526-10,546.

State of California Governor's Office of Emergency Services, 1988, Parkfield earthquake prediction response plan, $70 \mathrm{p}$.

Swanson, D.A., Casadevall, T.J., Dzurisin, Daniel, Malone, S.D., Newhall, C.G., and Weaver, C.S., 1983, Predicting eruptions at Mount St. Helens, June, 1980 through December 1982: Science, v. 221, p. 1369-1376.

Tajima, Fumiko, and Kanamori, Hiroo, 1985, Global survey of aftershock expansion patterns: Physics of Earth and Planetary Interiors, v. 40, p. 77-134.

Veneziano, D. and Van Dyck, J., 1986, Statistical analysis of earthquake catalogs for seismic hazard: Proceedings, International Symposium on Engineering Geology Problems in Seismic Areas, Bari, Italy.

Walck, M.C., 1984, The $P$-wave upper mantle structure beneath an active spreading centre: The Gulf of Califomia: Royal Astronomical Society Geophysical Journal, v. 76, p. 697-723.

Walck, M.C., and Clayton, R.W., 1987, $P$-wave velocity variations in the Coso region, California, derived from local earthquake travel times: Journal of Geophysical Research, v. 92, p. 393405.

Working Group on California Earthquake Probabilities, 1988, Probabilities of large earthquakes occurring in California on the San Andreas fault: U.S. Geological Survey Open-File Report 88398, 62 p.

Wyss, Max, and Habermann, R.E., 1988, Precursory seismic quiescence: Pure and Applied Geophysics, v. 126, p. 319-332. 